\title{
From language standards to a Standard Language: The case of Modern Greek
}

\author{
Spiros A. Moschonas ${ }^{\star}$ \\ Faculty of Communication and Media Studies, National and Kapodistrian University of Athens, \\ 1 Sofocleous Str., 10559 Athens, Greece
}

\section{Article info}

History:

Received July 1, 2019

Accepted August 12, 2019

Published November 7, 2019

Key words:

history of language

pragmatics

sociolinguistics

\begin{abstract}
This study looks for changes in a standard variety through changes in that variety's standards. It concentrates on the continuing process of the standardization of Modern Greek and it discusses: a) an inaugural change in status planning involving the shift from Jannis Psycharis's codification of Modern Greek to a more "permissive" codification by Manolis Triantaphyllidis; b) the propagation of linguistic standards on a mass scale through the print and electronic media after the resolution of the "Greek Language Question"; c) the process of "deideologization" or "naturalization" of the established norms; d) a relatively recent instance of stylization of a certain highly prescribed variant (nasalization of voiced stops), which possibly marks a new phase in the standardization process.

The four cases of changing standards are discussed under a performative theory of standardization. A corpus-driven approach is employed that concentrates on correctives (metalinguistic speech acts of the type: "one should neither say nor write $\mathrm{X}$; instead, one should say or write $\mathrm{Y}$ ") and permissives ("one may say or write either X or Y provided that C"). Such triplets are located in texts that prescribe on language usage. A variety of such texts is taken into consideration: institutional Grammars, advice columns in the Greek newspapers, relevant radio and television broadcasts, Style Guides addressed both to the general public and to the media professionals.

It is shown that correctives and/or permissives form repertories that change over time. Such changes in language standards account for changes in the standard language. According to the performative theory, standard languages are subject to restandardization as language standards are subject to redefinition. The changes in corrective repertories bear testimony to a process of a continuing standardization of Modern Greek. This process is shown to be mediated, i.e. it has affected and has been affected by prescriptive practices in the print and electronic media.
\end{abstract}

\section{Contents}

0 Introduction $\quad 2$

1 Planning 5

2 Repertories $\quad 16$

3 Ideology 26

4 Style $\quad 30$

5 Conclusions and discussion $\quad 35$

Bibliography

^Email address: smoschon@media.uoa.gr. 


\section{Introduction}

A standard language can be one of three things: (a) a language; (b) a standard; (c) both a language and a standard. ${ }^{1}$

(a). Judging by popular epitomes of sociolinguistic wisdom, such as: general Introductions to Sociolinguistics (e.g., Trudgill, 1983, p. 17-20; Hudson, 1980, p. 32-34; Wardaugh, 1998, p. 29-37; Holmes, 2008, p. 76-78, p. 137-138; etc.), Encyclopedias of Linguistics (e.g., Inoue, 2006; Haugen, 2001; but cf. Linn, 2011), and similar reference works, (a) must be the view that prevails among sociolinguists. A standard, of course, is not considered, not even in introductory textbooks, to be 'a language' in any full-blown sense of the word. For linguists, languages are, after all, spurious entities, and of all spurious entities standard languages are the "least interesting" ones, according to Hudson (1980, p. 34). Standard languages are mostly written languages; they are believed to be uniform rather than variable; and only a percentage of a community's population has access to them. A standard, "whatever it is, is less than a language" (Trudgill, 1999, p. 118).

Let's dress view (a) into its becoming jargon. A standard is a particular 'variety', or a 'sub-variety' of a language, or a 'dialect' among other dialects. A standard variety, if a variety it is, need not be defined with reference to any particular set of prescriptive rules or any language ideology (Trudgill, 1999, p. 118, 125); i.e., a standard language need not be measured by any particular standard. The proviso is sometimes made that this variety is a "purely social one", not associated with any geographical region, and with only a small amount of geographical variation (Trudgill, 1999; 1983, p. 17-20; 2003, p. 128).

Interestingly enough, view (a), the view that identifies a standard language with a particular variety rather than with a (prescriptive) standard (or a norm), is not attested among sociolinguists only; it is also espoused, unanimously I would think, by proponents or "founders" of various 'standard languages', be they linguists or not, who usually identify a standard language - their preferred one-not with a "purely social variety" but rather with a pre-existing local or supralocal koine (several examples to be found in, e.g., Fodor \& Hagège, 1983-1990; the case of Modern Greek “koine” will be discussed below).

(b). In sharp contrast to (a), (b) takes a standard language to be just a standard (an ideology, a belief, a perceptual construct, an ideal, a norm, a set of prescriptive rules) rather than a particular variety. This view is very often attributed to Milroy \& Milroy (1999, p. 19), to whom

it seems appropriate to speak more abstractly of standardization as an ideology, and a standard language as an idea in the mind rather than a reality - a set of abstract norms to which actual usage may conform to a greater or lesser extent.

In the same vein, Lippi-Green (2012, p. 67) defines a "standard language ideology" as "a bias toward an abstracted, idealized, homogeneous spoken language", which "names as its model the written language, but [...] is drawn primarily from the spoken language of the upper middle class". Although "abstracted" and "idealized", such a language, she claims, can be "imposed and maintained by dominant bloc institutions".

A standard language, accordingly, is, primarily, what a standard is believed to be and, secondarily, what it becomes by being imposed on actual language usage. Although not prominent, the view that standard languages are superimposed standards rather than real (sub-)languages, also makes it into standard textbooks; Fromkin, Rodman \& Hyams (2011, p. 440), speaking of Standard American English (SAE), state that "SAE is an idealization. Nobody speaks this dialect; and if somebody did, we would not know it, because SAE is not defined precisely".

According to (b), then, a standard language is primarily a perceptual phenomenon, a construct of the mind, a make-believe activity, a "useful fiction" (in the sense of Veihinger, 1935). There is no objective

\footnotetext{
${ }^{1}$ A fourth possibility: (d) neither, should not be excluded on a priori grounds; but neither should we entertain ab init. the possibility of being wrong.
} 
standard variety; there is only a collective belief (not necessarily the sum of all individual beliefs within a community) that such a variety exists. Once established, this belief tends to verify itself: speakers are guided by their belief in the standards in using the standard they believe in.

(c). I very much sympathize with view (b), but it is the third option I wish to explore and defend in this paper, i.e. the view that a standard language is both a language (a variety, a sub-variety, etc.) and a standard.

There are two aspects to this view (Moschonas, 2005a,b):

First, a standard variety is subject to a continuous process of standardization, de-standardization or restandardization-despite the fact that the speakers of a language might not be aware of this transformative process as, perhaps, neither are the linguists among them. Although they are ideologically presented as stable, persisting, invariable, uniform "wholes", standard varieties exhibit considerable variation and are themselves subject to change. The relation between a standard and other varieties within a linguistic community is, accordingly, a dynamic one and in constant flux.

The division of labor between varieties also admits of rearrangements. As Fishman (1972, p. 19) had pointed out:

Note that not all languages have standard varieties. Note also, that where a standard variety does exist, it does not necessarily displace the nonstandard varieties from the linguistic repertoire of the speech community for functions that are distinct from but complementary to those of the standard variety. Note, additionally, that there may be several competing standard varieties in the same speech community. Note, finally, that hitherto nonstandard varieties may themselves undergo standardization, whereas hitherto standardized varieties may undergo destandardization as their speakers no longer view them as worthy of codification and cultivation. Standardization in not a property of any language per se, but a characteristic societal treatment of language, given sufficient societal diversity and need for symbolic elaboration.

Second, this process of continuous re-standardization could not take place-it would not even be understood-without appeal to certain standards, without ideological justifications of such standards and without metadiscursive practices through which standards and language ideologies are being propagated. There is always an interplay between language standards and standard languages. Accordingly, the relation between a standard and a standard variety should be seen as a dynamic one. A standard variety may actually "converge" to a standard or to what a standard variety is believed to be; but the standard may also be prescribed by a misguided, misplaced or ineffective norm, one which does not actually correspond to any particular variety, as it is very often the case in diglossia situations, where prevailing standards (of the high variety) are inconsistent with common usage (low varieties). There might also be conflicts in standards; Haugen's (1966a,b) seminal works on standardization, one should be reminded, are precisely about such conflicts. In certain communities, there are strong 'language ideological debates' (Blommaert, 1999), which, in some cases, seem to last for ages, as it was the case with the "Greek Language Question" (Mackridge, 2009; see infra).

The present study wishes to look for changes in a standard variety through changes in this variety's standards; and in so doing, to also try to answer the question as to whether and to what degree language standards could account for changes in standard languages.

The variety to be considered is Standard Modern Greek (henceforth, SMG). In the next four sections, I will outline four changes in the standards of SMG, while also seeking parallel or conflicting changes in SMG itself.

1. The first change to be considered - an inaugural one-involves planning. I will briefly look at the historical "moment" when Psycharis's standards of SMG were being replaced by Triantaphyllidis's; i.e., the moment when the "orthodox", "uniform", "pure" standard of demotic - the 
"vernacular" standard-, elaborated by the linguist and enthusiast Jannis Psycharis, gave way to the "mixed" standard of a linguist with a milder temperament, Manolis Triantaphyllidis: a

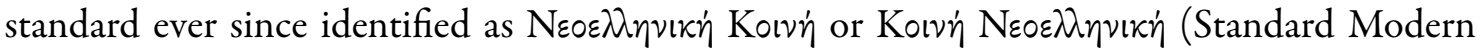
Greek, SMG).

Following this major shift in planning, three additional changes in SMG's standards can be attested. All three changes have been mediated, i.e. they were all initiated in and/or propagated through print or electronic media-in ways to be explained in the following sections. The first two changes concern mostly the written norm, and they will be examined in the print media (in the Greek newspapers); the last one concerns the pronunciation of SMG, and it will be examined in the framework of the Greek radio/television. The three changes, in a semi-chronological order, are the following:

2. With Triantaphyllidis's norm prevailing, the model for corrective instruction originally associated with demotic, a grammatical/morphological model, gave way to a new phraseological one, which, for all practical reasons, is more apt for fixing the long-accepted "mixed" standard. This important change - a change in standards-is attested in Usage Guides and also in most newspapers and periodicals with language advice columns-i.e., it has been a mediated change.

3. While prevailing, the new "mixed" norm gradually lost its ideological stigma vis-à-vis katharevousa, i.e. vis-à-vis the puristic and archaistic adversary to demotic. As a result, the use of the vernacular vs. the archaistic morphology in the new "mixed" standard also ceased to differentiate public discourse as to its political ideology, its cultural stance, or, more narrowly, its language attitudes. This has not been a change in standards only; it was an important change in SMG itself. It has affected several linguistic variables across the whole political spectrum of the Greek media—notably the Greek newspapers.

4. Finally, there are clear indications of recent de- or re-standardization processes taking place in the Greek audiovisual media (of which Politis, 2014, p. 210-306 offers a glimpse). In some detail I will present here only one instance of such tendencies: the prenasalization of voiced stops (Arvaniti \& Joseph, 2000). I will show that this prescriptive rule's lack of success coincides with a restandardizing process, through which nasalization has turned from a learned self-conscious behavior into an unconscious style marker.

In order to diagnose the above four changes in standards, a battery of simple sociolinguistic tests is employed, grouped under four separate but interrelated studies:

1. In order to demonstrate Triantaphyllidis's variationist, non-uniform norm, all references to variation in Triantaphyllidis's et al. (1978) major Grammar of SMG were quantified and classified into categories. The quantification allows for comparisons backwards, with Psycharis's earlier grammatical norm, and forwards, with recent, "descriptive" Modern Greek Grammars or Usage Guides.

2. In order to trace the changes in usage standards from Triantaphyllidis's "mixed" repertory to the modern patterns of usage advice provided on a massive scale in and about the media, "corrective instructions" (i.e., usage advices) in newspapers have also been classified, quantified and compared.

3. In order to test for the ideological connotations (or the lack thereof) of the norm that has evolved, several high/low morphological variants in the Greek press were tested to determine whether they correlate with the political-ideological stance of the newspapers (Kolia et al., 2013). It turns out that morphological variation has lost its ideological stigma; it is no longer dependent on the political ideology of the newspapers. 
4. Finally, as an indication of recent restandardization tendencies, the prenasalization of voiced stops by several Greek radio and TV news anchors has been correlated to the independent variable "scripted/unscripted-speech". It turns out that the prescriptive rule concerning the nasalization of voiced stops is not being followed by radio/TV announcers; a new usage has evolved in which nasalization is employed as a stylistic marker differentiating media genres or registers.

The four changes in the Modern Greek standard and/or the standard variety are examined successively in the next four sections. The threads that possibly unite these four changes will be pulled together in the Conclusions and discussion section, where I elaborate on the interplay between specific linguistic practices and language standards; I offer a unified framework for quantifying the effects of prescriptivism within a variationist paradigm; and I discuss relevant literature on the effects of prescriptivism on language change.

Bits and pieces of a comprehensive theory that links language standards to standard languages I will provide as we move along. However, a very general outline of the theory should be given right from the beginning to help the reader follow the general argument. I will call it the performative theory of language standardization. In a nutshell, metalinguistic statements (i.e., statements about language of the kind considered in this chapter) are not mere expressions of belief; their character is prescriptive and their illocutionary force is that of directive (metalinguistic) speech acts, i.e. speech acts that guide the users of a language to a particular linguistic behavior. Prescriptivism is epitomized in explicit corrective instruction or advice on issues of language usage. Just like any other speech acts, corrective instructions are subject to felicity conditions rather than truth conditions: they are not right or wrong, they simply are effective or ineffective in particular circumstances. Furthermore, for a corrective instruction to be successful, it has to be repetitive. Print and digital media provide platforms in which corrective instructions can be repeated and multiplied, if only by example. The corrective instruction has better chances of reaching a wider public when it is issued by an institution (such as an Academy) or by people with institutional power or by professional zealots (the correctors). Correctives also require a guarding or surveillance mechanism, which is instilled during education and remains operative at both the corporate level (correction as a professional practice) and the level of individuals (self-correction). Finally, in order for corrective speech acts to be successful, they have to be complied with by members of the linguistic community; corrective instructions have to be adopted within a particular medium, across a register, or for a certain stylistic purpose. Language users have to behave linguistically as they were instructed to; they have to start practicing according to the instruction. This final 'uptake' is not easy to come about. It is also difficult to diagnose, since it is always possible that corrective instructions are not being followed, or they are misexecuted, or merely not given heed to; or they are forgotten from one generation of speakers to the next. Indeed, the performative theory of standardization we lay out here is not incompatible with a view of the standard language as a 'variety' that has to be re-learned by each new generation of speakers under the guidance of institutions and always through some kind of mediation.

\section{Planning}

Planning of what came to be known as Standard Modern Greek has gone through at least two very distinct phases: the first is associated with the renown linguist Jannis Psycharis (1824-1929) or Jean Psychari, as he was known in France; the second, with Manolis Triantaphyllidis (1883-1959). The impressive figure of Psycharis marks the "Sturm und Drang" period of the demoticist movement; Triantaphyllidis, a less haughty linguist, is associated with the latter period of "the State's demoticism" (the names and the periodization are Triantaphyllidis's own, 1981, p. 119-144)2. The first period is marked by the publication in

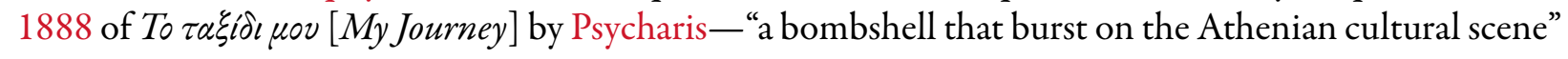

\footnotetext{
${ }^{2}$ Triantaphyllidis would have agreed with Geeraerts (2016) that Psycharis's codification of Modern Greek followed the "romantic model" while Triantaphyllidis's own is a more "rationalistic" one. But this would only mean that the distinction between the "romantic" and the "rationalistic" model is a pre-theoretic one.
} 
Spiros A. Moschonas

(Mackridge, 2009, p. 215); the second is marked by the quite unheroic act of the publication in 1941 of a

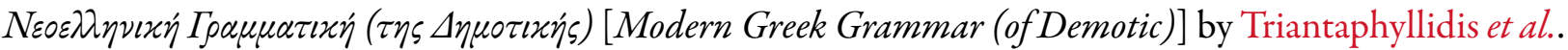

Psycharis did not write a full Grammar of demotic. The three volumes of his "Big" Modern Greek Grammar (Psycharis, 1929, 1935, 1937) barely reach beyond the phonology of Modern Greek. He was a

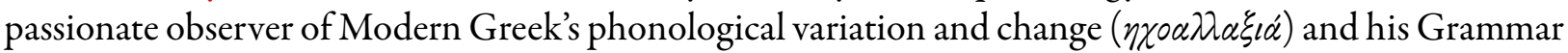
contains a wealth of observations on variant forms, as do many of his scholarly works, written mainly in French (Psycharis, 1930, p. 58-114, 168-179, 189-251, 284-319, 237-238, 664-710, passim.). Psycharis is known mostly from his popularizing and combative works, written in Greek, which had been extremely influential. Although most of these works are overtly prescriptive, Psycharis gave an example of demotic mainly through his own writing, his own novelistic style, and perhaps through his own stylistic exaggerations, of which he became famous and of which My Journey is the foremost epitome.

Just as his followers tried to adhere to a cohesive norm coming out of the master, there have also been attempts in the literature to extract a cohesive norm out of Psycharis's writings; see, e.g., Mandilaras (1972, p. 98-108). It is my opinion that such attempts for systematization are blind to the considerable variation that Psycharis's works exhibit; however, they are not without theoretical significance. They show what, even in the work of scholars, a standard amounts to: a finite and rather short list of dos and don'ts.

For the students of Modern Greek, this is roughly how Mandilaras (1972, p. 98-108) "rewrites" Psycharis's standard, i.e. how he re-standardizes the master's dogma, through a closed set of "correctives" (prescriptive statements of the form $A \rightarrow B$, i.e. "replace variant $A$ by variant $B$ ”):

Psycharis would rather write $\beta x \alpha \iota \varphi$ instead of $\varepsilon v \varkappa \alpha \iota \alpha v$ : $\xi \varepsilon \varphi \varepsilon \varepsilon \gamma \varepsilon \varepsilon, \beta \alpha \sigma i \lambda \varepsilon \beta \varepsilon, \alpha \beta \gamma \dot{\eta}, \pi \rho \omega \tau \varepsilon \beta 0 v \sigma \alpha$,

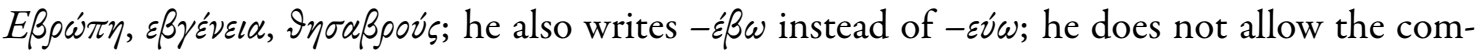
bination of two voiceless fricatives or stops; such combinations are turned into fricative + stop: $\lambda \varepsilon \varphi \tau \varepsilon \rho \iota \dot{\alpha}, \sigma \varkappa v \dot{\varphi} \tau 0 \nu \tau \alpha \varsigma, \dot{\varepsilon} \phi \tau \nu \mu \eta, \varkappa \alpha \varphi \varkappa \eta \vartheta \dot{\eta}, \pi \rho \alpha \chi \tau \iota x o ́$; Psycharis also changes fricatives into stops after

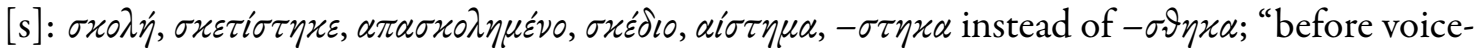
less consonants, $\nu[, \mu$, and $\gamma]$ are not fitting": $\sigma \nu \beta \iota \beta \alpha \sigma \mu o ́ s, \sigma \nu \beta o v \lambda \eta \dot{\eta}, \sigma v \chi \omega \rho \omega ́, \tau \eta[\tau \eta \nu], \tau \omega[\tau \omega \nu]$, $\delta \varepsilon[\delta \varepsilon \nu], \alpha[\alpha \nu], \pi \rho l[\pi \rho \iota v] ; \lambda \rightarrow \rho / \ldots \phi: \alpha \delta \varepsilon \rho \varphi o ́ s ; \tau \rightarrow \theta / \ldots \rho: \alpha \nu \alpha \vartheta \rho \circ \eta \dot{\eta} ; \gamma \rightarrow \varnothing / \ldots \mu: \pi \rho \alpha \mu \alpha ; \gamma$

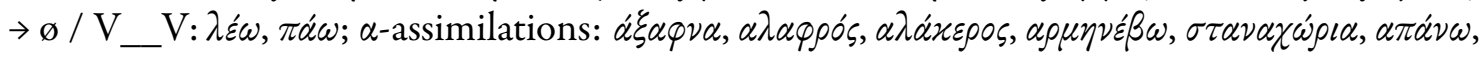

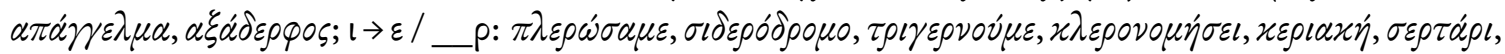

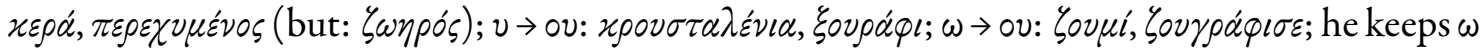
in comparatives: $\lambda \iota \gamma \omega \dot{\tau} \varepsilon \rho \circ$; he omits initial unaccented $\varepsilon$ and $\iota: \varphi \eta \mu \varepsilon \rho i \delta \alpha, \pi \circ \mu \circ \nu \eta \dot{\eta}, \pi \circ \varphi \varepsilon \dot{\varepsilon} \rho \varepsilon \tau \alpha \iota$ (also

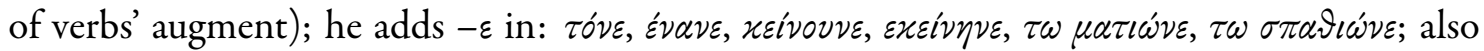

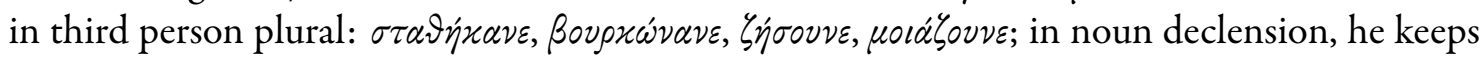
the same stress position, according to the dominant nom. case: $\vartheta \dot{\alpha} \lambda \alpha \sigma \sigma \alpha-\vartheta \dot{\alpha} \lambda \alpha \sigma \sigma \alpha \varsigma$ (instead of

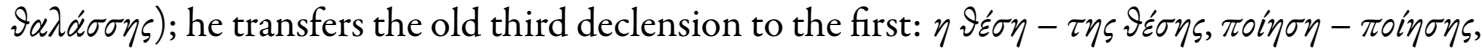
$\lambda \varepsilon^{\xi} \xi \eta-\lambda \varepsilon^{\prime} \xi \eta \varsigma, \sigma \eta \mu \varepsilon i \omega \sigma \eta-\sigma \eta \mu \varepsilon i \omega \sigma \eta \varsigma$, etc.; plural: $\varepsilon \pi \alpha \nu \alpha \dot{\lambda} \lambda \eta \psi \varepsilon \varsigma, \varphi \rho \alpha \dot{\sigma} \sigma \varepsilon \varsigma, \lambda \varepsilon \dot{\xi} \xi \varepsilon \varsigma ;$ masculine and feminine

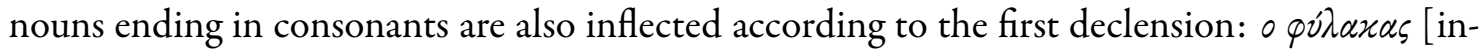

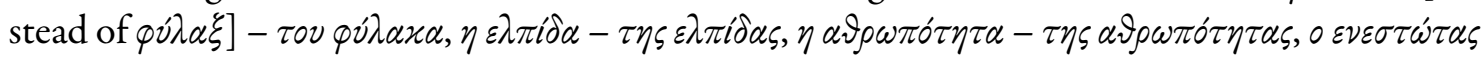

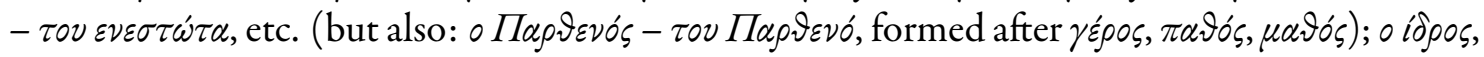

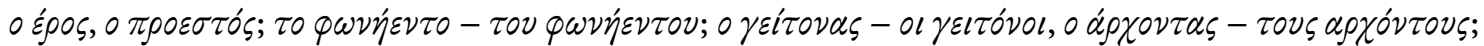

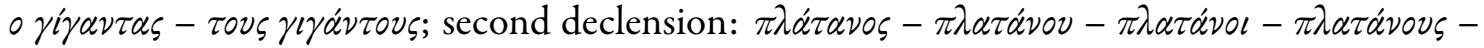

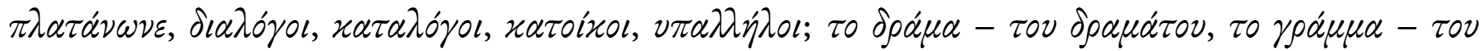

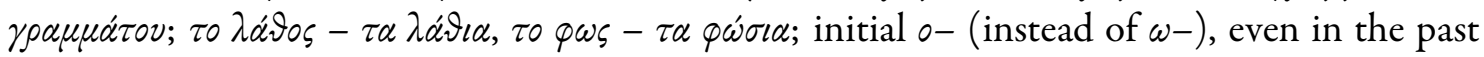

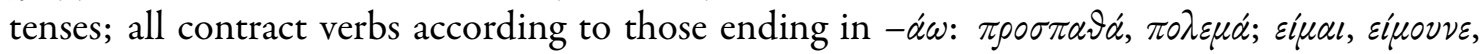

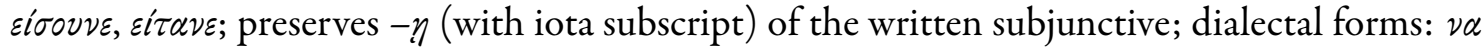

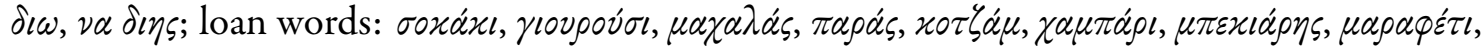

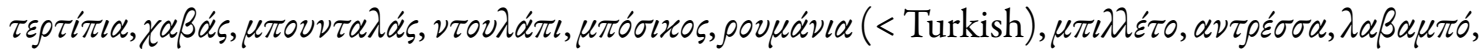

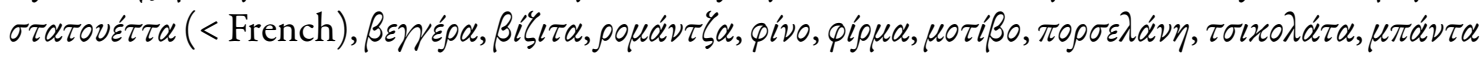

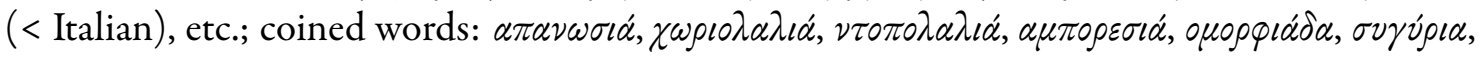




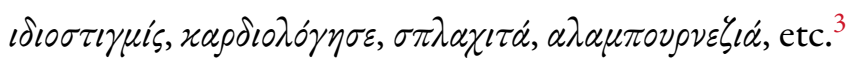

The above list summarizes how Mandilaras summarizes Psycharis's norm. Notice the anachronism in Mandilaras's description of Psycharis's norm: in almost every "rule" of the form $A \rightarrow B$, e.g. $\lambda \rightarrow \rho / \ldots \phi$ : $\alpha \delta \varepsilon \rho \varphi o ́ s$, A seems to be a variant that was standard but Psycharis did not choose or became standard despite what Psycharis opted for. Mandilaras is not simply saying: "of the available variants these are the ones Psycharis opted for", i.e. the variants B; he is also implying that "those other variants, A, are the ones he should have opted for, because it is those that were or became standard-despite Psycharis's own preferences. This kind of portraying Psycharis's norm is not merely anachronistic; it is itself normative: it implies that Psycharis should have opted otherwise, he shouldn't have made the choices he made.

Mandilaras also presupposes that there has been a particular list of $d o s$ and don'ts, a norm that Psycharis unequivocally adhered to. The truth is that, as Psycharis kept elaborating his personal style, he changed his mind several times favoring different variants and following different "rules" at different times. Horrocks (2010, p. 448-449, citing Mackridge, 1988) comments on just one instance of such a change in standards, an instance that, paradoxically, marks the birthdate of Psycharis's standard, if we assume it coincides with the publication of My Journey:

It is important to note [...] that changes were made between the first edition of My Journey in 1888 and the second in 1905. Psycharis took great pride in his Constantinopolitan connections, and the language of his youth at first took precedence in his writing, leading to the use of many now non-standard features in the first edition. By the time of the second edition, however, his conception of demotic had changed in the face of criticism of his usage.

Horrocks (2010, p. 449-451) goes on listing quite a few phonological, morphological, and syntactic Constantinopolitanisms that Psycharis abandoned. A meticulous comparison of the two editions of My Journey by Balomenou (2012) reveals a total of 910 deliberate changes, mostly morpho-phonological ones; just a few are replacements of localisms, be they Constantinopolitanisms or other, while new localisms appear in the second edition. Rather, the most important changes in the 1905 edition (judging from the number of their instances) are, according to Balomenou (2012), the following:

endings in $-n \#$ are replaced by $-n e \#$ (in line with Psycharis's general preference for open ending syllables), affecting many declensional paradigms, such as third person plural verb-endings

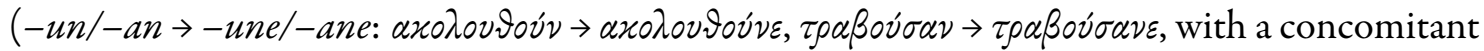

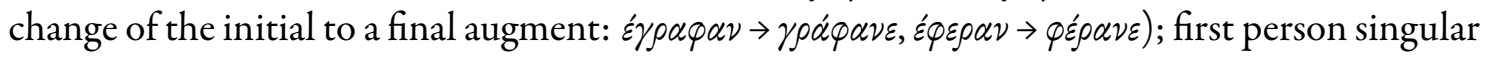

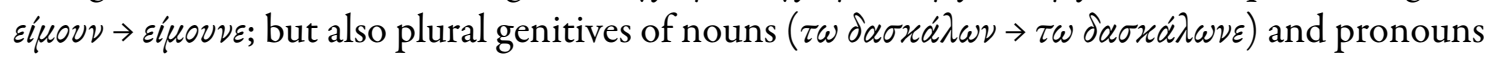
$(\tau \dot{\sigma} \sigma \omega \nu \rightarrow \tau \dot{\sigma} \sigma \omega \nu \varepsilon)$. The perfective marker $-k s-$ is simplified to $-s-\left(\rho \omega \tau \dot{\eta}^{\prime} \xi \omega \rightarrow \rho \omega \tau \dot{\eta}^{\prime} \sigma \omega, \sigma \pi \circ \nu \delta \dot{\alpha} \xi o \nu \mu \varepsilon\right.$ $\rightarrow \sigma \pi \circ \nu \delta \dot{\alpha} \sigma o v \mu \varepsilon)$. The particle $\pi \circ v$ is replaced by either the complementizer $\pi \omega \varsigma$ or a relative form $\left(\pi \circ v \rightarrow \pi \omega \varsigma / \sigma^{\prime} \pi \circ\right)$. Finally, and much less importantly, the accusative of the object clitics, common in the dialect of Constantinople, is replaced by the genitive form, common in the Southern dialects $(\mu \varepsilon \rightarrow \mu \circ v, \sigma \varepsilon \rightarrow \sigma 0 v)$.

All changes of the form $\mathrm{A} \rightarrow \mathrm{B}$, "variant $\mathrm{B}$ replacing variant A", are instances of what we will later call: "correctives", i.e. self-conscious acts of correcting the speech of one's own and of others. Psycharis's changes between the two editions (his "correctives") demonstrate, I would think, the following preliminary claims: first, and most obviously, some variation should be assumed to exist before the elaboration of a standard; second, some variation might exist - inevitably, perhaps-within a standard; and, third, the variation within a standard is, at least to a certain degree, subject to whims, arbitrary, immotivé. From these three preliminary claims one may deduce that the rationalization of a standard is a later development in its

\footnotetext{
${ }^{3}$ Notice, in passing, that contrary to what is generally believed, Psycharis was lenient towards the use of internal loans, i.e. adaptations of ancient Greek words in the modern language.
} 
evolution; concomitantly, the retrospective recognition of variants which became standard at an earlier stage of the language is but an anachronism. As for Psycharis's Constantinopolitanisms, quite a few, of course, were abandoned in the second edition of My Journey. But Psycharis's main concern was not the idiom of Contantinople; as the above list demonstrates, his concern was rather to prescribe the usage of variants which lay claim to becoming standard. Some of his preferred variants deviate from what became a standard ( $\tau \dot{\sigma} \sigma \omega \nu \varepsilon$ instead of $\tau \dot{\sigma} \sigma \omega \nu$ ), while others became an integral part of the standard ( $\rho \omega \tau \dot{\eta} \sigma \omega$ instead of $\left.\rho \omega \tau \eta^{\prime} \xi \omega\right)$.

Although there are no studies of linguistic variation in Psycharis's novels, his novelistic style is oral and playful, no matter how "artificial" it sounds to the modern ear (Chrissomali-Henrich, 2005, p. 202-203). His literary standard, precisely because it is idiosyncratic, is also far from uniform. Strangely enough, it does not comply with the standards attributed to him, as the following excerpt, chosen almost randomly

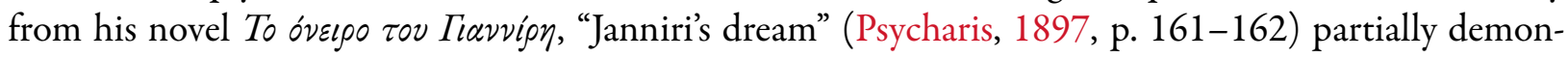
strates:

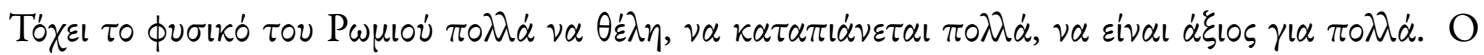

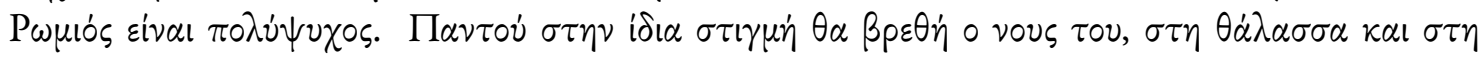

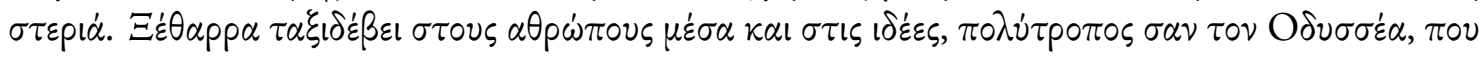

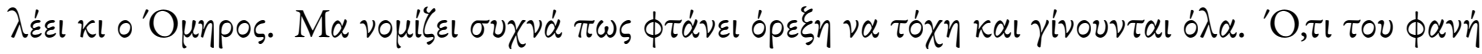

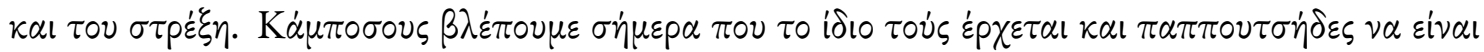

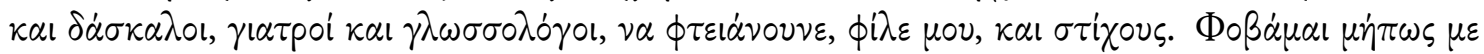

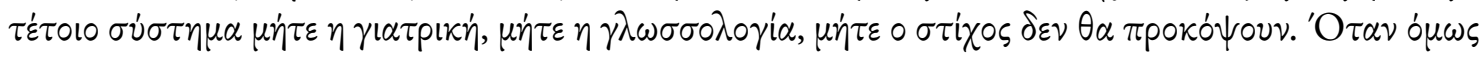

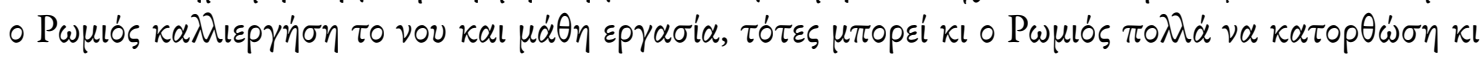

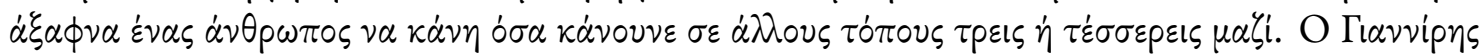

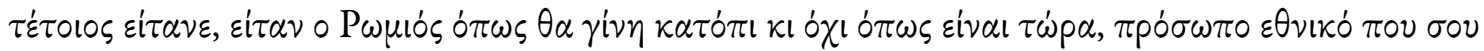

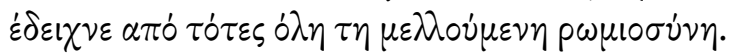

It is only natural for the Greek [Romios, n. masc., sing.] to seek after many things, to be busy with many things, to be competent at many things. The Greek has many souls. His mind will wonder everywhere at the same time, at the sea and on the land. He travels within people and through ideas, fearless, a man of twists and turns, like Ulysses, as Homer would have it. He is confident that when there's a will, there's a way. He fancies himself to be this or that. We see so many today who claim to be at the same time shoemakers and teachers, doctors and linguists; some even write lyrics, my friend. I'm afraid that with this mentality, neither medicine, nor linguistics, nor poetry will ever make any progress. But when the Greek cultivates himself and sets his mind to learn a specific task [job], then he can achieve much and one man alone would suddenly do what in other countries takes three or four men to do. Janniris was this kind of man, he was the Greek to become, not the Greek as he is now, he was an individual of the nation revealing in himself the whole of the future Greekhood [Romiosini].

Perhaps this is not great literature. The character, Janniris, is higly ideologized: onto him is projected Psycharis's stereotype of Greekhood (and manhood). Perhaps the character was created after the writer himself ("Janniris" could very well be a portmanteau for "Jannis Psycharis"). But the language is fluent. Some deviations from today's orthography are insignificant; the subjuntive ending $-\eta$ was also retained in later writers; and personally, I find the $\varepsilon i v \alpha \iota-\varepsilon i \tau \alpha \nu \varepsilon(\varepsilon)$ orthography much more systematic than the $\varepsilon i \nu \alpha \iota-\dot{\eta} \tau \alpha \nu(\varepsilon)$ orthography. There are no "extremities" of those Psycharis had often been accused. The style is oral, conversational even - or it pretends to be. There is variation in word order ( $\pi \circ \lambda \lambda \alpha \nu \alpha \vartheta \varepsilon \lambda \eta$,

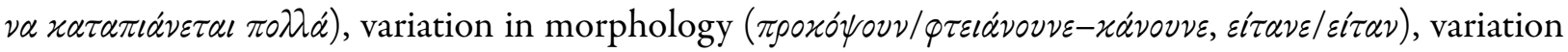

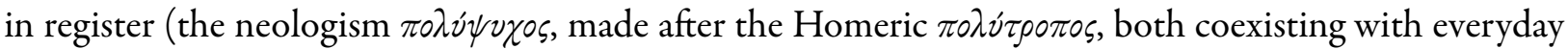
words, e.g. $\pi \alpha \pi \circ v \tau \sigma \dot{\eta} \delta \varepsilon \zeta$ "shoemakers", and "demotic" variants, e.g. $\tau \dot{\tau} \tau \varepsilon \zeta$ ). One gets the impression that Psycharis is striving afer a written standard that would allow him to be oral. Bad novelist perhaps; competent writer nevertheless, Psycharis standardized the language by example, through his own writings, 
not only prohibiting but also exploiting some variation. True, Psycharis might have envisaged "a single language variety $[\ldots]$ for all purposes, both oral and written, allowing little leeway for variation according to linguistic register" (Mackridge, 2009, p. 226); but he himself did not write in such a uniform variety.

The idea that Psycharis followed a very strict and uniform standard most probably originated in the writings of his enemies. It is being perpetuated in the relevant historiography, where it is often claimed that Psycharis, influenced by the systematic "natural laws" of the neogrammarians, allowed of no exceptions to his rules (Kriaras, 1981, p. 182-183; Babiniotis, 2011, p. 432-435; cf. Mackridge, 2009, p. 215-228). The conception of Psycharis's language as "orthodox" and "dogmatic", "artificial", "puristic", "uncompromising", "overdemoticized" or "excessively $\mu \alpha \lambda \iota \alpha p \eta$ " ("hairy", i.e. vulgarized) is an ideological misconception - a méconnaissance-constructed by his enemies and uncritically reproduced by historians. We will come back to the issue of uniformity in the Conclusions and discussion section, where we will also discuss some of the problems that standardization by example poses for our performative theory of language standardization.

Manolis Triantaphyllidis was not one of Psycharis's opponents; but Psycharis did not want him as an ally either. He spoke of Triantaphyllidis with scorn; he called him "naïve" ( $\alpha \gamma \alpha \theta$ ós). He considered him to be an advocate of a "compromise" with katharevousa, the archaistic high variety. He accused Triantaphyllidis of "flirting" with katharevousa and tried to expose his "mixed" standards (Psycharis, 1924). And he was right. Triantaphyllidis himself had admitted the need for a compromise with katharevousa, although he also opted for a more "uniform" 'school demotic' (cf. Mackridge, 2009, p. 228). But all this was past, even as it happened. Retrospectively, the only thing that matters is that Psycharis's standard failed; Triantaphyllidis's prevailed.

The major reference work of demotic, the Modern Greek Grammar (of Demotic) by Triantaphyllidis et al., was published in 1941, a period of hardship. Triantaphyllidis chaired the committee that was set up by Ioannis Metaxas the dictator with the task to compile a grammar of Modern Greek based on the demotic norm; there is a consensus that the Grammar published in 1941 was mainly the work of one man, Triantaphyllidis.

The new Grammar marked an important shift in the standards of demotic. Psycharis had proposed a radical grammatical modernization of the language. It sought to impose on the standard the systematicity of its oral varieties, it would employ rural variants and provide for the morpho-phonological adaptation of learned or archaistic vocabulary. His norm was in sharp contrast to the archaistic norms of the high, written variety of katharevousa (actually, there had never been a single variety of katharevousa just as there was no single variety of demotic, both standards varying according to writer). In contrast, Triantaphyllidis's norm was based on what has been ever since considered to be the urban variety of the educated middle class (cf. Mackridge, 1985, p. vi). This new norm was much more tolerant towards learnedisms, not avoiding unadapted archaisms or foreignisms. Neither standard (or should I say, neither variety), neither Psycharis's nor Triantaphyllidis's, were pure; but Triantaphyllidis's own was manifestedly not so. Triantaphyllidis did not merely elaborate on Psycharis. He believed that a controlled mix of demotic with the high variety would facilitate its acceptance, it would cause a de-ideologization of demotic, making it easier for the State to embrace it. Thus, through the State's adoption, an end would be put to the perennial "Greek Language Question” (Frangoudaki, 1977, p. 104-116; Moschonas, 2010). Triantaphyllidis preferred to call his Grammar "the State Grammar".

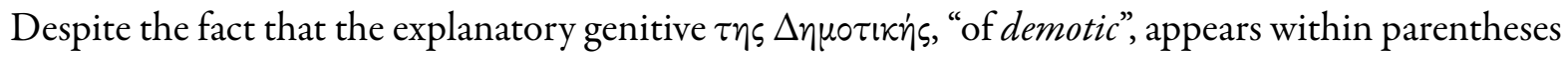
in the title of this State Grammar, Triantaphyllidis would most probably have preferred the term "Modern Greek koine" - i.e. what today is called Standard Modern Greek. His standardization formula, simply put, was the following:

Koine $[$ Standard Modern Greek $]=$ Low $[$ Demotic $]+$ High $[$ Katharevousa $]$ (as needed). 
Triantaphyllidis et al. (1978) proposed a standard that was far from uniform. The Grammar was at the same time prescriptive and variationist; see Triantaphyllidis's own Preface to the Grammar, especially $\kappa \alpha^{\prime}$, $\left.\kappa \beta^{\prime}-\kappa \delta^{\prime}\right)$. Fig. 1 shows page 102 of the Grammar, where derivation is discussed and several high/low (katharevousa/demotic) variants are listed. The terms Triantaphyllidis prefers for such variants are $\lambda o^{\prime} \gamma(\varepsilon \varsigma$,

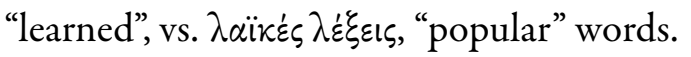

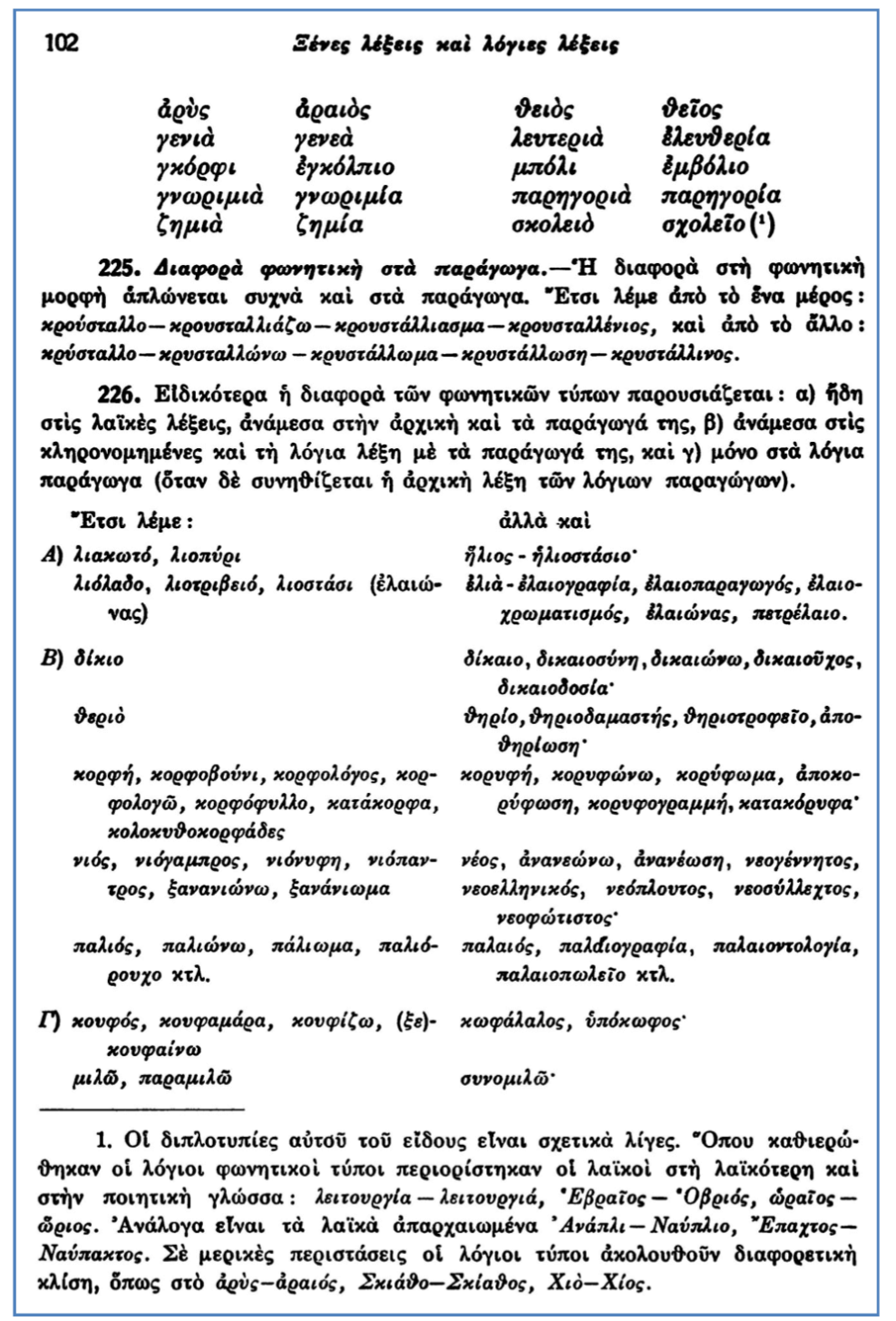

Figure 1: Page 102 from Triantaphyllidis et al. (1978).

Page 102 belongs to Part II of the Grammar, entitled "The Words”, which is almost completely devoted to lexical variation. It should be stressed at this point that Triantaphyllidis's attitude towards foreignisms was not puristic (for his early work on borrowing, see Papanastasiou, 2011). Excerpts from pages 231 and 232, shown in Fig. 2, belong to Part III of the Grammar, where Modern Greek morphology is presented. In Fig. 2 we see a much more common way of handling variation: a declensional paradigm is presented first and under it, following a series of examples (in the gray box), the possible variants or "exceptions" appear. Notice that the vocative form $\pi \dot{\alpha} \tau \varepsilon \rho$ is also used in the nominative by many speakers of Modern

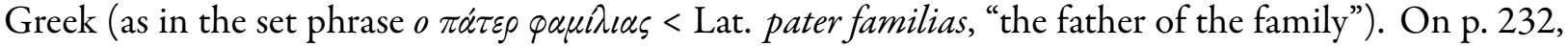
Triantaphyllidis simply lists as variant these forms (o $\left.\pi \alpha \tau \varepsilon \rho \alpha \varsigma / \pi \alpha \tau \eta^{\prime} \rho / \pi \dot{\alpha} \tau \varepsilon \rho\right)$, although, by the standards of Ancient Greek or of katharevousa or, for that matter, by today's standards, the nominative $\pi \dot{\tau} \tau \varepsilon \rho$ should have been treated as a blatant mistake. 


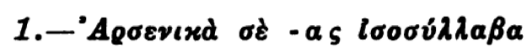

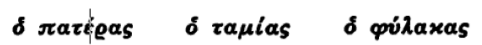

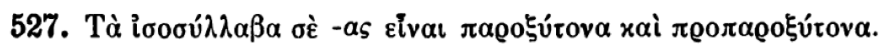

\begin{tabular}{|c|c|c|c|c|c|c|}
\hline \multicolumn{7}{|c|}{ Evixòs } \\
\hline${ }^{\circ} \mathrm{Ovo \mu}$. & $\delta$ & $\pi \alpha \tau \hat{\varepsilon} \varrho \alpha \varsigma$ & $\delta$ & 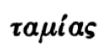 & $\delta$ & qv́laxas \\
\hline$\Gamma \varepsilon v$ & $\tau o \tilde{v}$ & 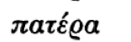 & $\tau o \tilde{v}$ & $\tau \alpha \mu i \alpha$ & $\tau o \tilde{v}$ & qúlaxa \\
\hline Ait. & $\tau \dot{\partial} v$ & 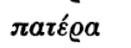 & $\tau \grave{o v}$ & 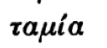 & tò & $\varphi v ́ d a x \alpha$ \\
\hline $\mathrm{K} \lambda \eta \tau$. & & 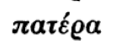 & & $\tau \alpha \mu i \alpha$ & & púdaxa \\
\hline \multicolumn{7}{|c|}{ 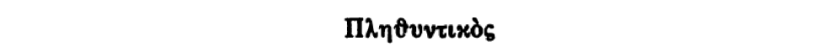 } \\
\hline${ }^{\circ} \mathrm{O} v \boldsymbol{}$ & of & $\pi \alpha \tau \varepsilon \varrho \varepsilon \varsigma$ & oi & $\tau \alpha \mu i \varepsilon \varsigma$ & oi & 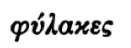 \\
\hline$\Gamma \varepsilon v$. & $\tau \tilde{\omega} \nu$ & $\pi \alpha \tau \varepsilon \varrho \omega \nu$ & $\tau \tilde{\omega} \boldsymbol{\nu}$ & $\tau \alpha \mu \iota \tilde{\omega} \nu$ & $\tau \tilde{\omega} \boldsymbol{v}$ & $\varphi v \lambda\langle a ́ x \omega \nu$ \\
\hline Ait. & toùs & 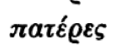 & 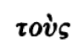 & $\tau \alpha \mu i \varepsilon s$ & toùs & púlaxes \\
\hline $\mathrm{K} \lambda \eta \tau$. & & $\pi \alpha \tau \dot{\varepsilon} \varrho \varepsilon \varsigma$ & & 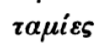 & & 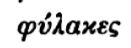 \\
\hline
\end{tabular}

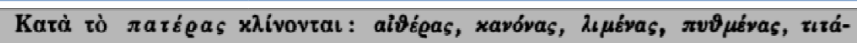

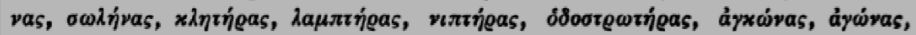

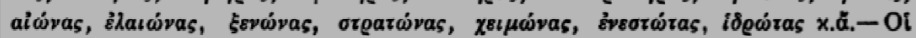

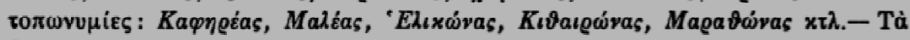

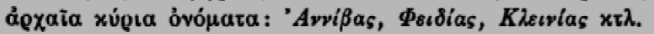

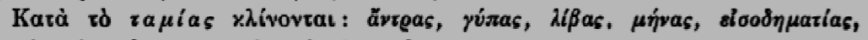

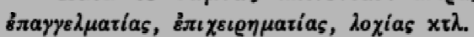

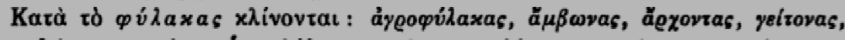

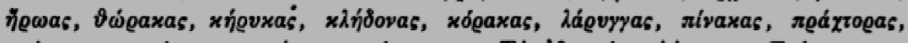

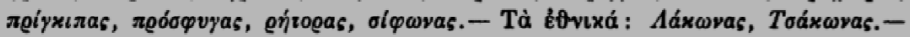

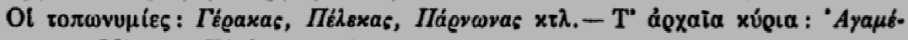

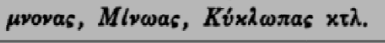

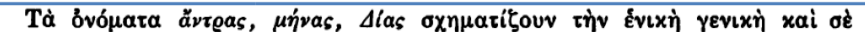

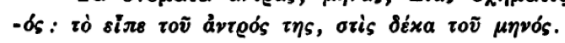

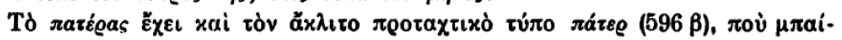

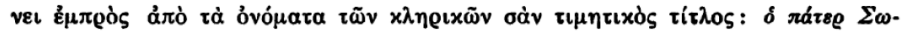

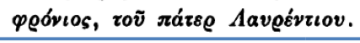

Figure 2: Excerpts from pages 231 and 232 from Triantaphyllidis et al. (1978): a declensional paradigm followed by examples and variants.

Parentheses are also used in Triantaphyllidis's Grammar as a typographical device for indicating variation; usually the forms within parentheses are the less preferred ones:

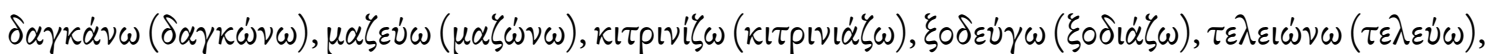

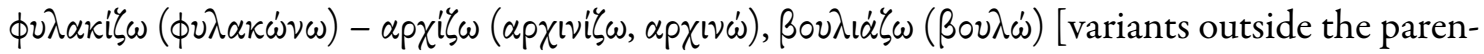
theses "are preferred in prose"] (Triantaphyllidis et al., 1978, p. 349).

Sometimes though, the typographical device of parentheses seems to indicate unconditional, free variation:

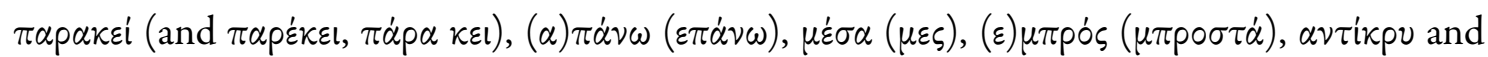

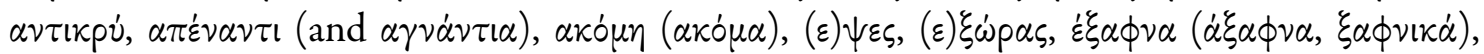

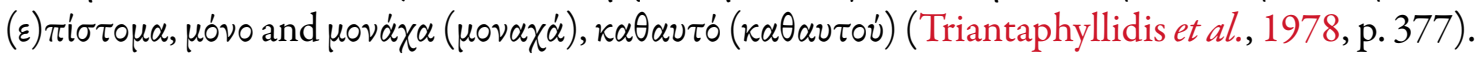

\section{Study 1: Correctives in Triantaphyllidis's Grammar}

But how much variation is there in Triantaphyllidis's Grammar? And how much variation is excluded or simply left unaccounted for? To answer these questions in a precise manner, we need an exact procedure for measuring prescriptivism—or its lack thereof.

One such procedure is to count what I have elsewhere (Moschonas, 2005c, 2008) called "correctives" (or corrective instructions). A corrective can be defined as a directive act of a metalanguage-to-language 
direction of fit. ${ }^{4}$ There are at least two types of correctives: correctives proper and permissives. In their simplest form, correctives proper consist of three parts: a prohibitive ('one should neither say nor write $\mathrm{X}^{\prime}$ ); a normative ('one should say or write Y'); and an explicative part ('because Z'). For example, the following is a corrective:

"we [should] say/write $\sigma v \beta ı \beta \alpha \sigma \mu o ́ s ~[$ sivivazmos], "compromise" (Y) instead of $\sigma u \mu \beta ı \beta \alpha \sigma \mu o ́ s[$ simvivazmos] (X), because our phonology does not accept the combinations [nasal] + [fricative]" $(\mathrm{Z})$ (Psycharis, 1888, p. 163 ff.; 1905, p. 155 ff.)

A permissive is also a directive act of a metalanguage-to-language direction of fit. In their simplest form, permissives also consist of three parts: a permissive part ('one may say or write $\mathrm{X}$ in addition to/alongside $\mathrm{Y}$ '); a normative part, which usually expresses a usage condition on $\mathrm{X} / \mathrm{Y}$ variation (' $\mathrm{X}$ occurs under condition $\mathrm{C}_{1}$; $\mathrm{Y}$ occurs under condition $\mathrm{C}_{2}$ '); and an optional explicative ('because $\mathrm{Z}$ '), which usually repeats the normative/conditional part. For example, the following is a permissive:

"one may say/write $\delta \alpha \gamma \kappa \omega \dot{\nu} \nu \omega$, "to bite" $(\mathrm{X})$,

but $\delta \alpha \gamma \kappa \dot{\alpha} \nu \omega(\mathrm{Y})$

is preferred in prose $\left(\mathrm{C}_{2}\right)$.

(Triantaphyllidis et al., 1978, p. 349)

Permissives like this one are usually functional in character; each variant is restricted to a domain, assigned a function, or is assumed to have a certain stylistic load. One may also postulate free variational permissives of the form:

\section{$\mathrm{X}$ or/and $\mathrm{Y}$.}

Of course, such permissives, positing a free, unconditional variation, are difficult to come up with in traditional grammars (although we've already seen a few examples from Triantaphyllidis's; see also below re: his "parallel" and "equivalent" variants). The scarcity of unconditional permissives should not surprise us. The tendency to functionalize variation is common to many; it is something like a "natural instinct". Descriptive grammars are assumed to do just that: account for variation by assigning different functions to variants, according to the doctrine of "form-function symmetry" which would assign to each form a different function (Poplack, van Herk \& Dawn, 2002, p. 88-89; Poplack \& Dion, 2009, p. 557; Poplack, Lealess \& Dion, 2013, p. 189; Anderwald, 2016, p. 83, following Zwicky, 2009, calls this doctrine the "principle of one right way"). A similar foundational doctrine of sociolinguistics prescribes that "there are no free variants". I will refer to these doctrines as the form-function fallacy.

Permissives are also victims to this fallacy. Typically, even if they do not explicitly state that one variant is preferred over the other, permissives may still imply, especially in the context of traditional grammars, that one or the other variant is the preferred one: permissives are conditional by implicature. Besides, a permissive can be very easily turned into a corrective, by stating that the condition for a variant to occur has been violated. For example, in the place of the functional permissive from Triantaphyllidis's Grammar cited above, the following corrective can be made up:

4"Direction of fit" is a classificatory criterion employed by John Searle in his "A taxonomy of illocutionary acts" (in Searle, 1979, p. 1-29). According to Searle, there are four possible directions of fit between speech acts (words) and states of affairs (world): a) words-to-world, b) world-to-words, c) both of the above, d) none of the above. Directives (commands, requests, etc.), of which correctives arguably form a subcategory, are assumed to have a world-to-words direction of fit (Searle, 1979, p. 14). Obviously, Searle's taxonomy is too narrow. There is at least one category of speech acts, namely the correctives (both correctives proper and permissives), which seem to have a words-to-words direction of fit (from metalanguage to language). If correctives are assumed to have the force of directives and provided that facts about language are facts about the world, then correctives should also be taken to have the world-to-words direction of fit characteristic of the directives. I consider this a theoretical issue not of significance for the discussion that follows. More on the performative theory of correctives in the Conclusions and discussion section. 
one should not write $\delta \alpha \gamma \kappa \omega \dot{v} \omega \omega$, "to bite" (X),

because $\delta \alpha \gamma \kappa \dot{\alpha} \nu \omega(\mathrm{Y})$

is preferred in prose $(\mathrm{Z})$.

The corrective is already implied in the permissive, and for this reason I will not refrain from calling both correctives proper and permissives by their general name: correctives.

So far we have seen examples of correctives (either correctives proper or permissives) in their regular forms (or in forms regularized for convenience). Actually, in Grammars and Usage Guides, correctives rarely appear in their regular, full forms (Moschonas \& Spitzmüller, 2010, p. 23-26). Correctives might be elliptical (missing a part, i.e. X or Y are not both specified or no Z is offered). Missing an explicative part is common: in many instances no justification is offered for a corrective; or the explicative provides what appears to be a circular justification ("one should not say or write X, because it is not advisable-correct, proper, appropriate, well-expressed, etc.- to say or to write X”); or it invokes a more general corrective, to which it is not but an instance. In such cases, we might have to work from analogy with other correctives, or consider similar correctives the one in question clusters with; or we might have to probe a bit deeper into the general prescriptive mentality of a text in order to understand the reasons for its preferences. Correctives also differ as to their specificity. We can distinguish type correctives (general instructions) from token correctives (specific instructions); again, a token-instruction may be offered as an example to a more general type-instruction, i.e. ' $\mathrm{x}_{1}, \ldots, \mathrm{x}_{\mathrm{n}}$ should be avoided as tokens of $\mathrm{X}$ '; or ' $\mathrm{y}_{1}, \ldots, \mathrm{y}_{\mathrm{m}}$ should be preferred as tokens of $Y^{\prime}$; or a token corrective may simply be an instance of a general "rule", i.e. of a general type-instruction. Permissives can also be elliptical, type, or token, as we can see in the examples that follow, which were all taken from Triantaphyllidis et al. (1978) and they are chosen to illustrate the differences between the various types and forms of correctives and/or permissives: ${ }^{5}$

Type correctives: "the koine, the common form of the language [Y] should be given; and this has a double sense: without archaisms, i.e. learned forms $\left[\mathrm{X}_{1}\right]$, and without dialectalisms [or localisms: $\left\llcorner\delta \omega \omega \mu \alpha \tau \iota \sigma \mu o^{i}\right]$, i.e. dialectal forms $\left[\mathrm{X}_{2}\right]$ - except, of course, when any of these are essential for the common language" (p. $\eta^{\prime}$ )

Token correctives: "some by mistake say $\alpha \pi \circ-\theta \alpha \nu \alpha \tau i \zeta \omega[\mathrm{X}]$, 'immortalize', while the correct form is $\alpha \pi-\alpha \theta \alpha \nu \alpha \tau i \zeta \omega$ ” [Y] (p. $154 \$ 342)$

Type/elliptical correctives $(\mathrm{X} / \varnothing)$ : “The right thing is to avoid having many abstract nouns depending on each other with genitives” $[\mathrm{X}]$ (p. $230 \$ 524$ )

Type/elliptical correctives $(\varnothing / \mathrm{Y})$ : "It is necessary, as more people get educated, that the learned words expressing concepts of the Modern Greek culture $\left[\mathrm{Y}_{1}\right]$ spread and be popularized to the wider population. And, on the other hand, those living in the cities should also be acquainted, with the help of literature and education, with popular words [ $\left.Y_{1}\right]$ ” (p. $182 \$ 415$ )

Token/elliptical correctives $(\mathrm{X} / \varnothing)$ : "many writers insist on using an orthography that is un-

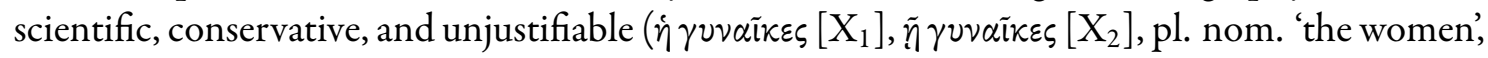

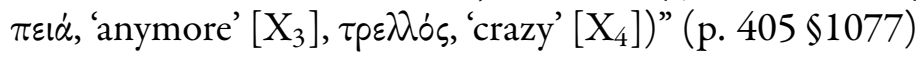

Token/elliptical correctives $(\varnothing / \mathrm{Y})$ : "during the last decades, it is often necessary to devise fem. forms for masc. nouns denoting professions [Y]. In the people's language $[\lambda \alpha \ddot{x} \dot{\eta} \gamma \lambda \dot{\omega} \sigma \sigma \alpha]$ these

\footnotetext{
${ }^{5}$ In all the examples that follow I have omitted the explicative part $\mathrm{Z}$ (even when one is provided), which would make all the examples Z-elliptical; hence, by elliptical it is hereby meant X/Y-elliptical. Correctives proper are not so easy to find in Triantaphyllidis's Grammar-and this is a surprising result. X/Ø-token elliptical correctives, i.e. correctives without a preferred variant, are difficult to find anywhere, except as examples to $\mathrm{X} / \varnothing$-type correctives ("avoid dependent genitives"; "avoid passives"; "avoid obscurity"; etc). Elliptical permissives are symbolized (X/Y), since X/Ø and Ø/Y do not differ in the case of permissives.
} 


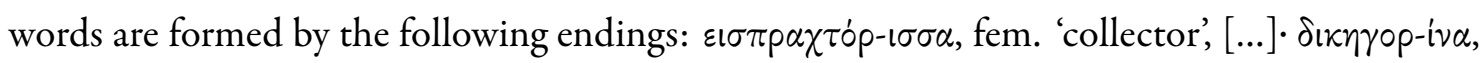
fem. 'lawyer', [...]” (p. 217 n. 1)

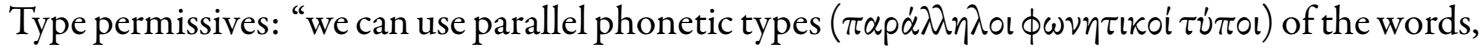
one of learned origin [Y] and the other of popular origin $[X]$ " (p. 101 \$224); "words can have

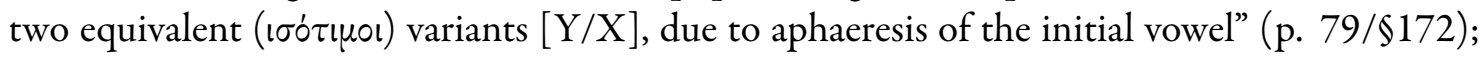
"usually, older loans [Y] are declined; newer ones are not [Y]" (p. 255 \$598)

Token permissives (corresponding to the three type-permissives of the previous paragraph): " $\varepsilon \kappa-$ $\kappa \lambda \eta \sigma i \dot{\alpha}[\mathrm{X}]$ but also $\varepsilon \kappa \kappa \lambda \eta \sigma i \alpha$ [Y]" [are parallel phonetic types] (p. $101 \$ 224$; cf. p. 103 n. 2);

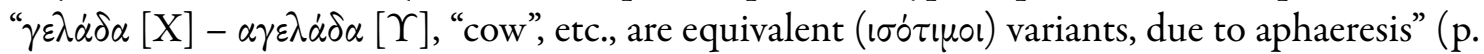

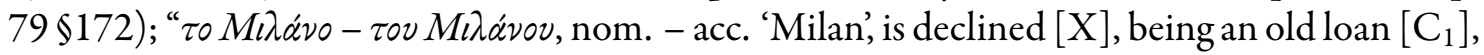
but $\tau 0^{\prime} O \sigma \lambda_{0}-\tau 0 v^{\prime} O \sigma \lambda o$, nom. - acc. 'Oslo' [Y], is not, being a new one $\left[\mathrm{C}_{2}\right]$ ”

Type/elliptical permissives $(\mathrm{X} / \mathrm{Y})$ : "As for those nouns denoting profession that do not have a fem. form, if it is still necessary to refer unambiguously to a woman, we can use the masc. form modified by the word yvvaika, 'woman' $[\mathrm{X} / \mathrm{Y}]:[\ldots]$ ".. (p. 217 n. 1)

Token/elliptical permissives (X/Y, corresponding to the type/elliptical permissive of the previ-

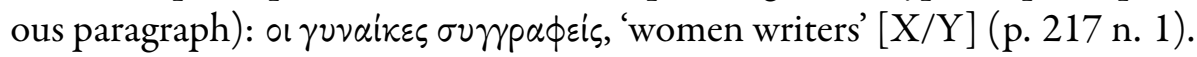

As it is the case with all speech acts, be they linguistic or metalinguistic, there are of course indirect correctives, which are difficult to pin down, because they often masquerade as descriptive or "constative" acts (Austin, 1975, 3), i.e. as unbiased scientific statements. For example, a declension table in a grammar textbook, such as the one in Fig. 2, will usually be interpreted as a systematic exposition of grammatical facts (as a complex 'expositive', in Austin's terms); but it might also, indirectly, have the illocutionary force of a corrective, i.e. the force of an 'exercisitive', in Austin's terms, or of a 'directive', according to Searle's commoner terminology. We cannot know what its particular force is, unless we are aware of variants that the table omits or mishandles, or unless we can think of an alternative table (e.g., one emphasizing katharevousa variants rather than demotic ones); not unless, that is, we have become critical of the table in one way or another. It is not only permissives that can be easily transformed to correctives proper; almost any descriptive grammatical statement could be interpreted as prescriptive, i.e. as a corrective, under particular circumstances. In things linguistic, one can very easily switch from 'this is how things are' to 'this is how they should be'.

For this reason, I have only counted explicit permissives in Triantaphyllidis's Grammar. As explained already, correctives proper would be difficult to pin down, because they remain ambiguous as to their force. Indeed, some of the most well-known correctives in Triantaphyllidis's Grammar are its famous omissions; the Grammar has been criticized precisely because it omits, e.g., the learned adjectives in -

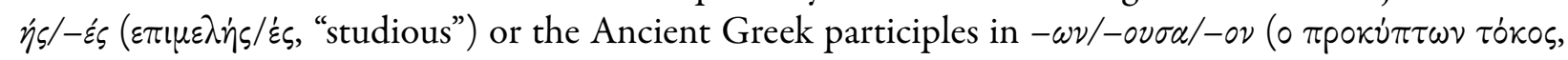

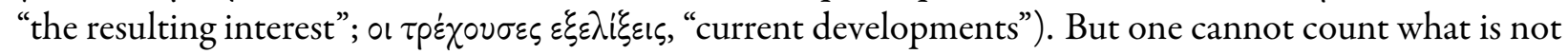
there.

Following Setatos (1991, p. 34-36), permissives were categorized according to the type of differentiation (i.e., the normative condition) that they are instances of. The results are summarized in Table 1.

Table 1 is quite revealing as regards Triantaphyllidis's attraction and tolerance towards variation. We notice first that there are only a few references to localisms and dialectalisms (48/1 689, i.e. 2.8\% of the total number of permissives), which, as we have seen, played an important role in the formation of Psycharis's standard. There is a relatively high number of references to high/low (diglossic) variants $(278,16.5 \%)$, which are suggestive of Triantaphyllidis's "compromise" with katharevousa, for which he had been accused by Psycharis. It is very interesting however that the Grammar contains references to standards beyond demotic and katharevousa; there is mention of new trends, of urban koines, and local 


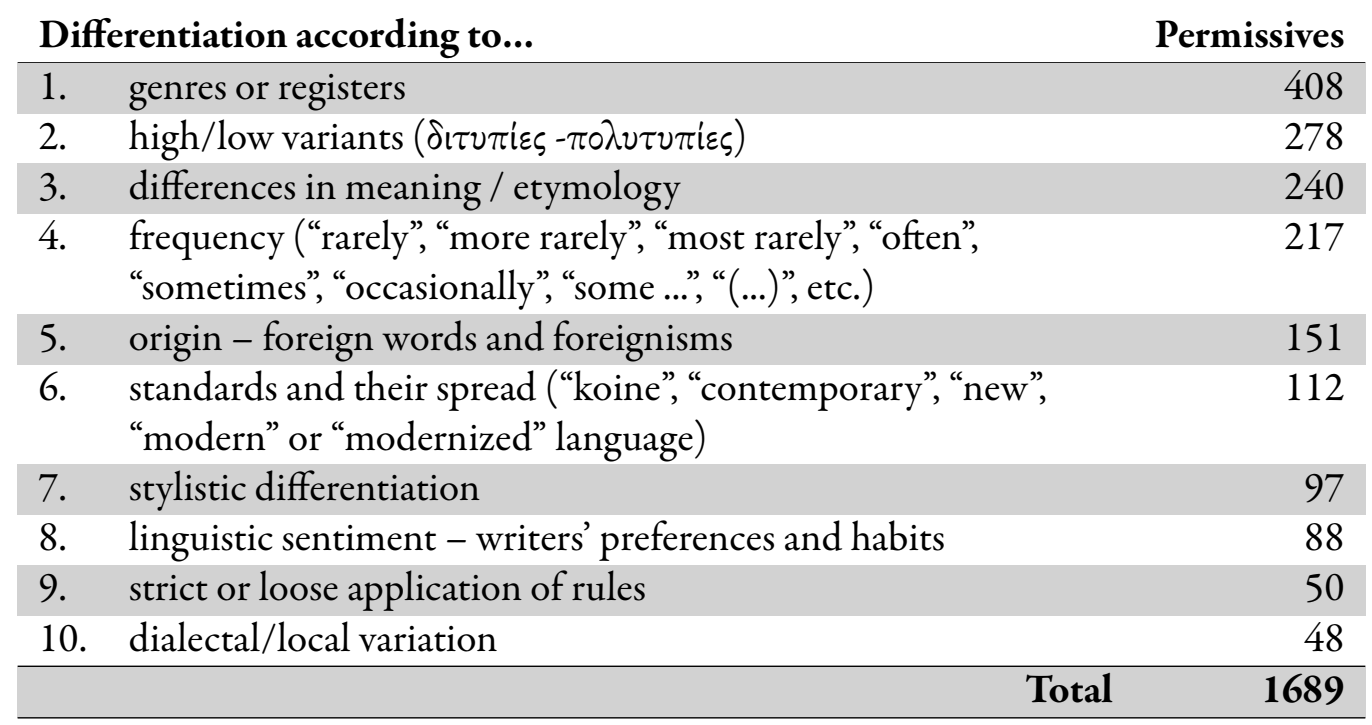

Table 1: Types of variation (permissives) in Triantaphyllidis et al. (1978).

standards (112, 6.6\%); the grammatical statements are sensitive to tendencies $(217,13 \%)$ and it is often stated (metalinguistically, so to speak) that the very grammar rules can only be applied loosely (50, 3\%). It should also be noticed that Triantaphyllidis and his associates seem to employ consistently a somewhat primitive sociolinguistic system of usage labeling, possibly of lexicographic origin.

Further, Triantaphyllidis's account of language contact is not a puristic one, as evidenced by a considerable number of references to word origins, foreignisms, loans, adaptations, calques, etc. (151, 8.9\%). One can barely find in the corpus of the Grammar twenty (20) correctives proper concerning foreign words or foreignisms, and these are mostly orthographic, e.g. they provide instruction on how better to transliterate foreign words or foreign author names.

Triantaphyllidis leaves plenty of room to stylistic variation-broadly conceived: as accommodation to a genre or register $(408,24 \%)$; as a formality scale, an alignment with the situation, an indicator of the speaker's intention or the speaker's specific speech act (97, 5.7\%); as a marker in a literary style (88, 5\%); etc. There are also in the Grammar 268 citations from 44 Modern Greek authors and only 25 from traditional folk songs-although in the Introduction to the Grammar (p. $\left.k \beta^{\prime}\right)$ it is expressly stated that the "the grammatical norm that the Grammar teaches is founded on the grammatical basis of the traditional folk songs and of the new literature", a claim which turns out to be inaccurate concerning its first part.

The Modern Greek Grammar (of Demotic), however, is far from being a stylistics Guide. Its main contribution is the systematic presentation of Modern Greek morphology. "[T]he Trianta[ph]yllidis grammar has not yet been superseded as the most authoritative account of Modern Greek morphology" (Mackridge, 2009, 301). It is the morphology part of the Grammar that is being very often epitomized, starting with Triantaphyllidis's own "Short Grammar" (1965), intended for school use.

Iordanidou (1999) is one of the earliest studies showing that today's SMG admits of considerable variation (that is, it is not a "uniform" standard) ${ }^{6}$. Indeed, Triantaphyllidis's "mixed" standard has become, one might say, naturalized (or it is being justified as such) precisely in the framework of modern, descriptive linguistics. It prevails in reference works such as descriptive Grammars and Dictionaries. What once had been accused of as an artificial "mixed" norm has now become, quietly, a perceptual guide to Modern

\footnotetext{
${ }^{6}$ Haugen (1966b, p. 932-933) discusses three procedures for the construction of a standard: the comparative-suitable for related dialects—, the archaizing — resorting to a reconstructed older form —, and the statistical - favoring the forms that have the widest usage. But he does not envisage any of the standards thus obtained as being variational themselves; in all three cases, he thinks of the standard as "unitary". For a recent discussion of "unitary" vs. "compositional" standards, see Pickl (2019). I consider any standard as admitting of variation, not just the "compositional" ones, for which SMG qualifies.
} 
Greek's “richness” or "plurality”. Triantaphyllidis's standardization formula (Koine $=$ demotic + learned forms, as necessary) has assumed the status of a descriptive principle. Recent Modern Greek Grammars, including Holton, Mackridge \& Phillipaki-Warburton (1997), as well as all major Dictionaries of Modern Greek, persistently mark real or alleged differences between "learned" and "popular" forms or vocabulary

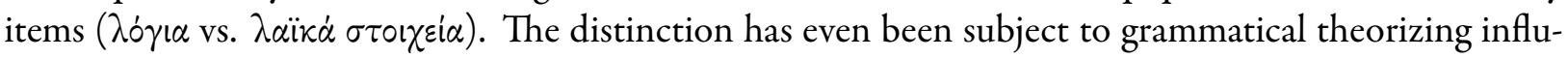
enced from markedness theory (Anastasiadi-Symeonidis \& Fliatouras, 2003). One almost needs to be reminded that permissives, too, are acts of prescription.

Grammarians of Modern Greek now take for granted the existence-and prominence-of the urban variety presumably spoken and written by the educated middle class (cf. Mackridge, 1985, p. vi). Holton, Mackridge \& Phillipaki-Warburton (1997, p. XV) state in their Introduction to their scholarly Grammar of Modern Greek that

the language described in our grammar is the form spoken and written by educated Greeks from the urban centers of Greece, which, while it is primarily based on demotic vocabulary, phonology, morphology and syntax, displays a significant influence from katharevousa.

This could have been a statement by Triantaphyllidis himself, despite the fact that Holton, Mackridge \& Phillipaki-Warburton's Grammar is markedly different from Triantaphyllidis's and also despite the authors" concession that "the Greek language has changed considerably since then [1941, when Triantaphyllidis's Grammar was published]" (ibid.).

How did Triantaphyllidis's standard manage to prevail-if, after all, it were his standard that has prevailed? To answer this question, we have to look at how standards are institutionalized, mediated and disseminated. Standards are not reproduced only through formal education. In the next section we will look at how corrective instructions are assembled in repertories and mediated through book-length Usage Guides, advice columns in the newspapers, TV and radio broadcasts, dedicated websites.

\section{Repertories}

Having adopted katharevousa (the high variety), the dictatorial regime of 1967-1974 did its best to discredit its use. Precisely because of its political association with the junta regime, the high variety lost its legitimacy. The misuses and abuses of katharevousa during the dictatorship were soon disparaged, contributing to the demotion of the high variety's status (Frangoudaki, 1992, p. 368-370).

In 1976, after the establishment of a parliamentary democracy, a language-educational reform put an end to the "Greek Language Question" by legislating for a standard that came to be known, among lin-

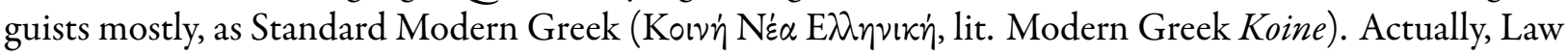

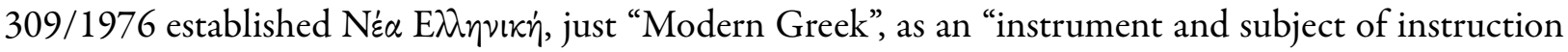
at all levels of general education". Modern Greek was defined as "demotic that has become a panhellenic instrument of expression as used by the Greek people and the esteemed writers of the Nation, expressed without idiomatic expressions and extremities". The law itself was written in katharevousa (Mackridge, 2009, p. 319).

In 1982, with a follow-up orthographic reform, the polytonic (multiple-diacritics) system of the ancient Greek texts, also used until then for the writing of Medieval and Modern Greek, was replaced by a monotonic (single-diacritic) system. The main implementer of this orthographic reform was Emmanuel Kriaras (1983, p. 213-263). The polytonic system was invented to mark the pitch-accent of Ancient Greek, which had changed into a stress-accent by the years of the Hellenistic Koine; the monotonic system is not just simpler, it better represents Modern Greek stress patterns. Kriaras's follow-up reform was thus not met with resistance, although in certain political and literary circles the advocacy for the polytonic

\footnotetext{
${ }^{7}$ For a strikingly similar formulation in a radically different sociolinguistic setting, cf. Longmore (2007): "without idiom or tone" (Hugh Jones).
} 
has not ceased. The conservative daily "E $\sigma \tau i \alpha$ " and the literary journal "N $\varepsilon^{\prime} \alpha \mathrm{E} \sigma \tau i \alpha$ ", among others, are still printed with the polytonic diacritics; but this was also the case of the political review of the left "O

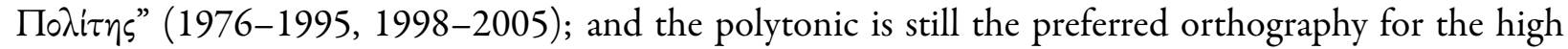
register of poetry. The association in public discourse of demotic with monotonic and of katharevousa with polytonic was and remains strong, despite being historically inaccurate; both Psycharis and Triantaphyllidis were using the polytonic orthography.

Language-ideological debates continued well after the official resolution of the "Language Question" (Moschonas, 2001a, 2004, 2009, 2014). Some debates presupposed and reproduced the old cleavage between katharevousa and demotic. For example, the long debate on whether Ancient Greek should be taught in secondary education (Kriaras, 2010; Koutsou, 2004; Panagiotakakis, 2014) was often argued for or against in the press and in book-length libels under the erroneous presumption that 'Ancient Greek $\approx k a t h a r e v o u s a$, i.e. that the archaistic, puristic variety was the closest equivalent to 'Ancient Greek', while

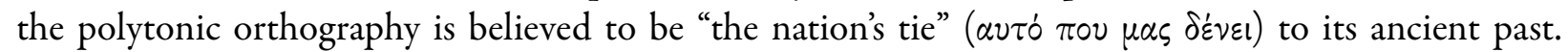
I suspect that, rendered in psychological terms, the identification of Ancient Greek with katharevousa qualifies as an instance of transference-just as the identification of language with its written form is an instance of metonymy. Ancient Greek is also spoken of in the print media as if it were a single, uniform variety (mostly with Attic Greek in mind).

Alongside the recycled ones, new issues also emerged after the language reforms, especially after the mid 1980s: the new reality of the E.U. brought to the fore issues of multilingualism and language contact. All through the 1990s, the mild concern over the influence of English on Modern Greek might have reinforced a puristic katharevousa-like attitude towards loans from English, especially in the field of technological terminology. Moschonas $(2004,2009)$ argues that the very fact of new issues being raised after the language-regime change of 1976; the ways all issues, new and old ones, evolved in the press; the arguments with which they were being debated; they all indicate that the "language-ideology brokers" (Blommaert, 1999, p. 9), no matter which camp they belonged to, all shared a common conception of SMG as a full-blown language, a language of "full languageness" (Blommaert, 1999, p. 431), homogeneous, of marvelous uniformity, but in constant need to remain secure from "internal and external enemies"- a language that has finally become coextensive with the nation's real or symbolic "territory" (Moschonas, 2004). Obviously, the "Language Question" was over. Unto us a Standard was born.

One may assume, following Thomas (1991, p. 100-114), that language standards (some of which relate to purism, so brilliantly studied by Thomas) follow the paths of ideologies, i.e. they propagate in waves, gradually expanding to outer concentric circles: from an elite to a small circle of devotees and promoters and, through them, to the "general public" (if there is such a collective entity). For this top-down model of dissemination to be effective, several conditions have to obtain: The standard has to be institutionalized; indeed, educational institutions play a huge role in disseminating and consolidating language standards. It also has to be mediated; all available media (the print media, radio, television, the internet) that are believed to have the power to "educate the public" are put to the service of standardization, if not in any other way, by example: by regulating their own usage. Not least, in order to be effective, dissemination of standards has to be achieved on a mass scale. With these three preconditions, a linguistic habitus is gradually formed, which will later be thought of, by linguists, i.e. by the main propagators of language standards, as expressing the "common linguistic sentiment" or a native speaker's "linguistic intuition", an intuition they will invoke again in order to redescribe the standards they or their colleagues of the past had prescribed (Bourdieu, 1991).

Let's see then how the standards of a Standard Language are being propagated through metalinguistic texts that undertake to elaborate on a Standard's standards. Again, we will concentrate on prescriptivism's minimal units: the correctives. Arguably, different groupings of correctives form different repertories, which can be compared either synchronically or diachronically; when compared synchronically, they reveal competing standards within a community at a particular period of time; when compared diachron- 
ically, they reveal changes in standards over time. Repertories are contained in what I will summarily call Usage Guides, i.e. metalinguistic texts that present and elaborate on repertories of correctives, to the study of which we now turn.

\section{Study 2: Usage Guides}

With the language-regime change of 1976, language ideologies emerged on a mass scale. As shown in Moschonas (2005c), after 1976 there was a sudden increase of publications about language use. Only a few of the early Usage Guides remain in circulation today (e.g., Diplas, 1977; mesevrinos, 1978; Dorbarakis, 1979). Later Usage Guides, however, are often reprinted, although rarely updated. Some of them contain texts that were first published in the press (e.g., Papazafeiri, 1987, 1997; Haris, 2003, 2008; Pappas, 2004); others are addressed specifically to journalists (e.g., Karzis, 1995; AПЕ 1988; Maronitis, n.d.; Tzanneta-

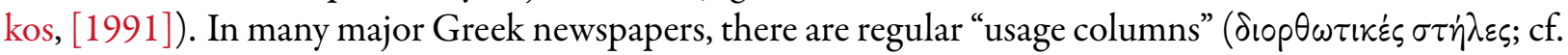
Moschonas, 2001b), a special category of articles offering advice on issues of language use. (I present and compare three instances of this genre below.)

It is not only in the print media that corrective instruction and advice is provided. Correctives are also broadcasted over the radio and television. Kriaras (1988) contains his famous television feuilletons, as one might call them, broadcasted over the state TV channel ERT1 over the period 1985-1987. The texts in Lypourlis (1994) were first broadcasted from the private radio channel Paratiritis (in Thessaloniki). The popular TV show "O issues of language usage. There are now several websites, which provide instruction on issues of grammar

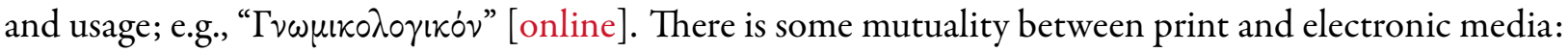
most entries from Haris $(2003,2008)$, originally published in the press, were also made available in the author's weblog [online]; conversely, Sarantakos (2007) reprints texts that first appeared in his weblog [online]; for other weblogs on language issues, see Vassilaki (2012). I will adopt the term 'Usage Guides' (Tieken-Boon van Ostade, 2010) for this genre of metalinguistic texts, irrespectively of the medium in which they appear and I will employ the term "usage columns" ( $\delta$ iop$\theta \omega \tau i k \varepsilon \dot{\varepsilon} \sigma \tau \dot{\eta} \lambda \varepsilon \varsigma)$ for any of those texts published in magazines or newspapers on a regular basis.

Moschonas (2001b) compares and analyzes samples from three usage columns:

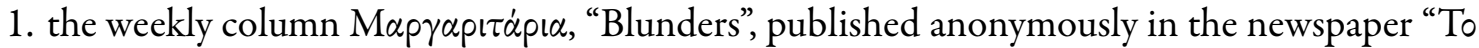

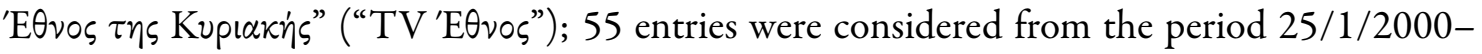
25/11/2001;

2. the weekly 2-5 columns (page-long) $\Gamma \lambda \omega \sigma \sigma o \mu \alpha \chi^{i \varepsilon \varsigma, ~ " L a n g u a g e ~ B a t t l e s ", ~ p u b l i s h e d ~ i n ~ t h e ~ T V ~}$ magazine "P $\alpha \delta ı \tau \eta \lambda \varepsilon \delta \dot{p} \alpha \sigma \eta$ ", signed under the pseudonym $\Gamma \lambda \omega \sigma \sigma \alpha \mu \nu \dot{\nu} \tau \omega \rho$, "language defender" [Nikos Politis]; 87 texts were examined: the first 21 and the last 66 of the whole period of publication, 16/4/1994-22/6/2001;

3. the biweekly 3-column (full-page) entitled Mıрpd $\gamma \lambda \omega \sigma \sigma \iota \alpha \dot{\alpha}$, "Minor Language Issues" (henceforth: "Minor L. Issues"), published in the Saturday's edition of the newspaper "T $\alpha$ N $\varepsilon \alpha$ ” ("T $\alpha$ $\left.\pi \rho o ́ \sigma \omega \pi \alpha-2 \operatorname{los} \alpha \omega^{\prime} \omega \alpha \varsigma^{\prime}\right)$, written by the columnist J. Haris (partly reprinted in Haris 2003): 43 texts were considered from the period 13/8/1999-4/8/2001.

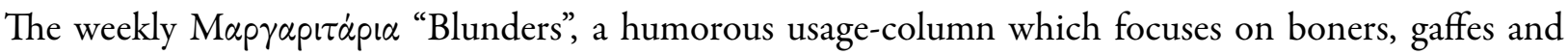
malapropisms said on television, deserves special mention, as it provides a straightforward instantiation of correctives. The structure of a corrective (prohibitive-normative-explicative) is recalled from the very layout of the column. Fig. 3 is a picture of the "Blunders" of 25/2/2001. The column usually contains 3-5 correctives; in this case, the minimal number is provided. Notice that each corrective (indicated by an asterisk $*$ ) is divided into precisely three parts. Each part is prefixed by a set phrase (printed in bold

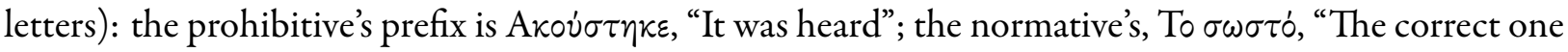




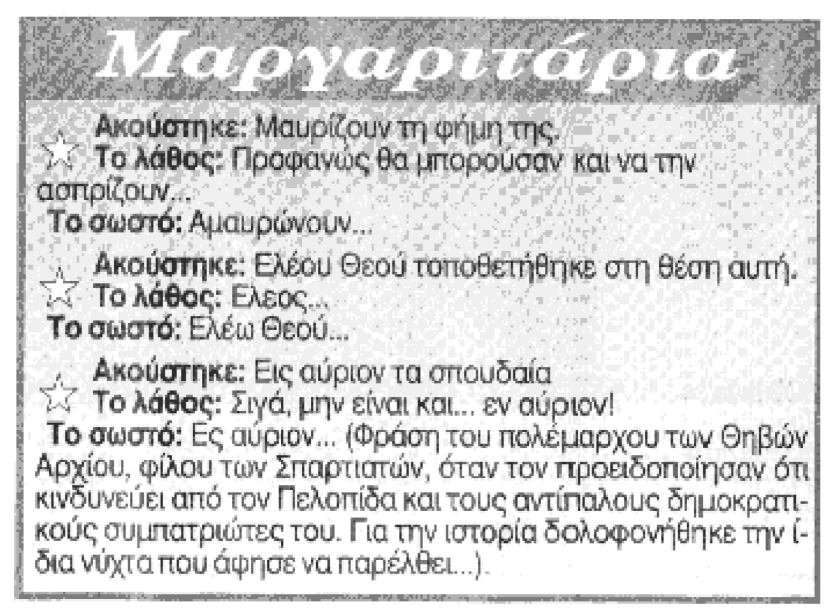

Figure 3: "Blunders", 25/2/2001.

is”, and the explicative's, To $\lambda \dot{\alpha} \theta \circ \varsigma_{5}$, “The mistake is”. First, the prohibitive is issued; last comes the normative; and in between we have the explicative (in the third corrective in Fig. 3, additional encyclopedic information, which would normally belong to the explicative, is provided after the normative part; this is uncommon). The explicative is usually a humorous remark. Here is a tentative translation of the three correctives in Fig. 3:

It was heard: They blacken [ $\mu$ avpiלouv, demotic] her fame

* The mistake is: Well, you couldn't expect them to whiten it...

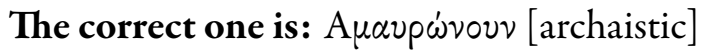

It was heard: He holds this position by divine right [ $\varepsilon \lambda \varepsilon \dot{\varepsilon} \circ v$, gen., $\left.\Theta \varepsilon \circ v^{\prime}\right]$

* The mistake is: Have mercy...

The correct one is: $\mathrm{E} \lambda \dot{\varepsilon} \omega$, dat.

It was heard: Serious business for the morrow [Eıs $\alpha$ vipıv $\tau \alpha \sigma \pi \circ v \delta \alpha i \alpha]$

* The mistake is: Fortunately, you didn't say $\varepsilon v$ av́pıov [in tomorrow]

The correct one is: Es avipiov

([because it is] a set phrase, said by Archias, friend of the Spartans, when he was warned of the plot against him; indeed, Archias died that very night [Plutarch, "The life of Pelopidas" 10.4; by the way, Perrin's edition reads sis aípıov $\tau \dot{\alpha} \sigma \pi 0 v \delta \alpha i a])$.

Most of the correctives, however, are not about linguistic mistakes (or what are considered to be such). They are about blunders, gaffes, slips of the tongue ("faults", in line with Goffman, 1981, p. 208-213). This is the case with the column's correctives shown in Fig. 4; I provide a translation of only the last triplet:

It was heard: We finished second among the first

* The mistake is: Well, you should become a statistics expert

The correct one is: Just 'second', the rest is otiose

"Blunders" are addressed to a wider audience and they often aim at ridiculing well-known media personalities. "Blunders" are direct, self-explanatory, and, one may assume, they share the commonest of the common presuppositions. From Fig. 3 already, the following two presuppositions can be deduced: first, set archaistic phrases should not be altered, should not be demoticized in any way; and, second, those who make the mistakes are ignorant, uneducated, and they deserve our scorn. The ultimate target of "Blunders", and perhaps of all prescriptivism, might not be the language, but the speakers who, through 


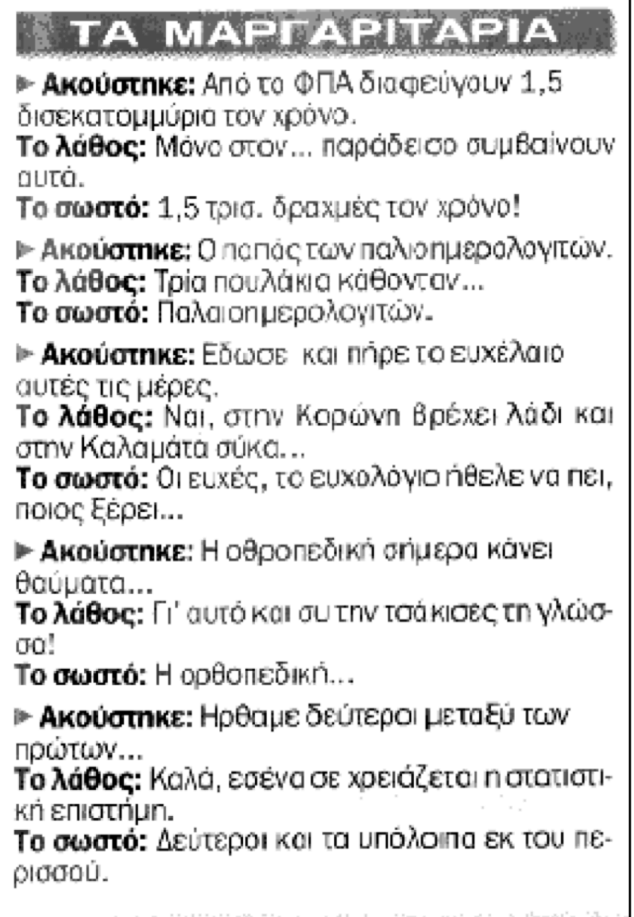

Figure 4: "Blunders", 27/5/2001.

their use of language, are exposed for "ignorance and want of taste" (Swift, 1984, p. 253). Social and linguistic prescription are commonly fused (Mugglestone, 2003, p. 1).

The identification of correctives in the other two columns, "Language Battles" and "Minor L. Issues", is not as straightforward. These two are much more argumentative-much more 'metalinguistic', one might say. They are guided by dogma and the corrective instructions they issue are much finer. "Language Battles" and "Minor L. Issues" did not merely address different audiences over different epochs in the evolution of the Usage-Guide genre; they also represented different mentalities. "Language Battles" is a somewhat old-fashioned column; it displays an encyclopedic, decontextualized approach to linguistic issues, which are described with all the perplexing formalities of traditional Grammars. And even though printed in a TV magazine, the column focuses mostly on written speech. "Minor L. Issues" also focuses on written speech, but its examples are drawn mostly from contemporary literature (originally written in Modern Greek or translated). The author of this column claims (falsely) that he relies on contemporary linguistics and he often asserts a "demythologizing" attitude to language issues. He is overtly demoticist, intolerant towards "unnecessary archaisms". Time and again, he pours scorn on the abuses of katharevousa. Despite the modesty of its title, "Minor L. Issues" becomes a polemical column when driven by ideological motives.

Some important differences in the language ideology and the mentality of the columnists can be deduced from Table 2. Table 2 employs binary semantic features to summarize the results of a content analysis of the three usage columns (Moschonas, 2001b). The question mark indicates that a usage column does not bear the semantic feature in question unequivocally; ' $\mathrm{n} / \mathrm{a}$ ' means that the semantic distinction is not relevant to the publication at hand:

As regards the general language ideology of the columnists (expressed en passant or in statements of intent), both "Language Battles" and "Minor L. Issues" declare being demoticist and they both accept the idea of a common, uniform language: a Standard. However, only the former accepts the ideology of "uninterrupted continuity" ( $\left.\alpha \delta \dot{\delta} \alpha \sigma \pi \alpha \sigma \tau \eta \sigma \nu v^{\prime} \chi \varepsilon 1 \alpha\right)$ of the Greek language, an ideology erroneously attributed to non-demoticists (Christidis, 2008, p. 105). "Minor L. Issues" is much less tolerant towards archaisms. Although, openly, both "Language Battles" and "Minor L. Issues" declare they are not puristic, in practice they adopt a puristic attitude towards loans, which, in the case of "Language Battles", amounts 


\begin{tabular}{|c|c|c|c|}
\hline & "Blunders" & $\begin{array}{c}\text { "Language } \\
\text { Battles" }\end{array}$ & $\begin{array}{c}\text { "Minor L. } \\
\text { Issues" }\end{array}$ \\
\hline demoticist & $\mathrm{n} / \mathrm{a}$ & $\begin{array}{c}+ \\
(?)\end{array}$ & + \\
\hline $\begin{array}{l}\text { common } \\
\text { /Standard }\end{array}$ & $\mathrm{n} / \mathrm{a}$ & $\begin{array}{l}+ \\
(?)\end{array}$ & $\begin{array}{l}+ \\
(?)\end{array}$ \\
\hline $\begin{array}{l}\text { historical } \\
\text { continuity }\end{array}$ & $\mathrm{n} / \mathrm{a}$ & + & - \\
\hline $\begin{array}{l}\text { archaisms } \\
\text { tolerated }\end{array}$ & $\begin{array}{c}+ \\
(?)\end{array}$ & + & - \\
\hline $\begin{array}{l}\text { declares } \\
\text { being puristic }\end{array}$ & $\mathrm{n} / \mathrm{a}$ & $\overline{(?)}$ & (?) \\
\hline is puristic & + & + & + \\
\hline $\begin{array}{l}\text { focuses on } \\
\text { written language }\end{array}$ & - & + & $\begin{array}{l}+ \\
(?)\end{array}$ \\
\hline pro-monotonic & $\mathrm{n} / \mathrm{a}$ & + & + \\
\hline $\begin{array}{l}\text { variation } \\
\text { tolerated }\end{array}$ & $\mathrm{n} / \mathrm{a}$ & $\begin{array}{c}+ \\
(?)\end{array}$ & $\overline{(?)}$ \\
\hline $\begin{array}{l}\text { right-wrong } \\
\text { (correctness) }\end{array}$ & + & + & + \\
\hline $\begin{array}{l}\text { good-bad } \\
\text { (eloquence) }\end{array}$ & - & - & + \\
\hline $\begin{array}{l}\text { Lexical- } \\
\text { Phraseological }\end{array}$ & + & + & + \\
\hline $\begin{array}{l}\text { Grammatical- } \\
\text { Morphological }\end{array}$ & - & + & - \\
\hline $\begin{array}{l}\text { Historical- } \\
\text { Etymological }\end{array}$ & - & + & - \\
\hline
\end{tabular}

Table 2: Comparison of three usage columns. Source: Moschonas (2001b, p. 60).

to suggestions for adaptation of foreign words through calquing, and in the case of "Minor L. Issues", in the selection between available translation loans. Both columns focus on written language: "Language Battles" draw their examples mostly from newspapers, while "Minor L. Issues" draw mostly from contemporary literature. As regards the orthography, both are pro-monotonic. In contrast, "Blunders", as mentioned already, focus exclusively on unscripted spoken language. Despite occasional declarations to the contrary, no usage column in Table 2 is tolerant towards variation. They all employ a polar wrong-right distinction; correctness is thought to be absolute and non-gradable. "Minor L. Issues" occasionally evaluate discourse excerpts with a vague aesthetic criterion (along the scale 'good-bad' and its many synonyms). However, the correctness criterion prevails over the aesthetic one in all three columns.

An interesting phenomenon also captured in Table 2 is a gradual shift in the standards of the Standard Language, as witnessed by the models of corrective instruction that predominate in each usage column. The model of corrective instruction originally associated with Triantaphyllidis's Modern Greek Grammar (ofDemotic) is the Grammatical-Morphological model, which places emphasis on grammar, and especially

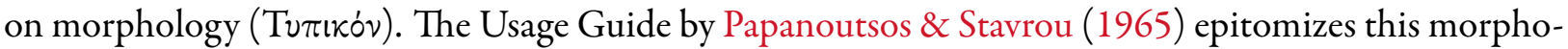
logical approach: it was meant as a companion to Triantaphyllidis et al. (1978) and, apart from some introductory orthographic remarks and an Appendix on the monotonic system, it provides instruction on the declension of nouns, adjectives, pronouns and on the conjugation of verbs. Here are the first three remarks (consecutively numbered) concerning noun declension (Papanoutsos \& Stavrou, 1965, p. 3132):

10. Singular nominative of the masculine nouns. It always end $s$ in $-\varsigma$; before $-\varsigma$ one of the five

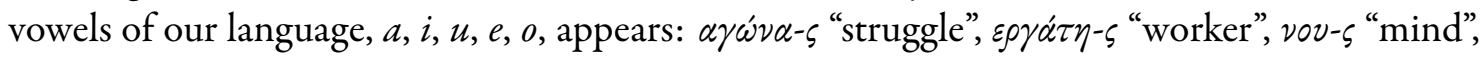


$\mu \varepsilon v \varepsilon \xi \dot{\varepsilon}-\varsigma$ "violet", $\lambda \alpha \sigma_{-} \varsigma$ “people”. [...]

11. The singular accusative of masculine nouns is formed by cutting out the $-\varsigma$ of the nominative: $\alpha \gamma \dot{\omega} \nu \alpha, \varepsilon \rho \gamma \dot{\alpha} \tau \eta, \nu \circ v, \mu \varepsilon \nu \varepsilon \xi \dot{\varepsilon}, \lambda \alpha o^{\circ}[. .$.

12. The singular vocative of masculine nouns in $-o \varsigma$ is formed in $-\varepsilon[-e]$ ( of the other nouns, it is identical with the accusative [...].

On the other hand, the Historical-Etymological model, originally associated with katharevousa (the high variety), stresses the "continuity" of the Greek language and it tends to explain contemporary morphology as a deviation from Ancient Greek grammar or as a step in the historical development of the "invariable" ( $\varepsilon v i \alpha i \alpha)$ Greek language. Despite its association with the archaistic high variety, the HistoricalEtymological model predominates in all discussions of orthography, with the exception of the monotonic system.

Finally, the Lexical-Phraseological model places emphasis on the Lexicon, it focuses on words and set phrases. It is a "folk" model, in that it concentrates on referential lexical elements, which are "easily susceptible of native awareness" (Silverstein, 2001, p. 400).

Now, all three models of corrective instruction are usually found in all Usage Guides, but not to the same degree. The comparison of the older "Language Battles", on the one hand, with the newer "Minor L. Issues" and "Blunders", on the other, is most revealing. "Language Battles", as we have seen, adopt an encyclopedic approach to language issues by employing all three models of corrective instruction; typically, a number of words or phrases are isolated, which are then "corrected" on the basis of both synchronic and diachronic morphology, as documented in traditional Grammars and other reference works. "Blunders" and "Minor L. Issues", on the other hand, seem to take for granted the Grammatical-Morphological model; instead, they base their tutoring on the Lexical-Phraseological model. Further support for this shift in standards is provided in Moschonas (2001b, p. 61-64 and 2005c).

Two points need to be made concerning this shift in standards. First, the Grammatical-Morphological model has not been abandoned; it is merely presupposed. It is now taken for granted, because the demotic variety which it supports has established itself as a "common language", the "language of the people", a "native" language-i.e., it has established itself as a Standard. Obviously, this has not always been the case. If we look again at the excerpt from Papanoutsos \& Stavrou (1965) above, we notice that the authors write as if they were addressing the non-native learner of Modern Greek. Thus, the Grammatical-Morphological model is invoked only when a variant needs to be justified as a standard one; otherwise, it is presupposed. Second, the Lexical-Phraseological model is ideal for accommodating a mixed Standard like Triantaphyllidis's, because it treats words and phrases as self-subsistent units. The correction of an archaistic phrase (e.g., $\varepsilon \lambda \varepsilon \dot{\varepsilon} \circ v \Theta \varepsilon \circ \dot{v} \rightarrow \varepsilon \lambda \varepsilon \dot{\varepsilon} \omega \Theta \varepsilon \circ v^{\text {; }}$ see Fig. 3 above) need not take into account any alternatives; actually, the only alternative to a wrong archaistic expression is the correct one! ${ }^{8}$ Each archaistic word or phrase is treated as a separate case, and each one is considered as "invariable" and "uniform" in its isolation-just like the Standard Language in which it belongs. The Lexical-Phraseological model allows the correction of archaisms and katharevousa-type constructions on a par with demotic words and constructions, "neutralizing" the prior distinction between high and low variants. Thus, the Lexical-Phraseological model provides an effective solution to the "problem" of a mixed, non-uniform Standard.

Correctives do not appear in isolation. They tend to form corrective repertories (Moschonas, 2008, p. 45), i.e. sets of correctives which are grouped together in a Usage Guide or in similar metalinguistic texts. Corrective repertories, one may assume, share common presuppositions and prevail among certain circles for a certain period of time. Corrective repertories are collective repertories.

\footnotetext{
${ }^{8}$ There are several Usage Guides dedicated to learned archaistic expressions; they are self-defined as Dictionaries and indeed they consist of entries ordered alphabetically; e.g. Markantonatos (1998). Iordanidou (2001b) is based on a corpus of texts drawn from Greek newspapers.
} 
Let me provide an example of such a repertory and demonstrate some of its presuppositions. Papakostas (2006) is a newspaper article entitled "The kind of language shaped by the media". It was written by a philologist who at the time was also a member of the Greek National Radio-Television Council

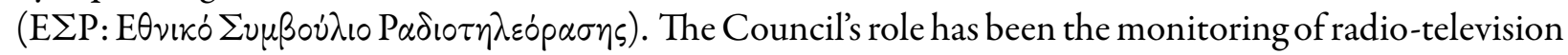
programs to assess whether they comply with existing laws and regulations. Law 3592/2007 art. $20 \$ 2$ does indeed recommend the "correct use of the Greek language" in the print and electronic media. Hence, the repertory we are going to examine now can be seen as an instance of institutional prescriptivism.

Papakostas (2006) believes that the public should be alerted to the following "pathological linguistic phenomena" (the explanations within brackets have been added by me):

* $\tau \omega \nu \nu \pi \alpha \rho \chi o ́ v \tau \omega \nu \pi \rho \beta \beta \lambda \varepsilon \dot{\psi} \psi \omega \nu$

[violation of the nominal agreement rule of archaistic morphology: "of the existing (masc.)

predictions (fem.)" instead of "of the existing (fem.) predictions (fem.)"]

* $\tau \omega \nu \alpha \nu \alpha \lambda \eta \phi \theta \dot{\varepsilon} v \tau \omega \nu \pi \rho \omega \tau \circ \beta 0 \nu \lambda \iota \dot{\omega} \nu$

[same as above: "of the undertaken (masc.) initiatives (fem.)"]

* $\pi \imath \theta \alpha \dot{\alpha}$ instead of $\pi \imath \theta \alpha \nu o ́ v$

[adverbial morphology: inappropriate "demotic" ending for "probably"]

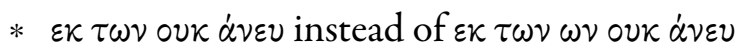

[the Ancient Greek expression for sine qua non, misphrased]

* $\varepsilon \nu \delta \varepsilon \chi o ́ \mu \varepsilon \nu \alpha$ instead of $\varepsilon \nu \delta \varepsilon \chi \circ \mu \varepsilon \dot{\varepsilon} \omega \varsigma$

[adverbial morphology: inappropriate "demotic" ending for "possibly"]

* $\pi p \circ \eta \gamma \circ v^{\prime} \mu \varepsilon \nu \alpha$ instead of $\pi p \circ \eta \gamma \circ v \mu \varepsilon \dot{v} \omega \varsigma$

[same as above: "previously"]

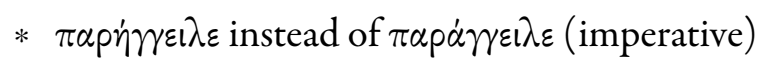

[violation of the archaistic rule that prohibits an internal augment in the aoristic imperative: "do give an order"]

* $\varepsilon \xi \dot{\eta} \tau \alpha \sigma \varepsilon$ instead of $\varepsilon \xi \dot{\xi} \tau \alpha \sigma \varepsilon$

[same as above: "do examine"]

* $\alpha \sigma \kappa \omega$ instead of $\varepsilon \xi \alpha \sigma \kappa \dot{\omega}$

[phraseology: confusion between "to practice" and "to exercise"]

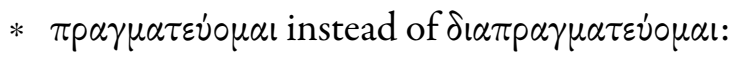

[phraseology: "deal with" instead of "negotiate"]

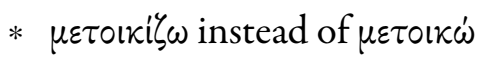

[phraseology: inappropriate form of the learnedism "to change residence"]

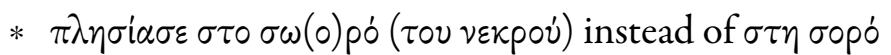

[orthography: "heap, pile" instead of "corpse"]

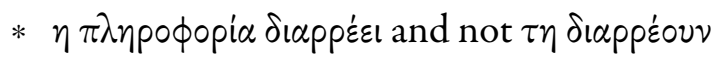

[phraseology: "the information leaked (intrans.)" and not

"they leaked (trans.) the information"].

The entries in Papakostas's index expurgatorius have a very clear form:

$\mathrm{X}$ [prohibitive] instead of $\mathrm{Y}$ [normative],

with only one variation in the last example:

$\mathrm{Y}$ [normative] and not $\mathrm{X}$ [prohibitive]. 
No explicatives are necessary. The examples speak for themselves. They are drawn from a common stock. This repertory clearly focuses on learned expressions. Most of the token correctives can be easily generalized to type correctives: e.g., that high variants, such as the adverbial suffix $-o s(-\omega \varsigma)$, should not be demoticized; that Ancient Greek agreement rules should be respected; that learned expressions should not be modified; etc. Most of the alleged mistakes are violations of archaistic grammar or phraseology. Obviously, archaistic rules are given priority over the rules of demotic. Of course, that SMG should be subject to such historical rules is an explicative that has to be filled in by the interpreter. It is not the only "hidden" explicative in this corrective repertory. There is also the quite common presupposition that deviations from the standard forms or meanings should not be allowed; that, in order for misphrasings or ambiguities to be avoided, the relation of form to function should be 1:1 (the form-function fallacy; see the distinction between $\alpha \sigma x \omega$ and $\varepsilon \xi \alpha \sigma x \omega$, which in no way represents actual usage); that expressions should be precise and clear; etc. The model of corrective instruction is clearly Lexical-Phraseological. Although most corrections are about grammar and morphology, the approach remains focused to lexis and phraseology. For example, there is no need to state the grammatical rule of agreement that accounts for the first two token correctives in the above repertory: the normatives that are implied ( $\tau \omega \nu \nu \pi \alpha p \times o v \sigma \dot{\omega} \nu$ $\pi \rho \circ \beta \lambda \varepsilon \dot{\varepsilon} \psi \omega \nu \nu$ and $\tau \omega \nu \alpha \nu \alpha \lambda \eta \phi \theta \varepsilon \varepsilon \sigma \dot{\omega} \nu \pi \rho \omega \tau \circ \beta \circ \nu \lambda \iota \omega \nu)$ could and should be learned as set phrases, just as the Lexical-Phraseological model requires. It is these and similar presuppositions that provide coherence to a repertory of correctives.

We have examined a corrective repertory which qualifies as an instance of institutional prescriptivism. However, this repertory may very well reflect the personal preferences of its creator. After all, it is possible that each speaker has their own corrective repertory, just as each speaker uses their own idiolect. But then individual repertories cannot be entirely different from each other, for the usual reasons: correctives are essentially dialogical acts (a speaker A instructs a speaker B to behave in a certain way and then speaker $\mathrm{B}$ complies with the instruction, or s/he doesn't); if correctives are to be binding for both speakers, they have to be conventional. In this respect, metalinguistic acts are no different from linguistic ones.

The question we have to answer now is whether there is perhaps an overarching repertory or a predominant tendency in all the available repertories. To answer this question, I conducted a corpus-based quantitative analysis of all the correctives that appeared in newspaper articles over the three-month period Nov. 1999 - Jan. 2000. A corpus was compiled through a press monitoring agency from 76 newspapers and 102 magazines. 80 texts with corrective instructions were selected out of a larger corpus of 364 texts about several language issues (percentage of texts with corrective instructions: 22\%). The corpus contained a total of 490 correctives (6.13 per text, on the average). Of the total number of correctives, $328 \mathrm{X} / \mathrm{Y}$-pairs were identified (4.1 per text), of which 252 were token pairs (3.14 per text) and 76 were type pairs ( 0.95 per text). In addition to X/Y-pairs, the texts also contained $162 \mathrm{X} / \varnothing$-elliptical correctives (2.03 per text). A detailed analysis of the corpus is presented in Moschonas \& Spitzmüller (2010), where comparisons are also made with a similar corpus of texts from the German newspapers. Table 3 presents a classification of the correctives in the Greek corpus only.

Since words are the most popular targets of prescriptivism, Table 3 begins with correctives concerning the vocabulary. Correctives in this category make reference to three kinds of words: loan, archaistic and demotic words. What is meant by "marked" archaistic or demotic forms are words that are often in popular

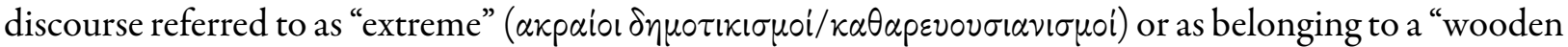
language" ( $\xi \dot{\nu} \lambda \iota \nu \eta \gamma \lambda \omega \sigma \sigma \alpha)$. The references to archaistic and demotic words outnumber the references to loan words. It seems that borrowings and foreignisms have ceased to be the main target of prescriptivism, as it used to be the case in the 1990s (Delveroudi \& Moschonas, 2003; Moschonas, 2001a, 2009). All the references to borrowings (not just words) in the corpus amount to $62(12.7 \%)$, while all references to high/low (diglossic) variants amount to 158 (32.2\%). These numbers suggest a concern about the ongoing diglossia situation more than a puristic attitude towards borrowing.

Correctives in the fields of Phraseology and Morpho-syntax could be grouped together. 'Morphology' and 'Syntax' should not be understood in any of the modern senses of these terms in contemporary 


\begin{tabular}{|c|c|c|c|c|c|c|}
\hline \multirow{5}{*}{ foreign words } & Lexicon: & 98 & $(20 \%)$ & Semantics: & 13 & $(2.7 \%)$ \\
\hline & & 30 & $(6.1 \%)$ & obscurity of learned/archaistic & 7 & $(1.4 \%)$ \\
\hline & \multicolumn{2}{|c|}{ English loans } & $24(4.9 \%)$ & forms & & \\
\hline & \multicolumn{2}{|c|}{$\begin{array}{l}\text { loans from other } \\
\text { languages }\end{array}$} & $3(0.6 \%)$ & $\begin{array}{l}\text { semantic differentiation or } \\
\text { change }\end{array}$ & 6 & $(1.2 \%)$ \\
\hline & \multicolumn{2}{|c|}{ loan translations } & $3(0.6 \%)$ & \multirow{2}{*}{ Discourse/Pragmatics: } & \multirow{2}{*}{15} & \multirow{2}{*}{$(3 \%)$} \\
\hline \multicolumn{2}{|c|}{ marked demotic forms } & 17 & $(3.5 \%)$ & & & \\
\hline \multicolumn{2}{|c|}{ marked archaistic forms } & 38 & $\frac{(3.5 \%)}{(7.8 \%)}$ & media discourse structure & 13 & \multirow{2}{*}{$\frac{(2.7 \%)}{(0.2 \%)}$} \\
\hline \multicolumn{2}{|c|}{ dialectal } & 6 & $(1.2 \%)$ & euphemisms & 1 & \\
\hline \multicolumn{2}{|c|}{ translation of archaisms } & \multicolumn{2}{|r|}{$(1.4 \%)$} & politene & 1 & $(0.2 \%)$ \\
\hline \multicolumn{2}{|c|}{ Phraseology: } & \multirow{2}{*}{29} & $(5.9 \%)$ & Orthography/Spelling: & 75 & $(15.3 \%)$ \\
\hline formulaic expre & & & $(4.3 \%)$ & in favor of monotonic & 5 & $(1 \%)$ \\
\hline$\alpha \phi o \rho \dot{\alpha} \sigma \varepsilon[$ to co & $\mathrm{rn} / \mathrm{be}$ & 8 & $(1.6 \%)$ & against monotonic & 4 & $(0.8 \%)$ \\
\hline about] & & & & in favor of the Roman script in & 3 & $(0.6 \%)$ \\
\hline & ho-syntax: & 199 & $(45.7 \%)$ & against the Roman scrint in & 10 & (2\%) \\
\hline violation of arc & tic rules & 27 & $(5.5 \%)$ & any registers & & \\
\hline agreement/attr & & 12 & $(2.4 \%)$ & loan transliteration & 7 & $(1.4 \%)$ \\
\hline demotic adv. en & $g(-\alpha)$ & 29 & $(6 \%)$ & 'final $-v$ ' rule (assimilation) & 5 & $(1 \%)$ \\
\hline stress mov. in d & nsion & 25 & $(5.1 \%)$ & CC clusters (dissimilation) & 1 & $(0.2 \%)$ \\
\hline wrong affix & & 36 & $(7.3 \%)$ & punctuation & 2 & $(0.4 \%)$ \\
\hline augmented imp & & 6 & $(1.2 \%)$ & misspellings & 38 & $(7.8 \%)$ \\
\hline prep + relative & & 1 & $(0.2 \%)$ & & & \\
\hline nouns with no & al/sing. & 60 & $(12.2 \%)$ & Miscellaneous: & 25 & (5.1\%) \\
\hline loan adaptation & & 25 & $(5.1 \%)$ & pronunciation & 2 & $(0.4 \%)$ \\
\hline mixed Greek-f & & 2 & $(0.4 \%)$ & pronunciation of loans & 7 & $(1.4 \%)$ \\
\hline compounds & & & & false etymologies & 6 & $(1.2 \%)$ \\
\hline foreign word $\mathrm{m}$ & hology & 1 & $(0.2 \%)$ & blunders/boners & 10 & $(2 \%)$ \\
\hline
\end{tabular}

Table 3: Correctives in the Greek press, Nov. 1999 - Jan. 2000. Source: Moschonas \& Spitzmüller (2010, p. 28-35).

linguistics. What is meant by 'Morpho-syntax' here is that part of traditional Grammars that deals mostly

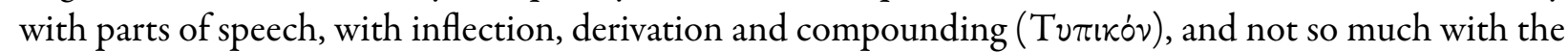
rules for the formation of sentences. Syntagms, in this traditional sense, are understood as, more or less, formulaic constructions which are built on phraseological units. Accordingly, there is no real boundary between Morpho-syntax and Phraseology.

Most correctives occur in these two overlapping fields: if we add the phraseological to the morphosyntactic correctives, we get a total of 228 (51.6\%); together with the lexical correctives, we reach a total of 326 correctives (more than $70 \%$ of the corpus). The increase in Lexical-Phraseological correctives, as we have seen already, is a relatively recent development in the evolution of Greek prescriptivism.

Although 'violation of archaistic rules' is a separate entry in Table 3, most of the corrective instructions under the heading of Morphology/Syntax are also preoccupied with the correctness of archaistic forms, in a manner reminiscent of the repertory by Papakostas (2006) that we have already discussed. For example, agreement or attraction phenomena are only stigmatised with respect to learned forms, such as archaistic participles: $\tau \omega \nu \nu \pi \alpha \rho x \dot{\nu} \nu \tau \omega \nu \pi \rho \circ \beta \lambda \varepsilon \dot{\varepsilon} \varepsilon \omega \nu$, "of the existing (masc.) predictions (fem.)". For the prescriptivists who criticise "extreme" demotic standards, the demotic adverbial ending $-\alpha$ (' $\alpha \pi \lambda-\alpha$ ' instead of ' $\left.\alpha \pi \lambda-\omega^{\prime} \varsigma^{\prime}\right)$ is like a red flag to a bull. Stress movement in declension is also subject to the katharevousademotic dichotomy, and it is prescribed according to the archaistic rules ( $\ \alpha \nu \varepsilon \pi \imath \sigma \tau \eta-\mu i-\omega \nu /-o v$ instead of 
$\prod \alpha \nu \varepsilon \pi \imath-\sigma \tau \dot{\eta}-\mu l-\circ v$, "of the University/ies"). Of the fomulaic expressions, the distinction $\alpha \phi \circ p \dot{\alpha} \sigma \varepsilon+\mathrm{N}$, "it concerns N", vs. $\alpha \phi o p \alpha \dot{\tau} \tau 0+\mathrm{N}$, "it is about N", seems to have become a riddle for the prescriptivists, who seek to differentiate between the two constructions by arbitrary form-function correlations (the $\alpha \phi \circ p \dot{\alpha} \sigma \varepsilon$ construction is actually an internal calque, based on the archaistic $\alpha \phi \circ p \dot{\alpha}+\mathrm{N}$ [dat.]). It should be stressed that lexical and morpho-syntactic variants are prescribed by convention, i.e. by invoking "strict", unexceptional rules that mostly regulate the high variants; for this reason, correctives usually lack an explicative part or they employ a circular reasoning: "this is the correct thing to say, because the correct thing to say is this". For the very same reason there is only a small number of correctives about the semantics, the pragmatics or the stylistics of expressions. As argued by Spitzmüller in Moschonas \& Spitzmüller (2010, p. 35-36), the opposite is the case with contemporary German prescriptivism, which "favors a more logical topos (based on a 'regularized' semantics of expressions and a 'tight' pragmatics of language use)".

As many sociolinguists have pointed out (Jaffe, 2000; Johnson, 2005; Sebba, 2007; cf. Jaffe et al., 2012), orthography is perceived to be an integral part of language, notwithstanding the fact that modern linguistic theories have given some priority to speech over writing. In Greece, the central subject of the relevant discussions seem to concentrate on two types of variation: 1. variation within Greek orthography (monotonic vs. the polytonic scripts); 2. variation with a non-Greek script (use of the Greek vs. the Roman alphabet; see Androutsopoulos, 2001, 2009). In my sample corpus, there are 5 occurrences of $\mathrm{X} / \mathrm{Y}$ types in favour of the monotonic system vs. 4 against it. There are only 3 mentions licensing the Roman script in some registers (such as e-mails) vs. 10 that are against the Roman script in any register.

Let us sum up our discussion so far. We have seen that SMG is supposed to be based on demotic, allowing nevertheless a certain number of archaisms and learnedisms, especially in the higher registers of the language, in line with Triantaphyllidis's standardization formula: 'SMG = demotic + learned forms (as needed)'. We also saw that the vernacular forms (the low variants), have gradually become standardized and "naturalized": they have become the language that is spoken (and written?) "naturally" by the "native speakers". It is now the archaistic, learned variants that are in need of corrective instruction. In order to accommodate them, a Lexical-Phraseological model has evolved, one that treats words and constructions individually, in isolation, as need arises. These variant words and constructions do not form part of a "uniform" system-precisely because the Standard lacks uniformity. The new corrective model places emphasis on phraseology and idiomaticity, irrespective of any morphological differences between demotic and katharevousa. The Lexical-Phraseological model that corresponds to the "mixed" standards of Standard Modern Greek is conventional in its rationale, i.e. it is based on the obligatoriness and the arbitrariness of lexical forms and syntactic constructions. Finally, in the contemporary Standard, purism is internal rather than external, i.e., it is preoccupied with internal rather than external loans-internal being the loans from Ancient Greek or from katharevousa-type varieties (Moschonas, 2010, p. 35). This preoccupation with internal loans is, of course, characteristic of the attitude and not of the actual practice of purism. Despite the lack of relevant studies, it seems a reasonable hypothesis that external purism is now being practiced on a mass scale and is being particularly successful in the field of technical terminology. Perhaps, it is the success of puristic practice that has somehow caused the attitude of purism to subside in the metalinguistic discourse. We will come back to this phenomenon (the collective awareness of a linguistic practice fainting precisely at the moment the practice becomes collective), when we discuss some recent literature on the effects of prescriptivism on language change, in the Conclusions and discussion section.

\section{Ideology}

A notion of 'neutrality' is often associated with a Standard Language. Neutrality is usually thought of in geographical terms and it is better explained with respect to accent. According to Henry Sweet, the English phonetician and grammarian, "the best speakers of Standard English are those whose pronunciation, and language generally, least betray their locality" (cited in Mugglestone, 2003, p. 4; cf. Jespersen, 1964, 
p. 61, who seems to have expressed a similar view as early as 1890). ${ }^{9}$

An accent that hides aspects of a speaker's identity is of course a possibility, but it cannot be described as "neutral", as it certainly reveals other aspects of that same identity (including the fact that a speaker seeks to hide his/her original locale). It takes a moment's thought to realize that this notion of accentual neutrality is absurd at a more elementary level. It is tantamount to the supposition that a standard accent is but the lack of accent-that it is "accentless" (Mugglestone, 2003, p. 40, 46)-either to its properties or to its implications for the speaker. But there is no variety without an accent. A 'neutral accent' is bound to be a perceptual or attitudinal phenomenon, characteristic not of the Standard Language as of its standards. To the degree that accents are markers of social class, the notion of 'accentual neutrality' could also be criticized as ideological, biased, class-discriminatory (cf. Crowley, 1989, ch. 6), even chauvinistic or racist. But this is the kind of excessive criticism that merely overlooks the essential: there is no neutral accent, because there ain't no accentless accent.

'Neutrality' (i.e., the attitude towards a Standard), does not apply to accents only; it is part and parcel of the ideology of a Standard Language as a whole. Again, I am only speaking here of SMG. Triantaphyllidis (1963, p. 181-187), the founder of SMG, admitted that his Koine, the one he so much contributed to codifying, was closely associated with nationalism, but he refused to identify it with any other ideologies involved in the "Language Question" debate, especially those that were stigmatized by the ruling political elites of his times (communism, socialism, slavism, atheism...). Writing a Grammar of the demotic was a task assigned to Triantaphyllidis et al. (1978) by the fascist regime (Mackridge, 2009, p. 301). This has been a puzzle for the supporters of Triantaphyllidis. But if a Standard is "ideologically neutral", then it should be neutral with respect to any ideology, including the fascist one. This de-ideologization of the Standard is on a par with the neutralization of an accent. Just as accentual neutrality implies that speakers of a Standard Language cannot be pinned down as to their origin (Crowley, 1989, p. 186), deideologization, i.e. 'ideological neutrality', should be taken to imply that speakers cannot be pinned down as to their ideologies. (But keep in mind: de-ideologization is just another ideology, perhaps the dominant one; just as a "neutral accent" is just another accent, the standard one.)

In the study that follows, we will consider a group of morphophonological variables whose high/low variants were closely associated with the katharevousa/demotic split of diglossia. The variables were also stereotypical, full of political implications; the use of each variant would signal not just a speaker's beliefs about language but also his/hers political affiliation. Our study shows that their social meaning has now, in the post-diglossia period, changed considerably. Variants have been "neutralized": they are not associated with political ideologies anymore, they are not ideologically-bound. Hence, the variables chosen provide evidence for the newly acquired "neutrality of the standard".

In Study 3 we look at the development of "ideological neutrality" as a pre-condition for what, in the next section, we will call 'stylization' (or 'styling'), i.e. the expansion of stylistic choices to the expense of ideological ones. In the next section (4) we will identify still another "neutral" variable, one that had not been associated with diglossia, although it has always been the subject of prescriptivism, and see how it is stylized in the media.

But first the study on de-ideologization:

\section{Study 3: Morphological variation in the Greek newspapers}

Morphological variation due to diglossia has been considered to be an indicator of ideological and/or stylistic differentiation in the Greek press. Unfortunately, the relevant linguistic studies seem intuitive and they do not provide quantitative results. In the relevant literature, there are roughly two explanations of morphophonological variation in the press: Chatzissavidis (1999a,b, 2000) seems convinced that the

\footnotetext{
${ }^{9}$ Actually, the idea of geographical neutrality and of a non-localized, non-dialectal norm is much older; it certainly goes back to Dante's De Vulgari Eloquentia, composed between 1302 and 1305; in it, the Italian poet argues for the existence of or the need for a Standard different from all local varieties (Ewert, 1940, p. 363); see Crowley (1989, p. 129 ff., 186), Mugglestone (2003, p. 7 ff., 258), concerning the history of English; cf. Rutten (2016) for a general discussion with reference to Dutch.
} 
linguistic variables associate strongly with the political affiliation of the newspapers, an affiliation he takes for granted; his research is not corpus-based and he provides no statistical results. Iordanidou (2001a, 2009), on the other hand, employs a corpus-based, qualitative approach, and comes to the following conclusions: considerable morphophonological variation is evidenced within the same newspaper, within newspapers of the same political affiliation (especially those of the center), even within the same article; morphophonological variation could only partly be accounted for by stylistic considerations.

I report here on Kolia et al. (2013), a students' research that I have supervised. Kolia et al. (2013) provide an elementary statistical analysis of morphophonological variation in the Greek press which sufficiently proves that a) there is no strong connection between the use of high/low variants and the political stance or ideology of a Greek newspaper, and b) morphophonological variants loosely correlate with a stylistic factor, the genre of a journalistic text, although the correlation is not statistically significant.

The research was conducted in the week 14-22 November 2009. Six (6) wide-circulation (national)

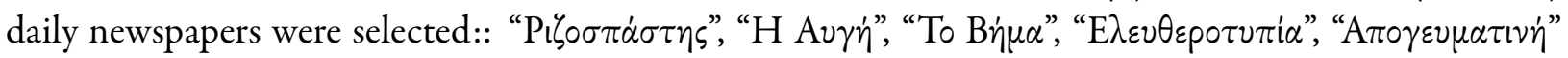

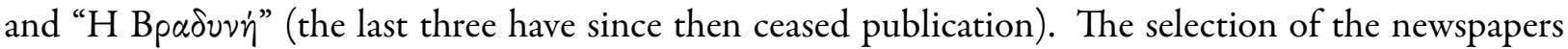
was such as to allow equal representation of the then existing political spectrum of Left, Center, Right.

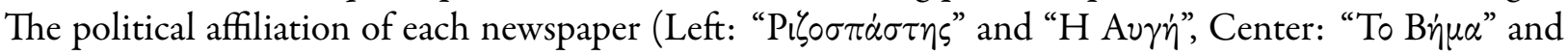

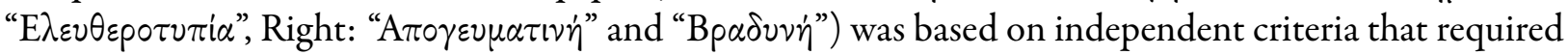
separate validation (a complex index was constructed which took into account: the view from the directors' table, the self-identification of major journalists in each newspaper, newspaper space devoted to party politics, and a few other factors).

The linguistic variables studied were the following (in each pair the first variant is presumed to be the low/demotic one, the second is the corresponding high/archaistic):

1. variation in the consonant clusters of the passive aorist's base; e.g., fricative-stop: $-\chi \tau-/-\phi \tau-/-\sigma \tau-\mathrm{vs}$. fricative-fricative: $-\chi \theta-/-\phi \theta-/-\sigma \theta$ - in forms such as $\{0 p i-\sigma \tau-\eta \kappa \varepsilon, o p i-\sigma \theta-\eta \kappa \varepsilon\}$, "was appointed/defined";

2. similar variation in the consonant clusters of independent word forms, e.g. $\{\chi \tau \varepsilon \varsigma, \chi \theta \varepsilon \varsigma\}$, "yesterday"; ${ }^{10}$

3. $3^{\text {rd }}$ person sing./pl. of passive aorist $\{-\eta \kappa \alpha /-\eta \kappa \alpha \nu,-\eta /-\eta \sigma \alpha \nu\}$ in word pairs such as $\{\kappa \lambda \dot{\alpha} \pi-\eta \kappa \alpha \nu,(\varepsilon) \kappa \lambda \dot{\alpha} \pi-$ $\eta \sigma \alpha \nu\}$, "were stolen";

4. $\{-\alpha,-\omega \varsigma\}$ adverbial endings in words such as $\{\alpha \pi \lambda-\dot{\alpha}, \alpha \pi \lambda-\omega \varsigma\}$, "simply"; ${ }^{11}$

5. variation of stress in the sing./pl. genitive of nouns and adjectives; e.g., $\left\{\varepsilon \gamma \kappa v \dot{v} \lambda \lambda \_0 v, \varepsilon \gamma \kappa v \kappa \lambda\right.$ íov\}, "circular", $\{\delta \eta \mu o ́ \sigma i \omega \nu, \delta \eta \mu \circ \sigma i \omega \nu\}, " p u b l i c " ;$

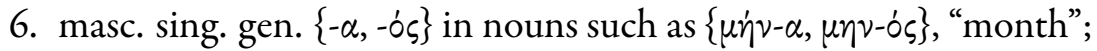

7. masc. sing. gen. $\{-\dot{\varepsilon} \alpha,-\dot{\varepsilon} \omega \varsigma\}$ in nouns such as $\{\varepsilon|\sigma \alpha \gamma \varepsilon \lambda \lambda-\dot{\varepsilon} \alpha, \varepsilon| \sigma \alpha \gamma \gamma \varepsilon \lambda-\dot{\varepsilon} \omega \varsigma\}$, "prosecutor";

8. masc. sing. gen. $\{-\dot{\eta},-\circ \dot{\zeta} \varsigma\}$ in adjectives such as $\{\alpha \delta \alpha-\dot{\eta}, \alpha \delta \alpha-\circ \dot{v} \varsigma\}$, "ignorant, naïve";

One more linguistic variable was taken into consideration, which, interestingly enough, seems to have completely lost its discriminatory power:

9. variation in the gen. fem. endings $\{-\eta \varsigma,-\varepsilon \omega \varsigma\}$ of the so-called "third-declension" nouns; e.g., $\{\kappa \nu \beta \varepsilon \dot{p} \nu \eta \sigma-$ $\eta \varsigma, \kappa \nu \beta \varepsilon \rho \nu \eta \dot{\sigma} \sigma-\varepsilon \omega \varsigma\}$, "government".

This latter variable is of some historical significance. After the language reform of 1976, it soon acquired the status of a "stereotype" (in the sense of Labov, 1972, p. 314); it was believed that the choice of one or the other variant was strongly indicative of a speaker's political affiliation. At the time the research took place (2009), the demotic, non-archaistic variant seems to have prevailed over $-\varepsilon \omega \varsigma$ (only $2 / 354$ instances

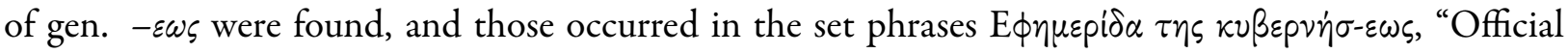
Government Gazette", and $\pi \dot{\alpha} \sigma \eta \varsigma$ $\phi \dot{v} \sigma \varepsilon \omega \varsigma$, "of all kinds"). For this reason, results are not shown for this

\footnotetext{
${ }^{10}$ The above two variables have been independently studied by Mikros et al. (1996), who found only a slight correlation with text genres (three types of texts were considered: governmental, journalistic and literary).

${ }^{11}$ Cases where each variant is presumably associated with a different meaning, according to the form-function fallacy, were not taken into account; e.g. $\alpha \mu \varepsilon \sigma \alpha$, "directly", and $\alpha \mu \varepsilon \dot{\sigma} \sigma \omega$, "immediately".
} 
variable. (That the $-\varepsilon \omega \varsigma$ variant does not show up in our sample corpus should not be taken to imply that it is completely absent from a larger corpus containing, e.g., legal documents).

Two research hypotheses were tested: 1 . the number of learned, archaistic morphological variants should increase as one moves, so to speak, from the left-wing to the right-wing newspapers; 2 . archaistic variants should also increase with the formality associated with each newspaper genre, assuming the following hierarchy: comments and notices ( $\pi \alpha p \alpha \pi \circ \lambda \iota \tau \iota \alpha \dot{\alpha}:$ short entries, mostly satirical $) \rightarrow$ feature articles $\rightarrow$ editorials (a newspaper's leading article). By combining the two hypotheses, the learned morphophonological variants are expected to increase on the two vectors: Left $\rightarrow$ Center $\rightarrow$ Right (Hypothesis 1) and also: Comment $\rightarrow$ Feature $\rightarrow$ Editorial (Hypothesis 2).

None of these hypotheses were confirmed, while the interaction of the two factors (political affiliation and genre) also did not provide statistically significant results. The results are diagrammed in Fig. 5a. No

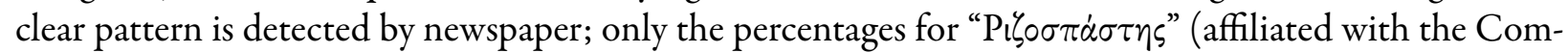
munist Party of Greece) seem to be lower compared to the percentages for the other newspapers. Fig. 5b presents the percentages of the high/learned variants not by newspaper but by political affiliation; figures

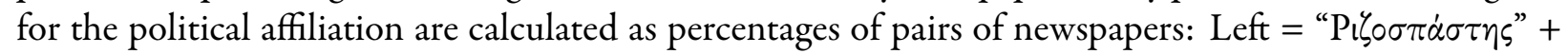

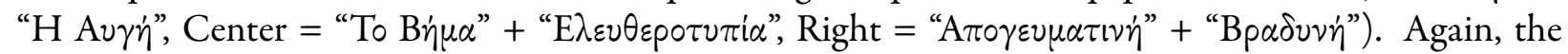
newspapers of the Left seem to have the lower percentages of high/learned variants, while the percentages for the newspapers of the Center are higher than those of the Right-contrary to what is expected. Thus, the hypothesis 1 is rejected.

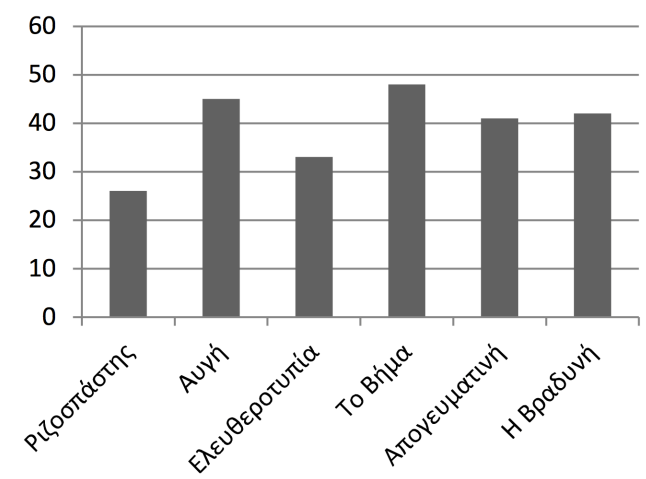

(a) Percentages of learned/high variants in six Greek newspapers.

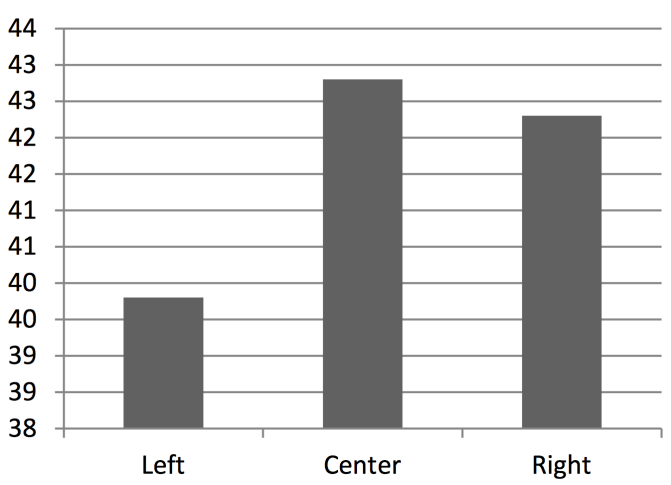

(b) Percentages of learned/high variants according to the political affiliation of the Greek newspapers.

Figure 5: Percentages of learned/high variants in Greek newspapers. Source: Kolia et al. (2013, p. 145).

In Fig. 6a, the percentages of high/learned variants are presented by newspaper and also by genre (editorial/leading article - feature article - short comment). There seems to be a slight correlation with genre, which becomes more evident if we group the newspapers by their political affiliation, as we did above: see Fig. $6 \mathrm{~b}$ for combined results by affiliation. The number of high/learned variants seems to decrease in accordance with the formality scale: Comment $\rightarrow$ Feature $\rightarrow$ Editorial (Hypothesis 2). However, the results are not statistically significant and do not allow any firm generalizations about how the linguistic variables chosen are stylized in the Greek press.

In conclusion, the use of high/low variants does not correlate significantly with either the political stance of the newspaper or with the presumed formality/informality of the newspaper genres. The view of Chatzissavidis (1999a,b, 2000) that there is a political ideologization of the diglossic variation should be rejected; however, since his research was conducted in the years 1997-1998, it could very well represent an earlier stage in the social life of high/low variants. It should also be pointed out that Chatzisavvidis took into consideration a slightly different set of variables. On the other hand, Iordanidou (2001a, 2009) 


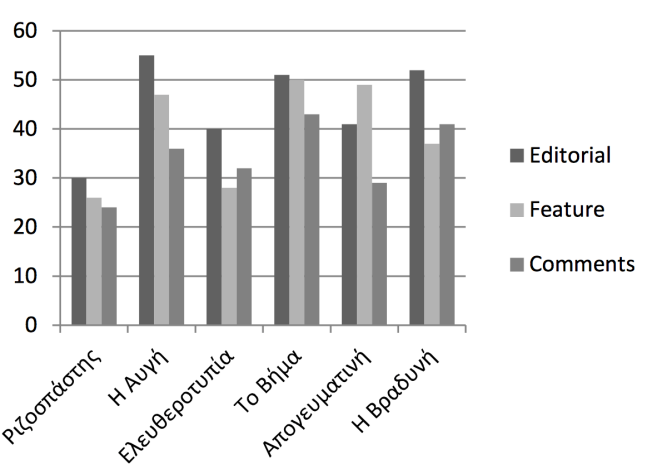

(a) Percentages of learned/high variants according to newspaper and genre.

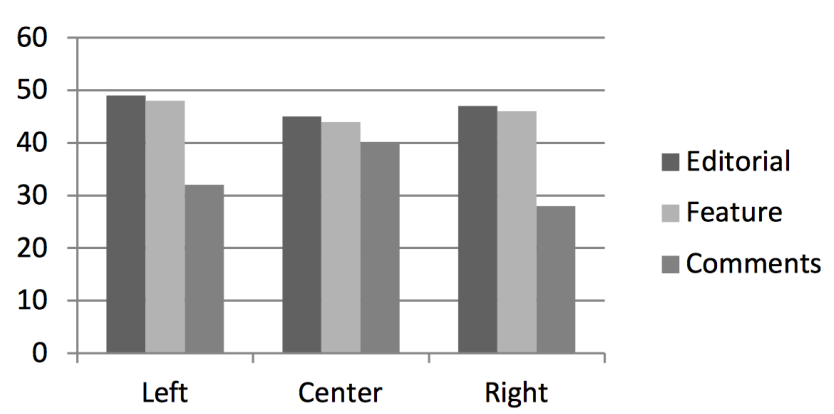

(b) Percentages of learned/high variants according to political affiliation and genre.

Figure 6: Percentages of learned/high variants in Greek newspapers. Source: Kolia et al. (2013, p. 148).

seems to be right in pointing out that considerable morphophonological variation exists within the same newspaper-spectrum, so to speak, which includes newspapers of both center and right political affiliations. From the existence of considerable variation within and across a political spectrum, we can certainly conclude that the major morphological markers of katharevousa have ceased to index a "conservative" political ideology, although some of the major morphological markers of demotic may continue to index a self-proclaimed "progressive" ideology (probably associated with some of the more radical varieties of the Left). In addition, the stylistic factor only marginally affects the use of the high/low variants.

It seems that the linguistic variables discussed in our study are in a process of "neutralization", of becoming de-ideologized, without at the same time being subject to widespread stylistic variation. At least, this seems to be the case in the major Greek newspapers. We have stressed that neutrality is an attitudinal factor. It is part of the language ideology surrounding a Standard. But since in our study this attitudinal factor has been mediated (our corpus is a representative sample of Greek newspapers of all political convictions), it can be considered to have affected or to have been affected by the language use in the media. An ideological process, namely the de-ideologization of the standards, seems to affect or to have been affected by changes in the Standard itself.

In this section we saw de-ideologization as a precondition for the development of stylistic variation. In the next and last section of this paper, we will look at how an ideologically "neutral" variable becomes subject to stylistic variation. Our evidence is rather meager, yet it can be taken to confirm the hypothesis that de-ideologization is a pre-condition for stylization. (I am not formulating a general sociolinguistic maxim; I am only trying to account for an accident in the continuing process of Modern Greek standardization.)

\section{Style}

Some linguists would identify a standard variety with some of a language's available stylistic resources. Accordingly, they will view re-standardization or de-standardization as a reallocation of these resources. Agha (2007) speaks of standard languages as registers. He also seems to think of standardization as a perceptual phenomenon, limited to "reflexive models of usage" and reproduced through "metadiscursive practices" (Agha, 2007, p. 6, 125, 191, 193, 199, 206-219, 228)-pretty much along the lines of view (b), in the Introduction to this paper. With a more down-to-earth approach, the recent twins Thøgersen, Coupland \& Mortensen (2016) and Mortensen, Coupland \& Thøgersen (2017) explicitly adopt the view of standardization (or de- or re-standardization) as "styling"; several of the studies in these two volumes also explore the effects of mediation and styling on language change. 
I will stick to the term 'stylization', which I will not try to define. For the purposes of my argument, any of the operational definitions of 'style' in classical variationist sociolinguistics would do; differences in style are accounted for by differences in genre (e.g., scripted vs. unscripted speech), formality and concentration (e.g., reading words vs. reading passages vs. participating in casual conversation), situation (formal vs. informal), etc. In the study that follows I will employ the independent variable 'scripted vs. unscripted speech' as an indicator of style.

In the previous section we examined the process of de-ideologization, i.e. the formation of a dominant attitude towards the Standard, through which a Standard is being established as "natural", "neutral", "undifferentiating". De-ideologization is a self-deception mechanism; it consists in paying little or no attention to variation by somehow loosening the indexical associations of variants. I prefer to think of 'neutralization' as a deceptive mechanism, but one can also think of it, in more neutral terms, as a collective belief about a Standard Language. Many informed observers of the language, such as linguists, especially those being busy with the very process of standardization, share this belief with the insecure speakers of a Standard Language, those who would anxiously ask "Do I have an accent?". The ordinary speaker presupposes a belief in the neutrality of the standard; the informed observer, theorizes it. Deideologization tricks both the ordinary user and the theoretician. When "neutrality" is established, new generations of speakers are conditioned to disregard the variation which had been obvious to previous generations and which, in the case of diglossia, would have been brought out by means of competing metalinguistic discourses.

Our hypothesis was that stylization develops only after de-ideologization and that the latter is a precondition for the former. In order for speakers to develop stylistic repertories, it is necessary that they are not restrained by ideological constraints or what could be considered as such. We cannot hope to confirm the hypothesis that there is a causative relation between de-ideologization and stylization; its testing requires comparative work beyond our capacity. But it seems a reasonable hypothesis for postdiglossia situations. We will illustrate it here with a further example: a study of the phonological variable of voiced stop prenasalization in media talk.

\section{Study 4: Nasalization in media talk}

The variable examined in this study is the prenasalization of the voiced stops. There are two variants in the pronunciation of a voiced stop in Modern Greek: [b, d, g] and [mb, nd, ng] (we will not examine here the related phenomenon of prenasalized devoiced stops, [mp, nt, $\mathrm{nk}$ ]; also, we will not be concerned with prenasalization across word boundaries).

The proper nasalization of voiced stops has always been a target for prescriptivists. However, as far as I know, the phonological variable has not been associated with any of the ideological camps of the "Greek Language Question”; hence, in this respect at least, it can be considered to be de-ideologized. Triantaphyllidis, with his characteristic permissiveness, mentions both variants in his Grammar (Triantaphyllidis et al. (1978), p. $35 \$ 72$ ). It is also a happy coincidence that the nasalization of the stops has been meticulously studied in Greek sociolinguistics; a clear picture of this phonological phenomenon has now emerged that can be contrasted to the prescriptive "rule".

But first, let us look at the prescriptive "rule", the corrective. Every speech-training coursebook I have consulted agrees on how nasalization should be prescribed (the most recent speech-training Guide I consulted is Sifonios, 2017, p. 20-31, which is addressed to media and communication professionals). The prescriptive "rule" seems widespread. Nasalization of voiced stops has been the subject of many letters to the editor, with complains about the incorrect pronunciation of many a broadcaster. The excerpt that follows is from Lypourlis (1994, p. 33-36), a Usage Guide that we mentioned in Sec.2 above; Lypourlis's advice is addressed to the "general public":

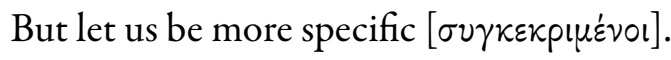


In the word I used just now, our television broadcaster-there is no doubt about it-will say

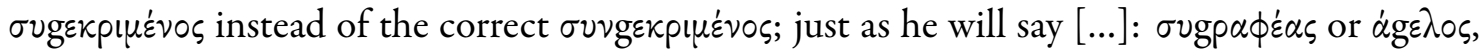

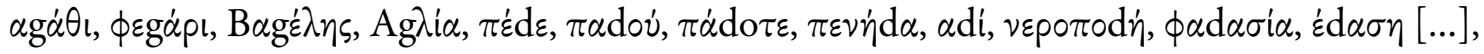

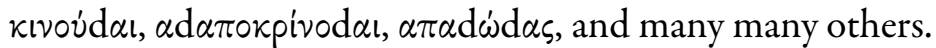

$[\ldots]$ Is there then any rule to teach us what in each case is the correct way to pronounce these words? Of course there is. Let us follow the rule then:

The sounds $\{\mu \pi\}(=\mathrm{b}),\{\gamma \kappa\}(=\mathrm{g}),\{\nu \tau\}(=\mathrm{d})$ - the rule goes-are pronounced without any nasal sound in front of them first in the beginning of the words. Thus I will say: baiv In the same way I will pronounce these sounds within a word—watch out! — after a consonant. Thus: bápbas, apgó, kabapdiva. The same way I will pronounce these sounds within a word

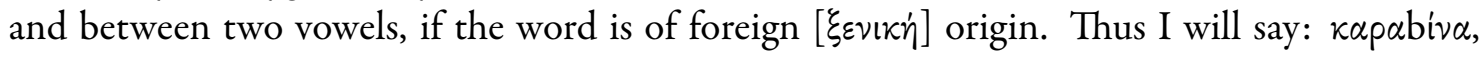

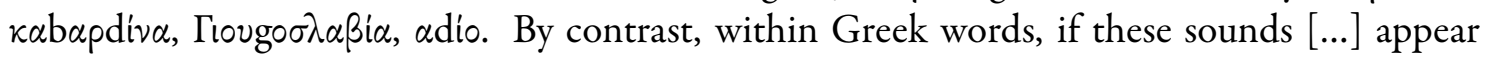
between two vowels, their pronunciation is such that a nasal sound is heard before them. Thus

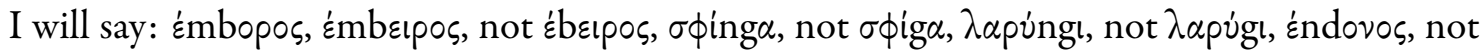
ह́dovos, etc. etc.

[...] When we bring in our language foreign words [...], we ought to be careful and pronounce them $[\ldots]$ as they are pronounced in the language from which we have taken them.. Thus, we

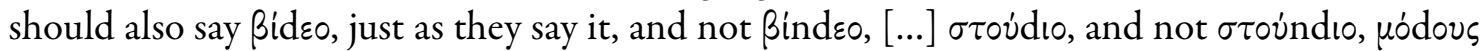

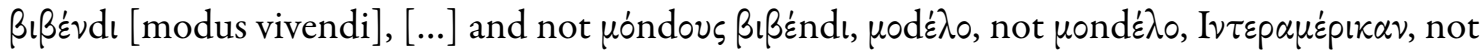

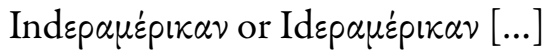

$[\ldots]$ is it a trivial thing for us to learn not to be humiliated in front of others by saying or writing their words in whatever way we like?

That this is a prescriptive rule we can tell from the very fact that both variants are mentioned, but only one is judged to be appropriate. There is a prohibitive and a normative part and there are also conditions that specify which is which. It is remarkable how complicated the conditions are; two factors need to be taken into account: phonological environment (\#_, C_, $V_{-}$V) and origin of the word (of Greek origin vs. of foreign origin); the two factors interact in the environment $\mathrm{V} \_\mathrm{V}$. Origin of the word is also invoked to justify a reverse puristic attitude: Greek words should be pronounced the Greek way, foreign words the way they are pronounced in their language of origin. This latter factor, origin of the word, presupposes considerable metalinguistic knowledge (i.e., knowledge about the etymology of words) that cannot be presumed to be available to an ordinary speaker of the language; only language experts have access to this metalinguistic information. The limited availability of metalinguistic knowledge and the overall complexity of the prescription suggest that the rule is primarily addressed to speakers who in applying it may be seeking some kind of what Bourdieu (1991) would call "symbolic distinction". In other words, the rule cannot be accessible to the ordinary speaker. The accusatory tone of Lupourlis's introductory remarks should also be pointed out: Lypourlis seems to be concerned about public discourse and he reproaches media professionals for their usage (on how media usage has become the target of prescriptivism, see Moschonas, 2014).

The prescriptive rule does not correspond to actual usage, although it may have influenced the linguistic behavior of trained professionals, such as actors or news broadcasters. The prenasalization of stops is a variable that has been extensively studied in Greek sociolinguistics (see, among others: Pagoni, 1990, 1991, 1993; Charalabopoulos et al., 1992; Mikros, 1997, 1999, 2008; Arvaniti \& Joseph, 2000). We rely on Arvaniti \& Joseph (2000), who have convincingly demonstrated that "age, not style, is the most important factor" in the variation of prenasalized voiced stops. Fig. 7 portrays the degree of nasalization of voiced stops in word-internal position by three age groups $(17-30,31-45,46-71)$ tested in two different tasks (reading a text vs. participating in conversation). The two youngest age groups exhibit the same pattern: a very low percentage of prenasalization in both reading and conversation, while the speakers in the 46-71 age group nasalize significantly more in both styles, and they also show a significant 


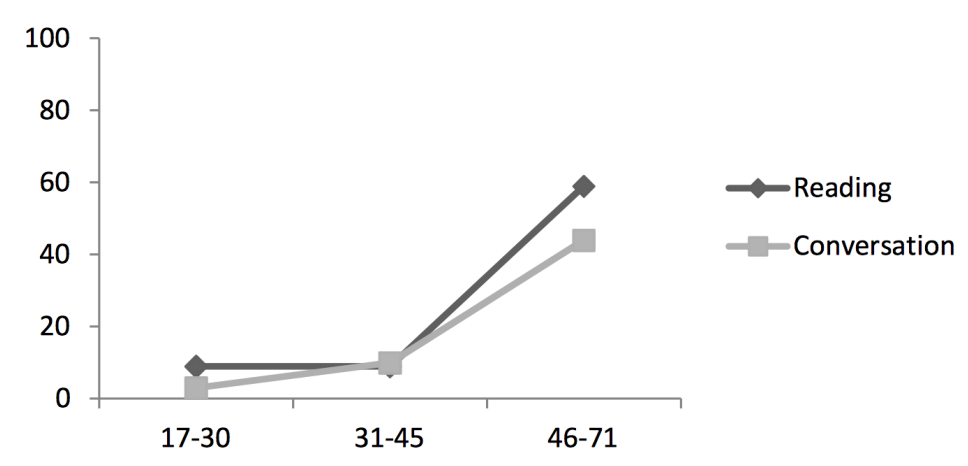

Figure 7: Percentages of voiced-stop prenasalization in word-internal position, by style and age. Source: Arvaniti \& Joseph (2000, p. 146).

difference between reading and conversation (Arvaniti \& Joseph, 2000, p. 145-146). In the relevant literature several other factors that might affect nasalization have been considered (e.g., contextual factors such as word-initial position vs. word-internal, post-consonantal vs. intervocalic, morpheme boundary, word boundary; the speed of speech, profession, educational status, region, etc.; see especially Mikros, 1997 for factors affecting radio talk). We cannot burden our presentation with all the details, but we can confidently state that the prescriptive rule we discussed above does not correspond to actual usage as described in the relevant sociolinguistic literature.

The age difference depicted in Fig. 7 suggests that the nasalization of voiced stops is an instance of phonological change in progress. Since this particular variable has been the target of heavy prescriptivism, the question arises as to whether the phonological change is indicative of a process of re- or destandardization. It would also be interesting to know whether this change has been mediated, i.e. whether it is initiated or reflected in the audiovisual media. To answer these questions, we conducted a small-scale research.

We considered the speech of seven news anchors, five women and two men, in television and radio broadcasts.We have reasons to believe that most if not all of those anchors were speech-trained and they were aware of the prescriptive rule concerning nasalization. To guard against extraneous factors, we only counted the occurrence of prenasalized voiced stops in word internal positions, between vowels $\left(\mathrm{V}_{-} \mathrm{V}\right)$.

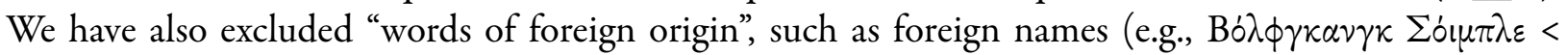
Wolfgang Schäuble, pronounced [soible] or [soimble] in Greek). Table 4 lists the names of the news anchors, the period of their broadcasts that were transcribed and the medium that was used for broadcasting (radio or television: most broadcasts were on television, but in two cases, those of the journalists S. Cosioni and N. Chatzinikolaou, we had to supplement data for unscripted speech from their radio broadcasts). The stylistic factor considered is scripted vs. unscripted speech. As scripted speech we define reading the news from cue cards or similar devices; unscripted speech occurs when the news anchors interview a guest or start a conversation with another journalist. To make sure that the speech was unscripted, the initial segments of a conversation were excluded from consideration.

The mean percentages for the prenasalization of intervocalic voiced stops in scripted and unscripted speech are listed in Table 4 and diagrammed in Fig. 8. A clear pattern emerges: all news anchors nasalize significantly less in unscripted speech. This pattern holds even in the exceptional case of E. Meleti, a television announcer who has also been a host in several lifestyle shows; overall, she nasalizes less than the other broadcasters, perhaps because she is a younger journalist or/and because she stylizes herself as a younger one.

Let us sum up our findings in this section. The prescriptive rule for the prenasalization of voiced stops has been a difficult one to follow; it is quite complex and it presupposes metalinguistic knowledge which might not be available to the ordinary speakers of SMG. The prescriptive rule considers two factors of 


\begin{tabular}{|c|c|c|c|c|}
\hline News anchor & Period, Medium & speech & $\%$ & $\#$ \\
\hline \multirow{2}{*}{ Tremi, Olga } & \multirow{2}{*}{ April 2015, Mega } & scripted & 55 & $33 / 60$ \\
\hline & & unscripted & 23 & $21 / 91$ \\
\hline \multirow{2}{*}{ Stai, Elli } & \multirow{2}{*}{$\begin{array}{l}\text { January-June 2013, } \\
\text { NET }\end{array}$} & scripted & 63.6 & $35 / 55$ \\
\hline & & unscripted & 21.8 & $12 / 55$ \\
\hline \multirow{2}{*}{ Kosioni, Sia } & \multirow{2}{*}{$\begin{array}{l}\text { March-July 2014, } \\
\text { SKAI (radio) }\end{array}$} & scripted & 52.4 & $44 / 84$ \\
\hline & & unscripted & 30.9 & $25 / 81$ \\
\hline \multirow{2}{*}{ Meleti, Eleonora } & \multirow{2}{*}{$\begin{array}{l}\text { November 2014, E } \\
\text { ("Hastag") }\end{array}$} & scripted & 14.7 & $18 / 122$ \\
\hline & & unscripted & 6.7 & $8 / 120$ \\
\hline \multirow{2}{*}{ Choukli, Maria } & \multirow{2}{*}{$\begin{array}{l}\text { January-June 2015, } \\
\text { ANT1 }\end{array}$} & scripted & 53.7 & $44 / 82$ \\
\hline & & unscripted & 32.9 & $23 / 70$ \\
\hline \multirow{2}{*}{$\begin{array}{l}\text { Chatzinikolaou, } \\
\text { Nikos }\end{array}$} & \multirow{2}{*}{$\begin{array}{l}\text { January-June } 2015 \text {, } \\
\text { STAR/Real FM }\end{array}$} & scripted & 52.2 & $35 / 67$ \\
\hline & & unscripted & 22.4 & $15 / 67$ \\
\hline \multirow{2}{*}{$\begin{array}{l}\text { Panagiotopoulos, } \\
\text { Nikos }\end{array}$} & \multirow{2}{*}{ June 2017, ERT } & scripted & 50.8 & $31 / 60$ \\
\hline & & unscripted & 15.7 & $13 / 70$ \\
\hline
\end{tabular}

Table 4: Nasalization in the scripted and unscripted speech of seven news anchors. All z-scores for the differences between scripted and unscripted speech are significant at $p<0.01$. Source: Data were collected by Stavroula Vergopoulou, Olympia Antonena and Melina-Dionysia Konti (Stai); Giorgos Koukoulis (Kosioni); Georgios-Konstantinos Oikonomopoulos (Meleti); Michalis Psimitis (Choukli); Kyrgia Ioanna and Ksiromamou Andrianna (Chatzinikolaou); Alexandros Potamianos (Panagiotopoulos).

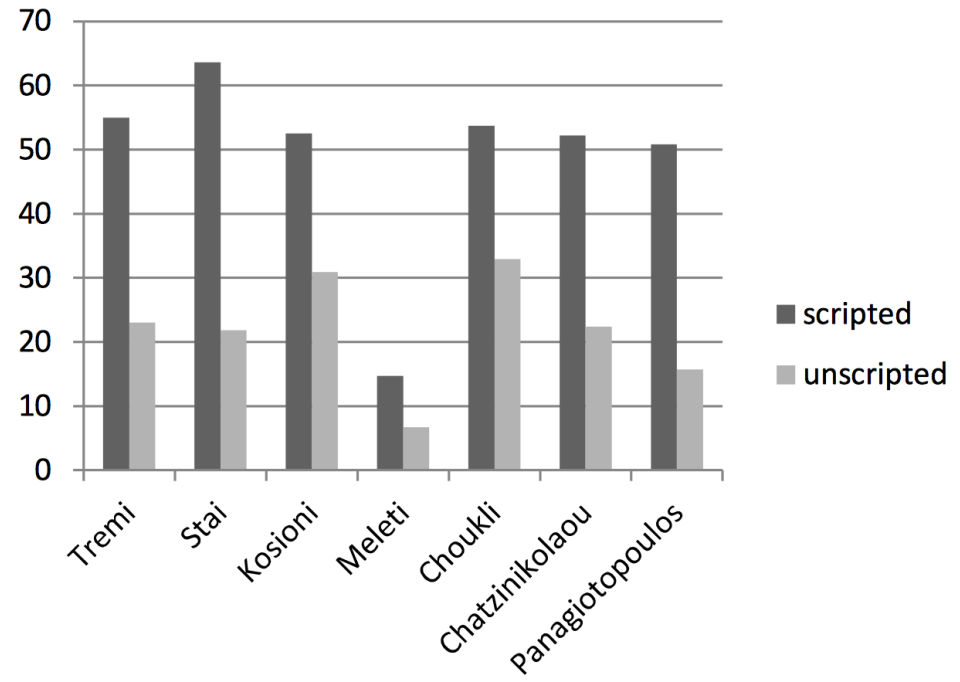

Figure 8: Percentages of nasalization in the scripted and unscripted speech of seven news anchors.

differentiation: linguistic environment (context) and word origin (Greek vs. foreign). In contrast, sociolinguistic research has established that the primary factors are: age and style (in this order of significance). Although style is a secondary factor, prenasalization seems to be systematically stylized in the media, as it is indicated by the significantly different results obtained for scripted vs. unscripted speech in our study. It seems that speech is most resistant to prescriptive instruction when it occurs unguarded. It is such unguarded use which is usually de-ideologized.

Is the prescriptive rule unsuccessful? Is it a rule whose application has been left unsupervised, one that could be enforced by making speakers aware of their mistakes, as the prescriptivists seem to believe? Or is the lack of nasalization just a new development in the phonology of a Standard Language despite the 
Standard's standards; a development which can be recognized as re- or de- standardizing the Standard precisely because it defies the prescriptive norm associated with it? If, as we have done from the beginning of this long paper, we adopt the view that a Standard Language should be defined jointly as both a Language and a set of standards, then the denasalization of voiced stops can be seen as a new development in SMG, which, precisely because it defies the prescriptive norm, it reveals a new de-/re-standardizing tendency.

\section{Conclusions and discussion}

In this paper I have presented a view of a Standard Language as both a standard (a norm, an ideal, an ideology) and a Language (i.e., actual usage which, more or less, conforms to the norm, the ideal, the ideology). We have seen that a Standard Language is impossible to define without reference to its standards. We have also seen that there is an interplay between the standards and the Language; that standards are informed by actual usage and that usage is prescribed to conform to the standards that prevail within a particular community over a certain period of time. Even when standards are defied and new (stylistic) uses are developed, these uses cannot be understood without reference to the standards, old or new. Fromkin, Rodman \& Hyams (2011, p. 440) were wrong: we can identify the speakers of a Standard Language by the standards they employ in their speech-of course not with absolute precision; norms are never precise.

There are aspects of language standards (and of the ideology surrounding them) that cannot be taken literally. For example, a Standard Language may be believed to be "uniform" or "neutral". Uniformity and neutrality (de-ideologization) are ideological constructs and they cannot be taken at face value. Milroy \& Milroy (1999, p. 22, 51, 58), among others, stress uniformity as the primary aim of standardization (cf. Milroy, 2001, p. 531: "standardization consists in the imposition of uniformity upon a class of objects"). One would have expected that they should merely expose uniformity as a pretheoretical notion, not that they would endorse it at the theoretical level. Uniformity, obviously, forms part of the "standard language ideology". It is a perceptual phenomenon; it might very well be a collective hallucination rather than the actual result of standardization practices. But then, this is the hazard to approaching standard languages through language standards: ideological categories, i.e. concepts and beliefs evidenced in the metalanguage that guides the practices of standardization, are often taken at face value and become part and parcel of the sociolinguistic theorization. The same applies to the concept of "neutrality".

Although the concepts of a Standard Language and of language standards cannot be kept apart, a procedure is needed for establishing how language standards affect a Standard Language or vice versa. We have identified the route from metalanguage (language standards) to language (Standard Languages) through what we have called a performative theory of language standardization. We have established a new type of speech act, with a direction of fit from the metalanguage to language, which has not been discussed in the speech act literature: the corrective.

What is meant by 'correctives' or 'corrective practices' is linguistic behavior shaped and motivated by usage evaluations such as "correct-incorrect", "right-wrong”, "proper-improper", "apt-inappropriate”, "good-bad", "beautiful-ugly", "tasteful-distasteful”, etc. Some of these antonyms are gradable; others are not. They all express metalinguistic evaluations: "correct or incorrect" means "correctly or incorrectly said or phrased". Of course, most correctives apply to the written language; that is, "correct or incorrect" means primarily "correctly or incorrectly written". Yet, speech, the oral language, can also be the subject of evaluation and correction, as in language teaching, in speech training, or in the instructions for becoming an efficient conversationalist, critically analyzed by Cameron (2000).

Corrective practices are known mostly, if not exclusively, through corrective instructions, which combine proscription with prescription: One should not say or write $\mathrm{X}$, one should say or write $\mathrm{Y}$ instead; or one should say both $\mathrm{X}$ and $\mathrm{Y}$ provided that $\mathrm{C}$. We can assume that there is at least one member of a linguistic community who follows these instructions, i.e. the one who did issue them. But actually, each corrective instruction is part of a repertory employed by many other members of a linguistic community at large or more narrowly of the community of literati. Corrective practices are social practices; they are 
collective and guided. One may assume that the groups of people who follow the correctives exhibit a certain social organization. Directives are directed. Although the corrective instructions are issued by the few, they are addressed to the many; potentially, they are addressed to everyone who is literate. To follow an instruction means that one is trying to conform her/his linguistic practice to it.

Corrective practices are not employed solely by proofreaders, editors or other craft professionals (Cameron, 1995, p. 34). Certainly, the practices of such groups of persons are of special interest, because they are much more organized (or "uniform", if you prefer) compared to the corrective practices of others. Yet, the corrective practice is a phenomenon much more widespread, surpassing any linguistic division of labor. Let us think for a moment of the corrective practices associated with the raising of children ("bad words"); or taboo words; or the corrective practice of euphemism; of political correctness; of avoiding sexist or racist expressions; let us think of censorship and self-censorship as a corrective practice; and, last but not least, of the practices associated with standardization.

Nor is the case that corrective practices apply only to words or particular expressions-although words are the easiest targets of corrective practices. Correctives can also be directed to speech acts (such as swearing) or to speech events (such as an interview or a talk show, which are usually subject to preset specifications). Correctives may be concerned with whole registers (as it is the case with Guides for essay writing, or Guides addressed especially to journalists, etc.); or with particular literary forms (e.g., the iambic meter of fifteen syllables is considered by many in Greece to be the "national rhythm"). A corrective behavior may be prejudiced against whole languages (e.g., many Greeks consider Italian to be a "musical language" and German to be a "barbarian" one).

No matter how general their definition, corrective practices are bound to have two components: corrective practices are at once linguistic and metalinguistic. Corrective practices are performed in a language on the basis of a metalinguistic standard or a norm or a language ideal or language ideology. Usually, the metalinguistic standard can be expressed as an instruction or a directive, consisting of a prohibitive part, a normative part, and an explicative part (i.e., respectively, a part employing a negative "should", "must" and similar deontic expressions; a part employing a positive deontic expression; and a part employing "because", "on account of..." and similar explanatory expressions). The explicative part, more often than not, comprises an evaluation such as "correct - incorrect", etc.: "one should not say or write $\mathrm{X}$; one should say and write $\mathrm{Y}$, because, e.g., $\mathrm{X}$ is incorrect and $\mathrm{Y}$ is more appropriate". Permissives, as we have seen, in their simplest form, also consist of three parts: a permissive ('one may say or write $\mathrm{X}$ in addition to/alongside $\mathrm{Y}$ '); a normative, which usually expresses a condition on $\mathrm{X} / \mathrm{Y}$ usage (' $\mathrm{X}$ occurs under condition $\mathrm{C}_{1}$; $\mathrm{Y}$ occurs under condition $\mathrm{C}_{2}$ '); and an optional explicative ('because $\mathrm{Z}$ ').

Corrective instructions, when followed, result to the respective corrective practice; that is, the result of a corrective is not to write or to say X but to write or to say Y instead or to differentiate the use of X and $\mathrm{Y}$ by some condition $\mathrm{C}$. Notice that a corrective is likely to be issued when both $\mathrm{X}$ and $\mathrm{Y}$ are attested, e.g. when there is noticeable linguistic variation. Also, a directive presupposes that one is aware of $\mathrm{X}$ and $\mathrm{Y}$; in a way, the corrective instruction is what brings $\mathrm{X}$ and $\mathrm{Y}$ to the attention of those who are apt to follow it. Correctives raise awareness about language.

Corrective practices are part of a re-/de-standardization procedures. Since the corrective practice combines a (collectively performed) activity with a metalinguistic standard (a norm, an attitude or an evaluation), standardization is a most appropriate field for studying the effects of corrective instructions. A standard language is, just like a corrective practice, two things at once, i.e. it is both a language (a dialect among other dialects) and a standard (i.e., a norm by means of which other dialects are "measured" and evaluated). What is more, in standardization several forces (administrative, educational, etc.) are united, and they are all necessary in order for correctives to assume efficiency and corrective practices to spread. Standardization is a multiplier of correctives.

The systematic study of corrective instructions has helped us diagnose the standards by means of which standardization is achieved; one can observe changes in these standards and form hypotheses about possible linguistic changes to which the changes in standards respond. The analysis of the explicative parts 
of such instructions - and the analysis of metalinguistic discourse in general-can help us understand whether and how linguistic change is perceived and ideologized within a linguistic community.

We have adopted a descriptive approach to prescriptivism. Just as language variables are tools for a descriptive approach to variation, correctives can be studied as sociolinguistic variables (with variants $\mathrm{X}$ and $\mathrm{Y}$ ). One can thus quantify the effects of prescriptivism. Indeed, correctives are the elementary units for the quantitative study of prescriptivism within a variationist paradigm. Correctives are mediators between metalanguage and language. Accordingly, the study of corrective instructions (in Usage Guides, traditional Grammars, language education textbooks, etc.) is important for diagnosing a) the corrective repertories that compete or prevail within a linguistic community; b) the evolution of such repertories and concomitant developments in a standard; c) the communication trajectories through which norms are propagated and diffused within a community. The study of correctives can also help us form informed hypotheses about $\mathrm{d}$ ) whether and how standardization, language attitudes or ideologies affect language change, i.e. whether there is a causal chain connecting correctives with changes of the type $X \rightarrow Y$.

The study of correctives as elementary units for the quantification of prescriptivism presupposes a performative theory of language standards and language ideologies in general (Moschonas, 2008; 2014, p. 422-424). Language ideologies should be seen as performing "speech acts" at a metalinguistic level. The "direction of fit" of such speech acts is from a (meta)language to a language or, alternatively, their perlocutionary effect is ultimately locutionary, i.e. the effect is some change in linguistic behavior. Since corrective instructions are prescriptive, their illocutionary force is that of a directive. Hence, the felicity conditions for corrective practices are also conditions for linguistic change: just as the performance of a speech act may be "happy" or "unhappy" under particular circumstances, effecting a linguistic change can be successful or unsuccessful in particular periods of time under socio-cultural conditions that need to be specified.

One may raise the objection that we have placed undue emphasis on metalanguage, that standardization is also possible by example, that one can set a standard by displaying its usage or developing a usage for it. We noticed that this might very well be the case with the standard set by Jannis Psycharis. Despite later attempts to "codify" his norm in a strict manner, Psycharis standardized Modern Greek by setting himself a literary standard that others also evoked in their attempts to write in the demotic; he standardized Modern Greek by showing that Modern Greek can be standardized. If so, standardization is a process of creating exemplary uses. Haugen (1966a,b) would have applied the term "elaboration" to this process.

From the perspective of the extended speech act theory developed in this paper, an exemplary usage, in order to count as such, would have to be considered as presupposing an indirect metalinguistic act, a token/elliptical one at that (of the type: $\varnothing / Y$. Employing this or that variant $(Y)$ in writing is implying that this or that variant should be employed in all writing, and this latter implication is not but a hidden metalinguistic act. How this act is "brought about", is a non-trivial question; however, the association of an exemplary use with the metalinguistic act prescribing this use could only be achieved within a wider metalinguistic discourse. The "Greek Language Question" has been the wider discourse-ideological framework that allows for such associations between precepts and usage. It is true though that a performative theory of standardization has to take into account two types of standards: the ones imposed through explicit guidelines and instructions and the ones set implicitly by the (educated) users of a language. Under certain conditions, the latter might prove just as effective as the former. It might also be the case that standards set by example are driven mostly by their 'aesthetic' appeal and/or prestige.

A performative theory of language ideologies and standardization should meet several other requirements. First, a typology of language ideological performatives should try to comprehend linguistic practices rather than individual acts. Language ideologies manage to perform their magic only through collective practices such as standardization, linguistic purism, language learning and teaching, etc. Obviously, such prescriptive practices should be assigned irreducible "collective intentions" (Searle, 2002, p. 90-105). Second, collective intentions have collective manifestations. Hence, performative types at a metalinguistic level should be associated with mass-mediated communicative sequences; they should also be associated 
with particular genres, such as usage columns in the newspapers or editors' manuals (Cameron, 1995). In other words, categories of performatives should not be uncritically carried over from the literature associating speech acts with specific utterance tokens.

For the study of the performative character of language ideologies, corrective practices are exemplary in several respects: Correctives are socially valued (they correlate to language standards as well as values, beliefs and attitudes within a community). They can be diagnosed at a linguistic level, although they are expressed, argued and debated at a metalinguistic level. They have straightforward "sincerity" and "content conditions", namely the ones recognized in corrective instructions. Corrective practices follow a certain social organization. Especially when serving standardization, correctives follow the route of mediation: from an elite to a small public of followers, devotees or propagators and from there to the general public. It is the mid-circle of followers and propagators who usually employ the print media for expressing their views about norms and language.

My view of a Standard Language has been exemplified by several studies in the development of SMG. In particular, I have been concerned in this paper with four stages in the evolution of SMG: the stage of planning (section 1), the stage of norm development and dissemination of the standards (stage 2), the stage of naturalization (or "neutralization") of the standards (stage 3) and the stage of de-/re-standardization through the development of uses that contradict the accepted standards. The latter three changes were all mediated, i.e. they were all initiated in and/or propagated through print or electronic media-in ways that were explained in the sections $2-4$. One can possibly argue that ideologically-driven change, if it occurs at all, is always a mediated change.

Due to the perennial "Language Question", in Greece diglossia has given rise to two conflicting standards, the archaistic or puristic standard and the demotic or vernacular one. Arguably, there is also a range of intermediate standards between these two extremes. SMG is supposed to be based on demotic, allowing nevertheless a certain number of archaisms, especially in the higher registers of the language. As the vernacular forms have gradually become standardised, it is the archaistic forms that are in need of corrective instruction and guidance. We have seen that a new morpho-syntactic/phraseological model has evolved that corresponds to these "mixed" standards of SMG.

In presenting the above-mentioned developments of SMG, I have not refrained from reporting on aspects of my work that are not accessible to the readers of the English literature on standardization. A significant problem with standardization studies is that most of them are part of a national literature and they are not accessible to the English reader, while only a handful of studies are comparative. Standardization studies have to overcome the language barrier set by each national literature on standardization.

There is now a considerable body of research on standardization, mediation and language change. The studies in Kristiansen \& Grondelaers (2013) focus on media norms in contemporary Europe in order to reveal the processes of 'demotisation' (a multiple-standard configuration in which more than one variety satisfies the 'best language' criterion) and 'destandardisation' (the configuration whereby the standard language ideal itself is lost; see especially Coupland \& Kristiansen, 2011). The empirical, experimental studies in Kristiansen \& Grondelaers (2013) seek to diagnose important shifts in the alignments between language standards and standard languages in several European countries. The twin volumes Thøgersen, Coupland \& Mortensen (2016) and Mortensen, Coupland \& Thøgersen (2017) seek to account for such realignments through the concept of 'styling'.

There are also significant studies that seek to diagnose the effects of prescriptivism on language change: Anderwald (2014, 2016), Hinrichs, Szmrecsanyi \& Bohmann (2015), Curzan (2014), Tieken-Boon van Ostade (2006); see also the works by Stuart-Smith listed in the bibliography, which seek to establish whether mediation is a contributory factor in language change. Anderwald (2016), Hinrichs, Szmrecsanyi \& Bohmann (2015), Poplack \& Dion (2009), Poplack, Lealess \& Dion (2013) are some of the most important recent works that seek to demonstrate the effects of prescriptivism by correlating two types of language corpora: prescriptive texts containing corrective instructions (as they occur in Usage Guides and traditional Grammars of the English language) with historical language corpora. 
I believe that the performative theory of standardization developed in this chapter could provide a unifying framework for the diverse approaches to prescriptivism evidenced in the relevant literature. It could also contribute to re-examining and problematizing some quite common misconceptions about standardization, such as the belief in the uniformity and the neutrality of a Standard or the belief that language standards, like Platonic ideas, do not change or they change very slowly. This may be the case for Standard English: it is indeed claimed that "proper English" is still defined by the same standards that were formulated in the late $16^{\text {th }}$ century (Machan, 2009; cf. Schaffer, 2010). Modern Greek, however, as well as many other "reformed" languages have seen abrupt changes in their standards. The literature on standardization can only profit from comparative empirical research on diverse languages and diverse standardization processes.

\section{Acknowledgements}

The idea of a performative theory of language ideologies and standardization was first presented under the title "On the performative character of language ideologies" in the $9^{\text {th }}$ International Pragmatics Conference, Riva del Garda - July 14, 2005. With its present four-part division, this paper, under the title Changes in language standards as changes in standard languages: The case of media norms, was first presented at the Sociolinguistics Symposium 19, Freie Universität Berlin, August 21, 2012, in the session "Changing linguistic norms in the audiovisual media" organized by Jakob Thoegersen and Tore Kristiansen. A paper on Triantaphyllidis's non-uniform standard was read at the Fourth Prescriptivism Conference, Universiteit Leiden, June 13, 2013, under the title Non-uniform standards: The case of Standard Modern Greek,

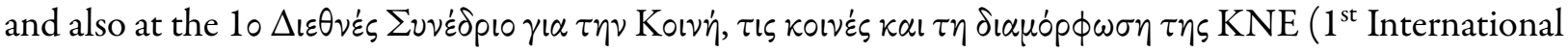
Conference on the Koine, the koines, and the formation of Standard Modern Greek), organized by the

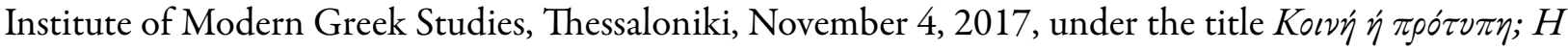

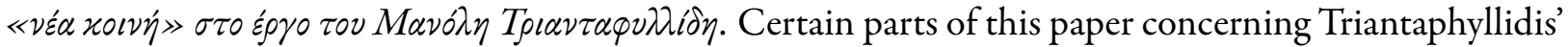
standardization and the "de-ideologization" of the Standard have appeared under the title Prescriptive acts: A performative theory of language standardization in Antos, G., Niehr, T. \& Spitzmüller, J. (eds), Handbuch Sprache im Urteil der Öffentlichkeit, de Gruyter, Berlin, 2019.

I am deeply indebted to the editors of "Diacronia" for giving me the opportunity to present my work on standardization and for helping me improve my argument with valuable comments and criticisms.

I wish to thank all the students in my classes of "Media Sociolinguistcs" and "Media Discourse Analysis" at the Dpt. of Communication and Media of the National and Kapodistrian University of Athens who (restrictive clause follows) have carried out assignments on the issues touched upon in this paper or they have come up with their own ideas. Their names are acknowledged in the References and the source-section of Fig. 5, 6, and Table 4, but it is appropriate that I renew here my thanks to: Alexandros Potamianos, Andrianna Ksiromamou, Apostolia Balomenou, Artemis Sofiou, Dimitra Koutsou, Ioanna Kyrgia, Melina-Dionysia Konti, Giorgos Koukoulis, Georgios-Konstantinos Oikonomopoulos, Michaela Kolia, Michalis Psimitis, Olympia Antonena, Anna Vassilaki, Stavroula Vergopoulou, Tina Fourlari.

\section{Bibliography}

Agha, A. (2007). Language and Social Relations, Cambridge University Press, Cambridge, Crossref.

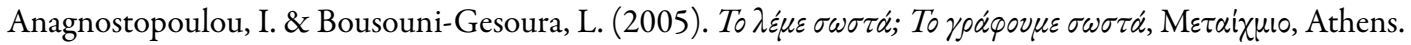

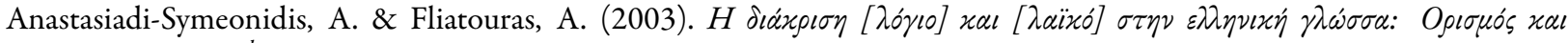
$\tau \alpha \xi\left\llcorner\nu o ́ \mu \eta \sigma \eta\right.$, in $\sigma^{\text {th }}$ International Conference of Greek Linguistics, University of Crete - Laboratory of Linguistics, Rethymno, p. $1-16$

Anderwald, L. (2014). Measuring the success of prescriptivism: Quantitative grammaticography, corpus linguistics and the progressive passive, in "English Language and Linguistics", 18 (1), p. 1-21, Crossref.

Anderwald, L. (2016). Language Between Description and Prescription: Verbs and Verb Categories in Nineteenth-Century Grammars of English, Oxford University Press, Oxford, Crossref. 
Androutsopoulos, J. (2001). A Agouraki, Y. et al. (eds), Proceedings of the $4^{\text {th }}$ International Conference in Greek Linguistics, p. 383-390, University Studio Press, Thessaloniki.

Androutsopoulos, J. (2009). 'Greeklish': Transliteration practice and discourse in the context of computer-mediated digraphia, in: Georgakopoulou, Al. \& Silk, M. (eds), Standard Languages and Language Standards: Greek, Past and Present, p. 221-249, King's College - Center for Hellenic Studies / Ashgate, London.

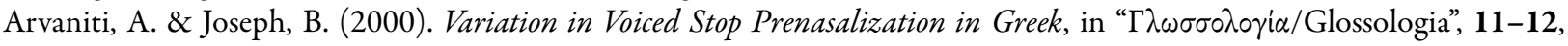
p. $131-166$.

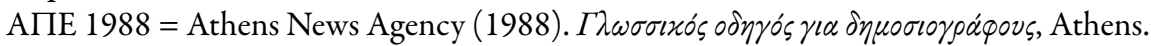

Austin, J.L. (1975 [1962 $\left.\left.{ }^{1}\right]\right)$. How to Do Things With Words, Oxford University Press, Oxford, Crossref.

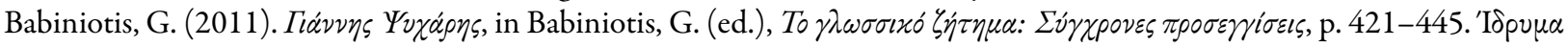

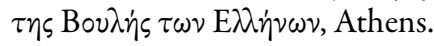

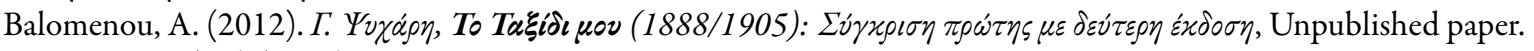

Blommaert, J. (ed.) (1999). Language Ideological Debates, Mouton de Gruyter, Berlin/New York, Crossref.

Bourdieu, P. (1991). Language and Symbolic Power, translated by G. Raymond \& M. Adamson, Polity, Cambridge.

Cameron, D. (1995). Verbal Hygiene, Routledge, London/New York.

Cameron, D. (2000). Good to Talk? Living and Working in a Communication Culture, Sage, London.

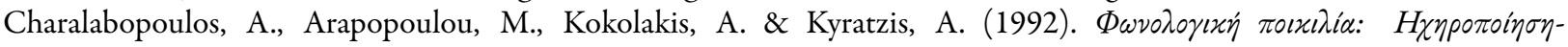

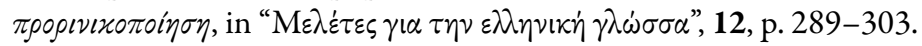

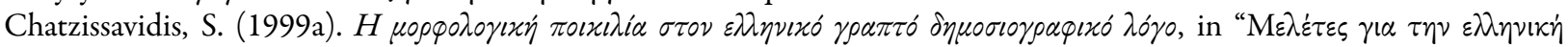

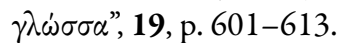

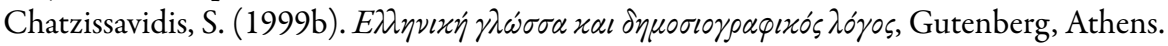

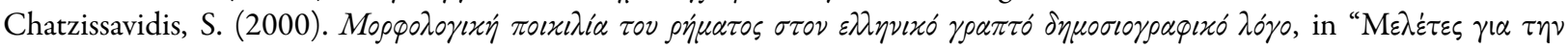
$\varepsilon \lambda \lambda \eta \nu \kappa \dot{\gamma} \gamma \lambda \omega \dot{\sigma} \sigma \sigma \alpha, 20$, p. 588-599.

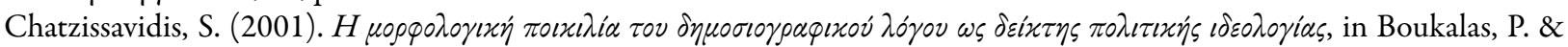

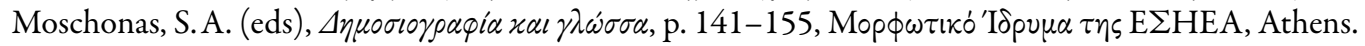

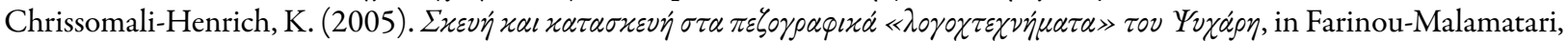

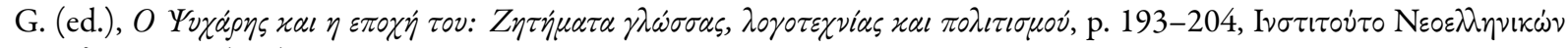
$\Sigma \pi \circ v \delta \omega \dot{\nu} \nu$, Thessaloniki.

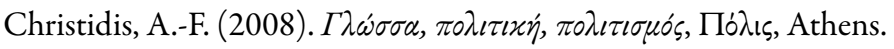

Coupland, N. \& Kristiansen, T. (2011). SLICE: Critical perspectives on language (de)standardization, in Kristiansen, T. \& Coupland, N. (eds), Standard Languages and Language Standards in a Changing Europe, p. 10-35, Novus, Oslo.

Crowley, T. (1989). Standard English and the Politics of Language, University of Illinois Press, Urbana/Chicago.

Curzan, A. (2014). Fixing English: Prescriptivism and Language History, Cambridge University Press, Cambridge, Crossref.

Delveroudi, R. \& Moschonas, S. A. (2003). Le purisme de la langue et la langue du purisme, in “Philologie im Netz", 24, p. 1-26, [online, accessed 9/8/2019].

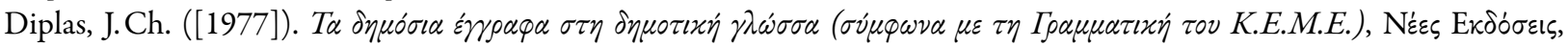
Athens.

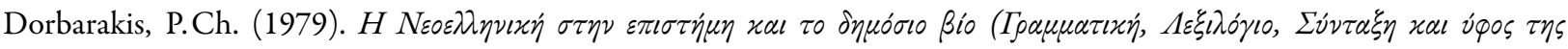
$\Delta \eta \mu о \tau \iota x \bar{s}), \mathrm{E} \sigma \tau i \alpha$, Athens.

Ewert, A. (1940). Dante's Theory of Language, in “The Modern Language Review”, 35 (3), p. 355-366, Crossref.

Fishman, J. A. (1972). The Sociology of Language: An Interdisciplinary Social Science Approach to Language in Society, Newbury House, Rowley, Mass.

Fodor, I. \& Hagège, Cl. (eds) (1983-1990). Language Reform: History and Future, 5 vols, Buske Verlag, Hamburg.

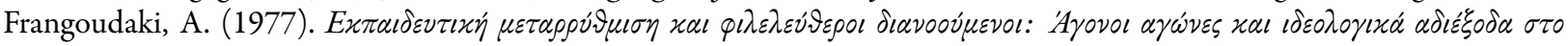

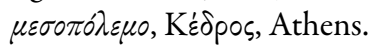

Frangoudaki, A. (1992). Diglossia and the Present Language Situation in Greece: A Sociological Approach to the Interpretation of Diglossia and Some Hypotheses on Today's Linguistic Reality, in "Language in Society", 21 (3), p. 365-381, Crossref.

Fromkin, V., Rodman, R. \& Hyams, N. (2011). An Introduction to Language, $9^{\text {th }}$ ed., Wadsworth, Boston.

Geeraerts, D. (2016). Cultural models of linguistic standardization, in “Diacronia”, 3, Feb. 12, art. A36, Crossref.

Goffman, E. (1981). Radio talk: A study of the ways of our errors, in Forms of Talk, p. 197-330, University of Pennsylvania Press, Philadephia.

Grondelaers, S. \& Kristiansen, T. (2013). On the need to access deep evaluations when searching for the motor of standard language change, in Kristiansen, T. \& Grondelaers, S. (eds), Language (De)standardisation in Late Modern Europe: Experimental Studies, p. 9-52, Novus, Oslo.

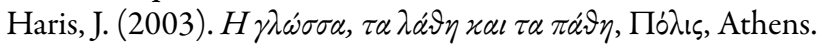

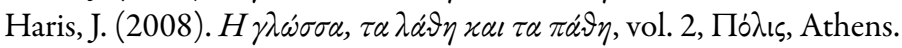

Haugen, E. (1966a). Language Conflict and Language Planning: The Case of Modern Norwegian, Harvard University Press, Cambridge, MA, Crossref. 
Haugen, E. (1966b). Dialect, language, nation, in “American Anthropologist”, 68 (4), p. 922-935, Crossref.

Haugen, E. (2001). Standardization, in Mesthrie, R. (ed.), Concise Encyclopedia of Sociolinguistics, p. 681-683, Elsevier, Amsterdam.

Hickey, R. (ed.) (2010). Eighteenth-century English: Ideology and Change, Cambridge University Press, Cambridge, Crossref.

Hinrichs, L., Szmrecsanyi, B. \& Bohmann, A. (2015). Which-hunting and the Standard English relative clause, in "Language", 91 (4), p. 806-836, Crossref.

Holmes, J. (2008 3 [1992 $\left.\left.{ }^{1}\right]\right)$. An Introduction to Sociolinguistics, Pearson, Harlow.

Horrocks, J. (20102 [1997']). Greek: A History of the Language and its Speakers, Wiley-Blackwell, Chichester, UK, Crossref.

Holton, D., Mackridge, P. \& Phillipaki-Warburton, I. (1997). Greek: A Comprehensive Grammar of the Modern Language, Routledge, London.

Hudson, R.A. (1980). Sociolinguistics, Cambridge University Press, Cambridge.

Inoue, M. (2006). Standardization, in Brown, K. (ed.), Encyclopedia of Languages and Linguistics, $2^{\text {nd }}$ ed, vol. 12, p. 121-127, Elsevier, Amsterdam, Crossref.

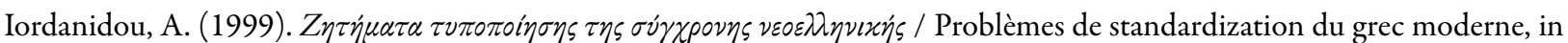

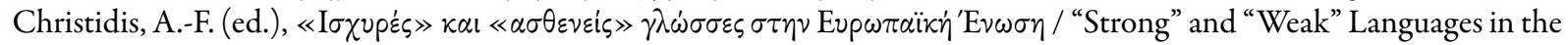

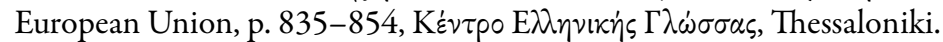

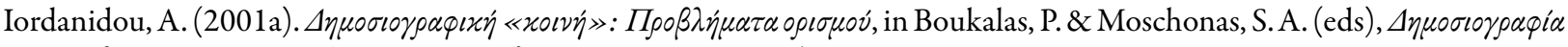

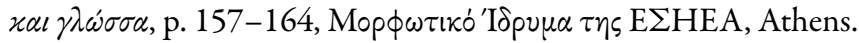

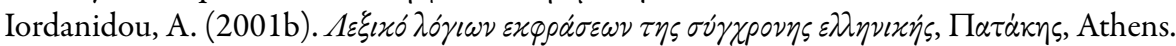

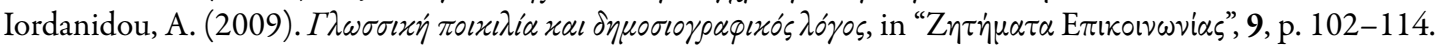

Jaffe, A. (2000). Introduction: Non-standard orthography and non-standard speech, in “Journal of Sociolinguistics”, 4 (4), p. 497513, Crossref.

Jaffe, A., Androutsopoulos, J., Sebba, M. \& Johnson, S. (2012). Orthography as Social Action: Scripts, Spelling, Identity and Power, de Gruyter, Berlin, Crossref.

Jespersen, O. (1964 $\left.\left[1946^{1}\right]\right)$. Mankind, Nation and Individual from a Linguistic Point of View, Indiana University Press, Bloomington.

Johnson, S. (2005). Spelling Trouble? Language, Ideology and the Reform of German Orthography, Multilingual Matters, Clevedon, UK, Crossref.

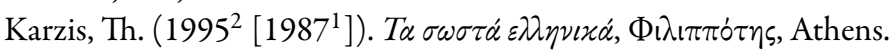

Kerswill, P. (2002). Koineization and accommodation, in Chambers, J. K., Trudgill, P. \& Schilling-Estes, N. (eds), The Handbook of Language Variation and Change, p. 668-702, Blackwell, Oxford, Crossref.

Kerswill, P. (2003). Models of linguistic change and diffusion: New evidence from dialect levelling in British English, in Britain, D. \& Cheshire, J. (eds), Social Dialectology: In honour of Peter Trudgill, p. 223-243, Benjamins, Amsterdam, Crossref.

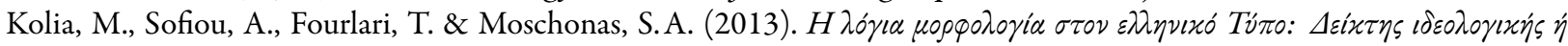
v

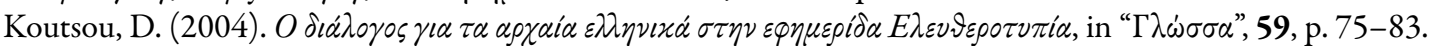

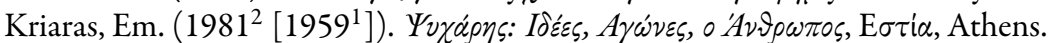

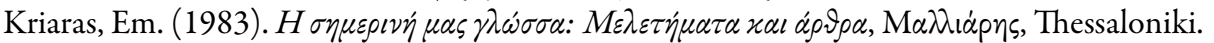

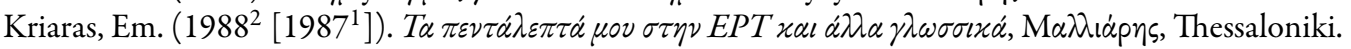

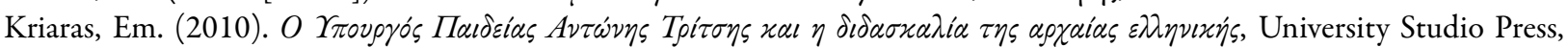
Thessaloniki.

Kristiansen, T. \& Grondelaers, S. (eds.) (2013). Language (De)standardisation in Late Modern Europe: Experimental Studies, Novus, Oslo.

Kristiansen, T. (2014). Does mediated language influence immediate language?, in Androutsopoulos, J. (ed.), Mediatization and Sociolinguistic Change, p. 99-126, de Gruyter, Berlin/Boston.

Labov, W. (1972). Sociolinguistic Patterns, University of Pennsylvania Press, Philadelphia.

Linn, A.R. (2011). Standardization, in Hogan, P.C. (ed.), The Cambridge Encyclopedia of the Language Sciences, p. 800-801, Cambridge University Press, Cambridge.

Lippi-Green, R. $\left(2012^{2}\left[1997^{1}\right]\right)$. English with an Accent: Language, Ideology and Discrimination in the United States, Routledge, London/New York, Crossref.

Longmore, P. K. (2007). "Good English without Idiom or Tone": The Colonial Origins of American Speech, in "Journal of Interdisciplinary History”, 37 (4), p. 513-542, Crossref.

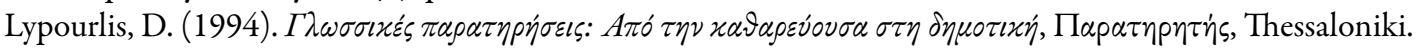

Machan, T.W. (2009). Language Anxiety: Conflict and Change in the History of English, Oxford University Press, Oxford.

Mackridge, P. (1985). The Modern Greek Language, Oxford University Press, Oxford.

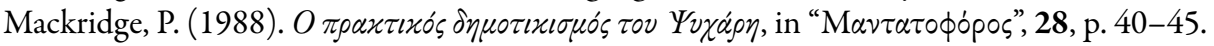

Mackridge, P. (2009). Language and National Identity in Greece, 1766-1976, Oxford University Press, Oxford, Crossref.

Mandilaras, B. G. (1972). Studies in the Greek Language, Athens.

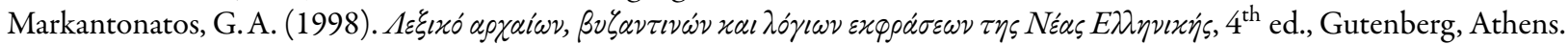




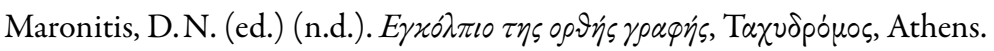

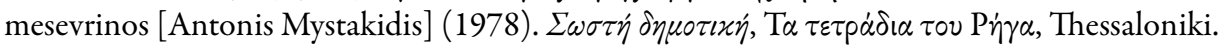

Mikros, G. K. (1997). Radio news and pnonetic variation in Modern Greek, in Drachman, G., Malicouti-Drachman, A., Fykias, I. \& Klidi, C. (eds), Greek Linguistics '95: Proceedings of the $2^{\text {nd }}$ International Conference on Greek Linguistics, vol. I, p. 35-44, The Department of Linguistics, University of Salzburg.

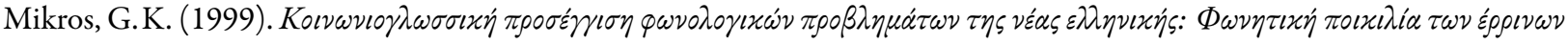
$\sigma \nu \mu \varphi \omega \nu \omega \nu$, Ph.D. thesis, Department of Linguistics, University of Athens.

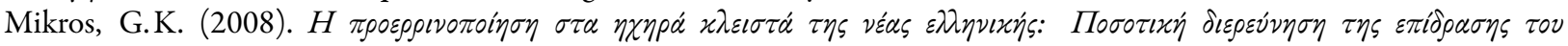

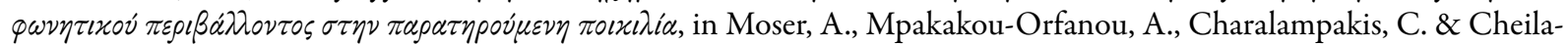

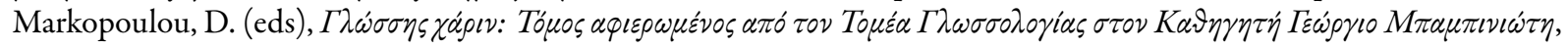

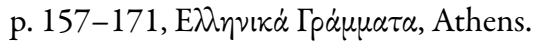

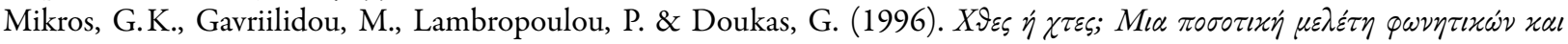

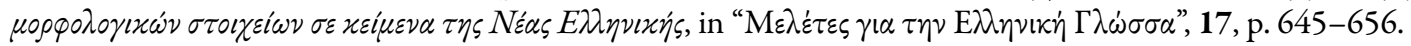

Milroy, J. (2001). Language ideologies and the consequences of standardization, in "Journal of Sociolinguistics", 5 (4), p. 530-555, Crossref.

Milroy, J. \& Milroy, L. (1999 $\left.\left.31985^{1}\right]\right)$. Authority in Language: Investigating Standard English, Routledge, London/New York.

Mortensen, J., Coupland, N. \& Thøgersen, J. (2017). Style, Mediation, and Change: Sociolinguistic Perspectives on Talking Media, Oxford University Press, Oxford, Crossref.

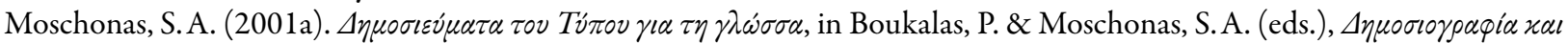

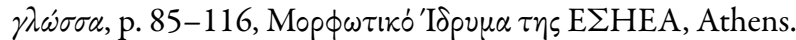

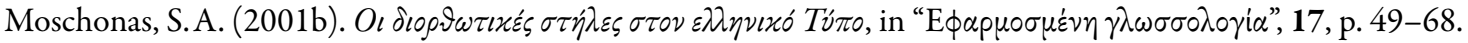

Moschonas, S. A. (2004). Relativism in Language Ideology: On Greece's Latest Language Issues, in "Journal of Modern Greek Studies", 22 (2), p. 173-206, Crossref.

Moschonas, S. A. (2005a). $\Gamma \lambda \omega \sigma \sigma i x \dot{\eta} \tau \nu \pi 0 \pi 0 i \eta \sigma \eta$, in "Cogito", 2, p. 57-58.

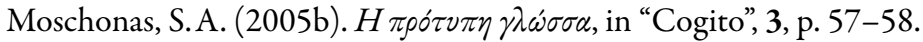

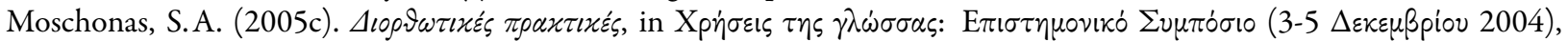

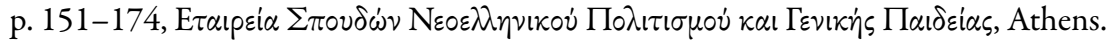

Moschonas, S.A. (2008). Vers une théorie performative du purisme, in "Le français moderne", 76 (1), p. 38-50.

Moschonas, S. A. (2009). "Language issues" after the "Language Question": On the modern standards of Standard Modern Greek, in Georgakopoulou, Al. \& Silk, M. (eds), Standard Languages and Language Standards: Greek, Past and Present, p. 293320, King's College - Center for Hellenic Studies / Ashgate, London.

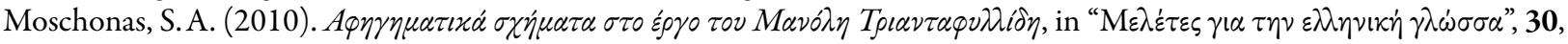
p. 398-410.

Moschonas, S. A. \& Spitzmüller, J. (2010). Prescriptivism in and about the media: A comparative analysis of corrective practices in Greece and Germany, in Johnson, S. \& Milani, T. (eds), Language Ideologies and Media Discourse: Texts, Practices, Politics, p. 17-40, Continuum Press, London.

Moschonas, S. A. (2014). The media on media-induced language change, in Androutsopoulos, J. (ed.), Mediatization and Sociolinguistic Change, p. 394-426, de Gruyter, Berlin/Boston.

Mugglestone, L. (2003 $\left.{ }^{2}\left[1995^{1}\right]\right)$. 'Talking Proper': The Rise of Accent as Social Symbol, Oxford University Press, Oxford.

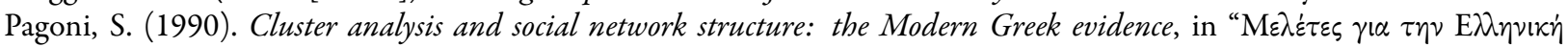
$\Gamma \lambda \omega \dot{\sigma} \sigma \alpha ”, 10$, p. 399-419.

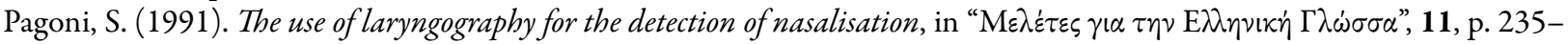
253.

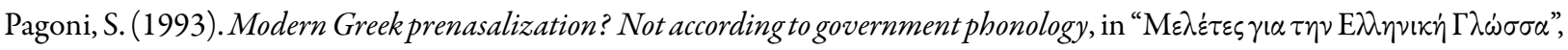
14, p. 355-369.

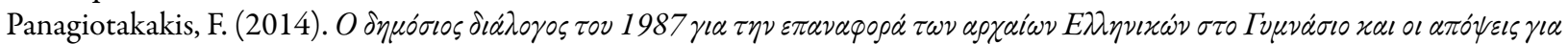
$\tau \eta \nu \varepsilon \lambda \lambda \eta \nu \iota x \dot{\gamma} \gamma \lambda \omega \sigma \sigma \alpha$, M.A. thesis, Department of Linguistics, University of Athens.

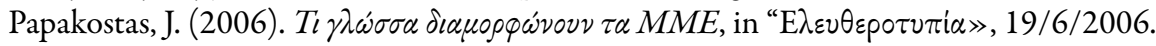

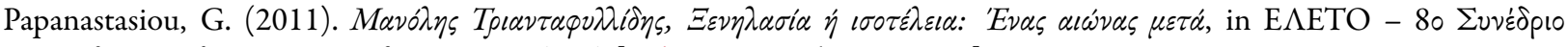

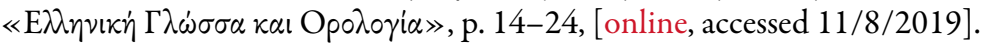

Papazafeiri, I. (1987). $\Lambda \alpha \dot{\imath} \eta \sigma \tau \eta \chi \rho \dot{\sigma} \sigma \eta \tau \eta \varsigma \gamma \lambda \omega \sigma \sigma \alpha \varsigma \mu \alpha \varsigma, \Sigma \mu i \lambda \eta$, Athens.

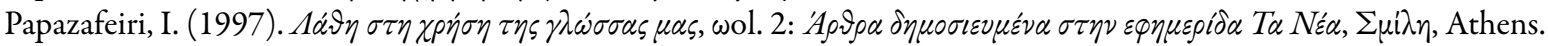

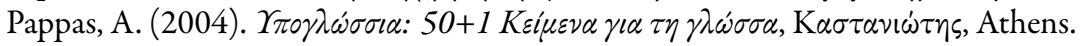

Pickl, S. (2019). Factors of selection, standard universals, and the standardisation of German relativisers, in "Language Policy", Crossref.

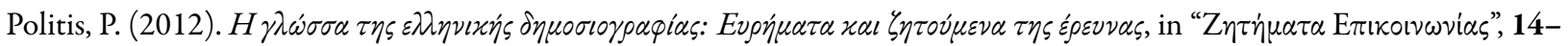
15, p. 59-72.

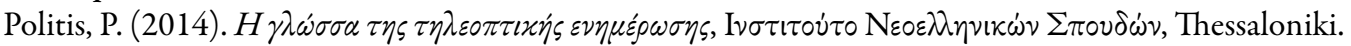




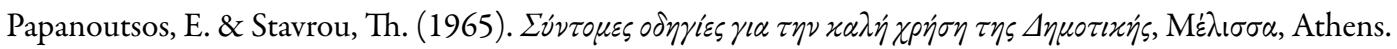

Poplack, S., van Herk, G. \& Harvie, D. (2002). 'Deformed in the dialects': An alternative history of non-standard English, in Watts, R. \& Trudgill, P. (eds), Alternative Histories of English, p. 87-110, Routledge, London.

Poplack, S. \& Dion, N. (2009). Prescription vs. praxis: The evolution of future temporal reference in French, in "Language", 58 (3), p. 557-587, Crossref.

Poplack, S., Lealess, A. \& Dion, N. (2013). The evolving grammar of the French subjunctive, in "Probus", 25 (1), p. 139-195, Crossref.

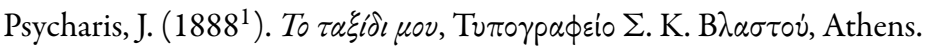

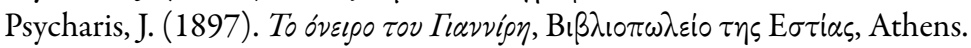

Psycharis, J. $\left(1905^{2}\right)$. To $\tau \alpha \xi i \delta \iota \mu o v$, E $\sigma \tau i \alpha$, Athens.

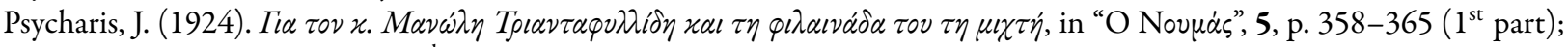
"O Novuás", 6, p. 405-412 (2 $2^{\text {nd }}$ part).

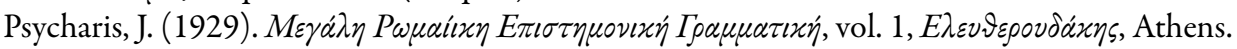

Psycharis, J. (1930). Quelques travaux de linguistique de philologie et de littérature helléniques: 1884-1928, vol. I. Les Belles Lettres, Paris.

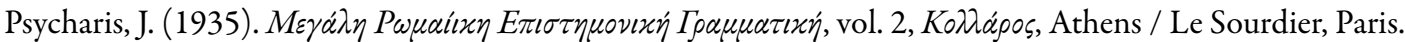

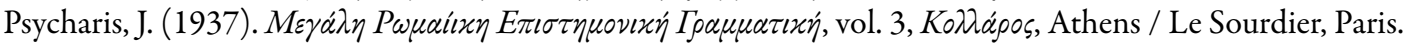

Rutten, G. (2016). Standardization and the myth of neutrality in language history, in "International Journal of the Sociology of Language", 242, p. 25-57, Crossref.

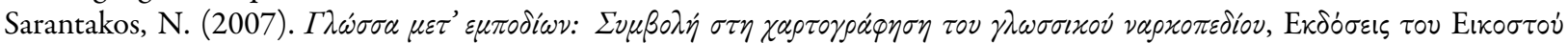

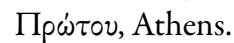

Schaffer, D. (2010). Old whine in new bottles: Mass-market prescriptivism from the 70s to the present, in Donaher, P. (ed.), Barbarians at the Gate: Studies in Language Attitudes, p. 44-87, Cambridge Scholars Publishing, Cambridge.

Searle, J. (1979). Expression and Meaning: Studies in the Theory of Speech Acts, Cambridge University Press, Cambridge, Crossref.

Searle, J. (2002). Consciousness and Language, Cambridge University Press, Cambridge, Crossref.

Sebba, M. (2007). Spelling and Society: The Culture and Politics of Orthography Around the World, Cambridge University Press, Cambridge, Crossref.

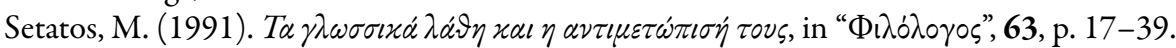

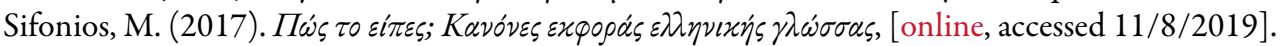

Silverstein, M. (2001 [1981']). The limits of awareness, in Duranti, A. (ed.), Linguistic Anthropology: A Reader, p. 382-401, Blackwell, Oxford.

Stuart-Smith, J. (2005). Is TV a contributory factor in accent change in adolescents?, ESRC End of Award Report, p. 1-23, R000239757, ESRC, Swindon, [online, accessed 1/8/2019].

Stuart-Smith, J. (2006). The influence of the media, in Llamas, C., Mullany, L. \& Stockwell, P. (eds), The Routledge Companion to Sociolinguistics, p. 140-148, Routledge, London.

Stuart-Smith, J., Timmins, C. \& Tweedie, F. (2007). 'Talkin' Jockney'? Variation and change in Glaswegian accent, in "Journal of Sociolinguistics", 11 (2), p. 221-260, Crossref.

Stuart-Smith, J., Pryce, G., Timmins, C. \& Gunter, B. (2013). Television can also be a factor in language change: Evidence from an urban dialect, in "Language", 89 (3), p. 501-536, Crossref.

Stuart-Smith, J. \& Ota, I. (2014). Media models, 'the shelf', and stylistic variation in East and West: Rethinking the influence of the media on language variation and change, in Androutsopoulos, J. (ed.), Mediatization and Sociolinguistics Change, p. 127170 , de Gruyter, Berlin.

Stuart-Smith, J. (2016). Bridging the gap(s): The role of style in language change linked to the broadcast media, in Thøgersen, J., Coupland, N. \& Mortensen, J. (eds), Style, Media and Language Ideologies, 51-84, Novus, Oslo.

Swift, J. (1984 [1710 $]$ ). The continual Corruption of our English Tongue, in Major Works, ed. A. Ross and D. Woolley, Oxford University Press, Oxford.

Thomas, G. (1991). Linguistic Purism, Longman, London/New York:

Thøgersen, J., Coupland, N. \& Mortensen, J. (eds) (2016). Style, Media and Language Ideologies, Novus, Oslo.

Tieken-Boon van Ostade, I. (2006). Eighteenth-century prescriptivism and the norm of correctness, in van Kemenade, A. \& Los, B. (eds), The Handbook of the History of English, p. 539-557, Blackwell, Oxford, Crossref.

Tieken-Boon van Ostade, I. (2010). The usage guide: its birth and popularity, in "English Today", 26 (2), p. 14-23, Crossref.

Tieken-Boon van Ostade, I. \& Percy, C. (eds) (2016). Prescription and Tradition in Language: Establishing Standards across Time and Space, Multilingual Matters, Bristol, Crossref.

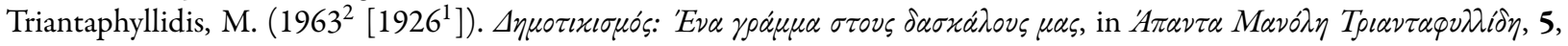

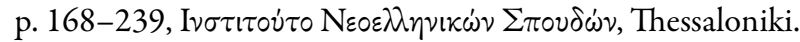

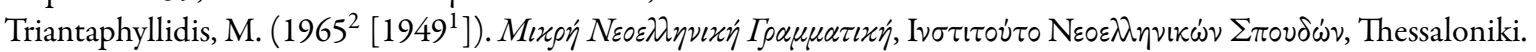

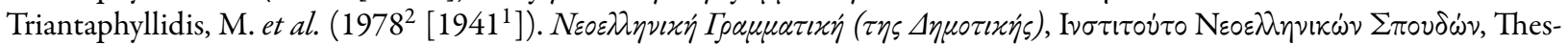
saloniki. 


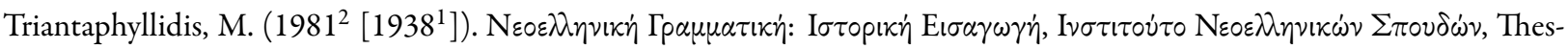
saloniki.

Trudgill, P. (1983 $\left.{ }^{2}\left[1974^{1}\right]\right)$. Sociolinguistics: An Introduction to Language and Society, Penguin Books, Harmondsworth.

Trudgill, P. (1999). Standard English: What it isn't, in Bex, T. \& Watts, R.J. (eds), Standard English: The Widening Debate, p. 117-128, Routledge, London.

Trudgill, P. (2003). A Glossary of Sociolinguistics, Oxford University Press, Oxford.

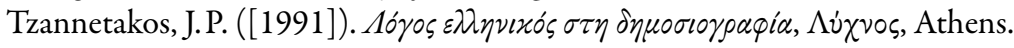

Veihinger, H. (1935). The Philosophy of 'As if': A System of the Theoretical, Practical and Religious Fictions of Mankind, translated by C.K. Ogden, $2^{\text {nd }}$ ed., Kegan Paul, London.

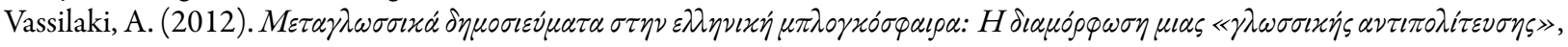
M.A. thesis, Department of Communication and Media, University of Athens.

Wardaugh, R. (1998 $\left.{ }^{3}\left[1986^{1}\right]\right)$. An Introduction to Sociolinguistics, Blackwell, Oxford.

Zwicky, A. (2009). One right way, [online, accessed 31/10/2019]. 